\title{
The Effects of Instructor Self-Disclosure on Students' Cognitive Learning: A Live Lecture Experiment
}

\author{
Stephen Michael Kromka \\ smk0023@mix.wvu.edu
}

Follow this and additional works at: https://researchrepository.wvu.edu/etd

Part of the Curriculum and Instruction Commons, Educational Psychology Commons, and the Higher Education and Teaching Commons

\section{Recommended Citation}

Kromka, Stephen Michael, "The Effects of Instructor Self-Disclosure on Students' Cognitive Learning: A Live Lecture Experiment" (2020). Graduate Theses, Dissertations, and Problem Reports. 7642.

https://researchrepository.wvu.edu/etd/7642

This Dissertation is protected by copyright and/or related rights. It has been brought to you by the The Research Repository @ WVU with permission from the rights-holder(s). You are free to use this Dissertation in any way that is permitted by the copyright and related rights legislation that applies to your use. For other uses you must obtain permission from the rights-holder(s) directly, unless additional rights are indicated by a Creative Commons license in the record and/ or on the work itself. This Dissertation has been accepted for inclusion in WVU Graduate Theses, Dissertations, and Problem Reports collection by an authorized administrator of The Research Repository @ WVU.

For more information, please contact researchrepository@mail.wvu.edu. 
The Effects of Instructor Self-Disclosure on Students' Cognitive Learning:

A Live Lecture Experiment

\author{
Stephen M. Kromka
}

Dissertation submitted

To the Eberly College of Arts and Sciences

at West Virginia University

in partial fulfillment of the requirements for the degree of

Doctor of Philosophy in

Communication Studies

\author{
Alan. K. Goodboy, Ph.D., Chair \\ Angela M. Hosek, Ph.D. \\ Matthew M. Martin, Ph.D. \\ Scott A. Myers, Ph.D. \\ Department of Communication Studies
}

\author{
Morgantown, West Virginia \\ 2020
}

Keywords: Instructor self-disclosure, relevance, affect, clarity, cognitive learning 


\begin{abstract}
The Effects of Instructor Self-Disclosure on Students' Cognitive Learning: A Live Lecture Experiment
\end{abstract}

\title{
Stephen M. Kromka
}

The purpose of this dissertation was to examine the causal influences of relevant (and irrelevant) instructor self-disclosure on student affect and cognitive learning. Relevant self-disclosure involves the instructor directly relating personal disclosures to important lesson content, whereas irrelevant self-disclosure involves the instructor's personal disclosures straying from the lesson topic. Given previous correlational self-disclosure research, the researcher predicted that relevant (compared to irrelevant) instructor selfdisclosure would lead to increased reports of affect toward the instructor. The researcher also predicted that instructor self-disclosure relevance (compared to irrelevance) would enhance lesson coherence, and in turn, foster students' cognitive learning. The researcher conducted a 15-minute live lecture teaching experiment on the topic of affectionate communication. The researcher randomly assigned students to attend a lecture with an instructor who used either relevant self-disclosure or irrelevant self-disclosure. Participants were 265 undergraduate students who listened to the instructor's 15-minute lecture and then completed a feedback questionnaire that included a short test on the lesson material and asked students to report on affect, lesson coherence, instructor credibility, topic familiarity, and lesson difficulty. Findings revealed that relevant instructor self-disclosure increased student affect in their likelihood to enroll with the same instructor again for a future class. However, relevant self-disclosure did not influence students' general affect toward the instructor. Moreover, instructor selfdisclosure relevance did not operate indirectly through lesson coherence to influence student test scores. However, there was a significant direct effect of self-disclosure relevance on student test scores such that, on average, students in the irrelevant condition scored $8.70 \%$ points lower on the short-term recall test. Overall, the results revealed that instructors should make sure that their personal disclosures are relevant to the lesson content or else it may significantly reduce student learning. The findings, theoretical implications, teaching implications, limitations, and suggestions for future research are discussed. 
Table of Contents

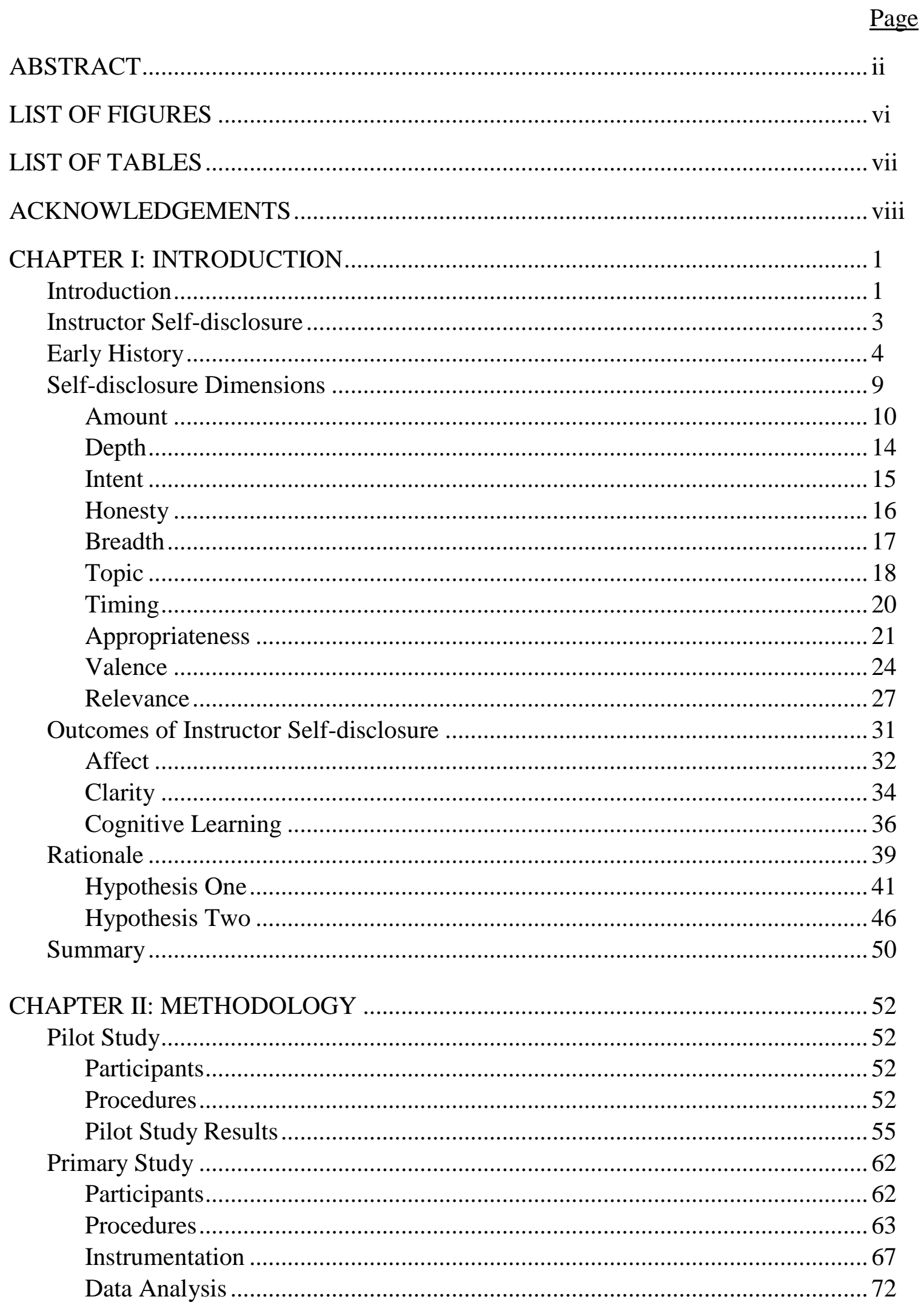




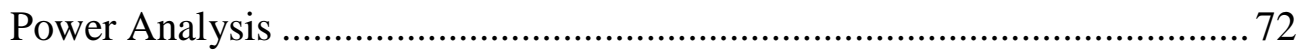

Confirmatory Factor Analysis................................................................... 73

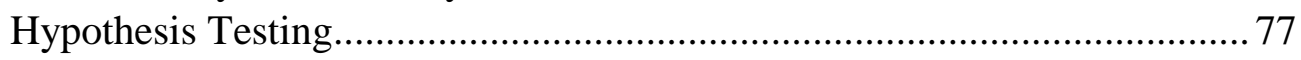

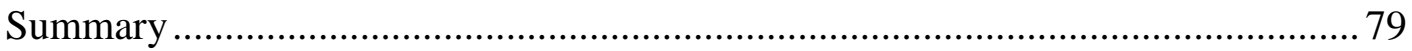

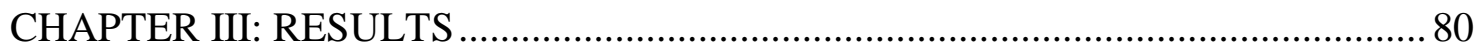

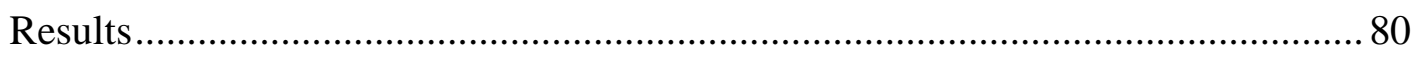

Instructor Self-disclosure Relevance Manipulation Check.................................8 80

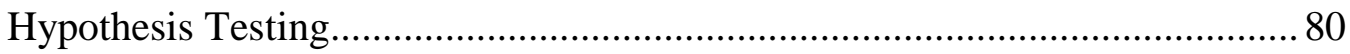

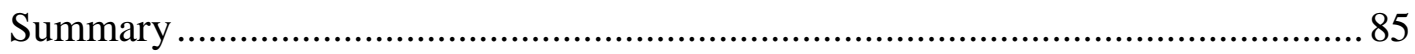

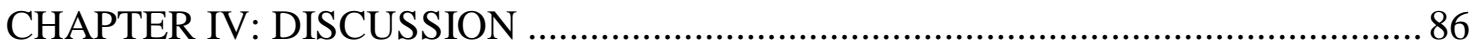

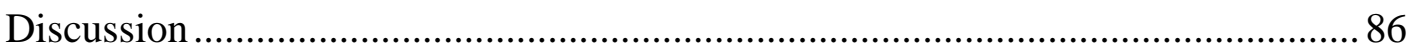

Hypothesis One: Instructor Self-disclosure and Student Affect ......................... 86

Hypothesis Two: Instructor Self-disclosure Relevance Directly Causes Student

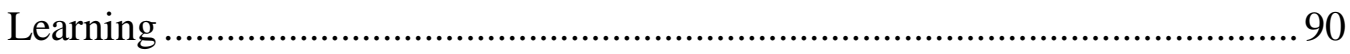

Implications for Theory and Teaching.......................................................... 96

Limitations and Future Directions ........................................................................ 103

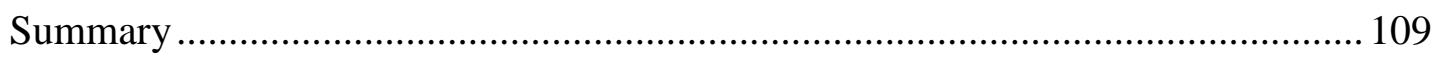

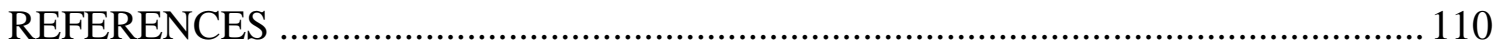

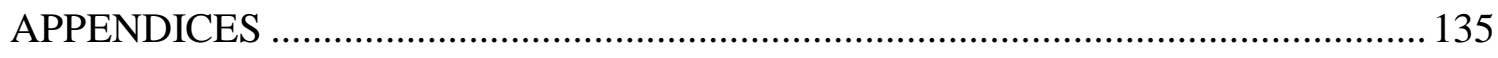

Appendix A. "Communicating Affection” Lesson Script - Relevant..................... 135

Appendix B. "Communicating Affection" Lesson Script - Irrelevant ................... 142

Appendix C. "Communicating Affection" PowerPoint Presentation ...................... 149

Appendix D. Pilot Study Cover Letter .................................................................. 155

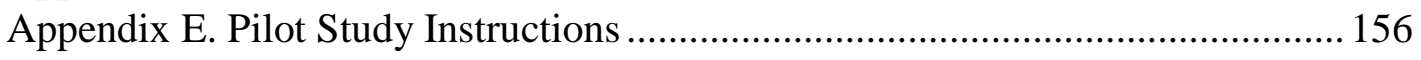

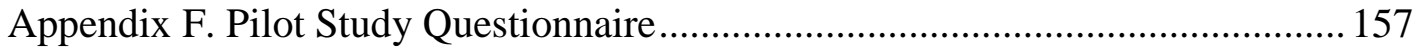

Appendix G. Demographic Information Questions …………................................ 159

Appendix H. Email Recruitment Script …………………...................................... 160

Appendix I. Pre-class Announcement Recruitment Script...................................... 162

Appendix J. Printed Bulletin Board "Mach Form" Recruitment Script................... 163

Appendix K. Part 1 Online Qualtrics Sign-up Survey ............................................... 164

Appendix L. Part 2 Reminder Email for the Week of the Study............................. 168

Appendix M. Part 2 Reminder Email for the Day of the Study ............................... 169

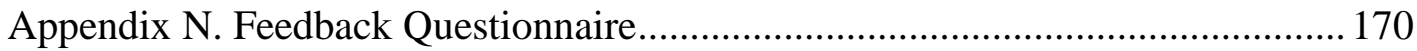

Appendix O. Researcher Introduction Script …………….................................. 175

Appendix P. Researcher Pre-feedback Questionnaire Script ................................... 176

Appendix Q. Extra Credit Research Receipt ........................................................... 177

Appendix R. Teacher Self-disclosure Scale for Relevance..................................... 178

Appendix S. Instructor Affect Assessment Instrument for Instructor..................... 179

Appendix T. Clarity Indicator Scale for Coherence ................................................ 180

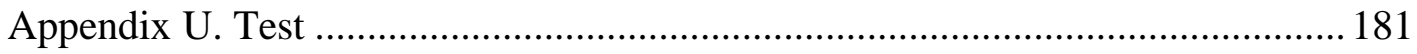


Appendix V. Shortened Student Comfort with Instructor Self-disclosure Scale ... 184 Appendix W. Shortened Instructor Credibility Scale ......................................... 185

Appendix X. Perceived Familiarity Scale ...................................................... 186

Appendix Y. Perceived Difficulty Scale .......................................................... 187 


\section{LIST OF FIGURES}

$\underline{\text { Page }}$

Figure 1. Hypothesized Conceptual Model of Hypothesis 2 .....................................50

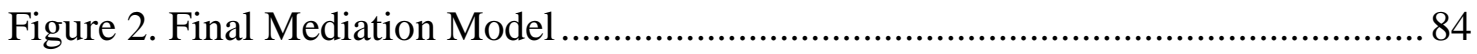




\section{LIST OF TABLES}

$\underline{\text { Page }}$

Table 1. Pilot Study Descriptive Information for Relevant Instructor Self-Disclosure...

Table 2. Pilot Study Descriptive Information for Irrelevant Instructor Self-Disclosure.

Table 3. Pilot Study Independent Samples Welch's t-test between Relevant and Irrelevant

Self-disclosure Conditions for Relevance. 59

Table 4. Pilot Study One-Sample t-test Examining the Difference between Relevant Selfdisclosures and Moderate Perceived Realism. 60

Table 5. Pilot Study One-Sample t-test Examining the Difference between Irrelevant Self-disclosures and Moderate Perceived Realism.... 61

Table 6. Descriptive Information for the 15 -item Test ........................................ 70

Table 7. Questions Answered Correctly and Incorrectly on the 15-item Test.............. 70

Table 8. Confirmatory Factor Analysis Goodness of Fit for Predicted Model Variables 75

Table 9. Factor Loadings and Variance Estimates for Scales ................................... 75

Table 10. Normalized Residuals Matrices for Scales ............................................ 77

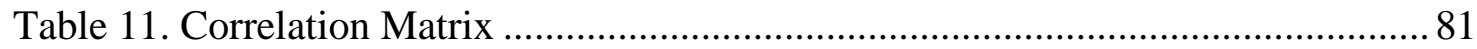

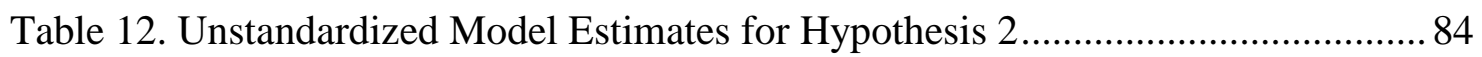




\section{ACKNOWLEDGEMENTS}

After finally completing a dissertation, I am sure that many new doctors feel the urge to exclaim, "I did it! I completed doctoral school all by myself." While that may be true for some folks, I have never felt that I was the only person responsible for my accomplishments. As the old proverb goes, "It takes a village to raise a child." In the same manner, I feel that it took the support from a village comprised of my advisor, faculty, friends, and family to help me persevere through my graduate education. I am grateful for all of their support over these last four years.

The first person I would like to thank is my advisor, Dr. Alan Goodboy. You have always been in my corner. I remember the boxing metaphor you once used to describe our relationship. You are the "cornerman" to my "boxer." You have always given me the autonomy to fight my own fights when it came to research, and you have always been in my corner when I needed you for feedback and assistance. Then after winning the fight against reviewer two, we would go out to celebrate at Tin 202 to share an old-fashioned cocktail together. Dr. Goodboy, you have been my dedicated mentor that has invested an extraordinary amount of time, energy, and resources into my education to help me become a more knowledgeable and confident social scientist. Under your guidance, I feel that I have truly "leveled up" in my knowledge of advanced statistics, instructional communication, and family communication. You have always pushed me to keep learning and searching for the answers. You would often ask me "What are you prepared to do?" as a way to motivate me to keep pushing farther in my educational endeavors. To answer your question, I am prepared to use everything you have taught me to advance instructional communication research and help my own students become successful in the field. On a more personal note, I have enjoyed our close friendship over the years. I will 
never forget our hikes up at Cooper's Rock, our adventures down High Street, or our shenanigans in New Orleans. Even though things were very difficult at times, I am glad that you accepted me as your advisee because working with you has been one of the most rewarding experience in my life. Thank you for being my advisor, my cornerman, and my friend.

I would also like to thank the devoted individuals on my dissertation committee: Dr. Matthew Martin, Dr. Scott Myers, and Dr. Angela Hosek. I appreciate the in-depth and helpful feedback that each of you provided to improve the final product of this dissertation. Thank you Dr. Martin for all of your support throughout the years. I still remember you helping me through my very first research paper proposal during your Comm 700: Survey of Human Communication Theory class when I was just a naïve little master student. Your class helped lay the foundation for my understanding of the communication field. Given your experience with instructor self-disclosure, I really appreciated you serving on my committee to provide your perspective on the research. Thank you Dr. Myers for being here from my very first day of graduate school to the very last moments of my dissertation defense. You have been with me through it all. In Comm 600: Communication in the Classroom, you taught me the art of APA and technical writing. You have helped me hone these skills and I shall continue to use them throughout my career in academia. Thank you Dr. Hosek for all of your constructive feedback on this dissertation. Your perspective helped me include important aspects of instructor self-disclosure that I did not consider initially.

Thank you to all of the faculty, staff, and fellow doctoral students in the WVU Communication Studies department. All of you helped me grow professionally and 
personally. A special thank you to Dr. Christine Rittenour, Dr. Megan Dillow, Dr. Jaime Banks, Dr. Elizabeth Cohen, and Ryan Thompson for all of your support with my research projects. Thank you Joy and Terri for always answering my silly questions and navigating me through my graduate student paperwork. Both of you facilitated my experience and made my life much easier. I appreciate that. A big thank you to all of my fellow doctoral students throughout the years as well. To Mckay and Kylie, you are the best cohort members I could have ever asked for. To Michelle, Erin, and Nora, I will miss the laughter from the Biddie Brigade. To Heath and Kevin, thank you for always coming down to my office to check in with me throughout the semester. To James, Catie, Joe, and Evan, thank you for laying the groundwork with your mentorship and positivity. Lastly, an extra big thank you to you, Sara Pitts. Our friendship has grown so much during these last few years. We have been there for each other academically, mentally, and emotionally. I'm not sure if I would have made it through this program without your support. Thank you for keeping me in line and dealing with my antics. I don't deserve you. I appreciate you so very much.

I would also like to thank my family. You have all provided me with the support to continue on with my education. Whether it was financial support, emotional support, or just having a drink with me at the end of a long semester, you were all there for me. Whenever I felt discouraged, I would look at photos of us to help motivate me to continue on. I wanted to do this for the betterment of our family. I wanted to show the kids that our family can achieve great things. We are a family that can accomplish anything if we put our minds to it. Thank you everyone for the support to continue my education over all these years. 
Lastly, I would like to thank my mother, Sandy. It is all because of you that I have been able to reach this life-changing accomplishment. My dissertation and diploma is not for me. It is for you, mom. I dedicate this all to you. You have always been my biggest motivator to keep pushing forward. You have inspired me to reach farther for myself and for the future of our family. So the dissertation and diploma may have my name on it, but it really is for you. Thank you for everything you have done to help me get to where I am at today. We are a different breed that will never die. 


\section{CHAPTER I}

\section{Introduction}

During a classroom lecture, instructors have the opportunity to share personal information with their students. Instructors often choose to reveal personal information about their family, friends, educational background, and favorite hobbies (Downs, Javidi, \& Nussbaum, 1988). Instructors choose to self-disclose to students for many reasons such as to spark attention, kindle classroom discussion, and provide personal examples of lesson content (McBride \& Wahl, 2005). For the most part, students appreciate when their instructors self-disclose in the classroom because they enjoy getting to know the instructor on a more personal level (Deiro, 1997). When instructors disclose personal information to their students, they are more willing to disclose their own personal experiences in kind (Woolfolk \& Woolfolk, 1975). Therefore, instructor self-disclosure fosters a classroom atmosphere that values individual experiences (Rouse \& Bradley, 1989). Researchers suggest that instructor self-disclosure is an effective teaching strategy because it has the potential to clarify course material and enhance positive student outcomes such as student affect and cognitive learning (Nussbaum \& Scott, 1979). Ultimately, instructors who share personal information with their students may be helping their students learn.

However, instructors who simply share personal information during instruction may not necessarily foster positive outcomes for students. The effects on positive student outcomes may depend upon the nature of the self-disclosure. Instructor self-disclosure is a multi-dimensional construct (Wheeless, Kretzchmar-Young, \& Nesser, 1978) that varies in amount, depth, intent, honesty, breadth, topic, timing, appropriateness, relevance, and valence (Altman \& Taylor, 1973; Cayanus \& Martin, 2008; Downs et al., 
1988; Myers, Brann, \& Members of Comm 600, 2009; Wheeless \& Grotz, 1976; Zhang, 2007). There is evidence that one of these self-disclosure dimensions, relevance, has the most promising potential to enhance both student affect and cognitive learning. Since effective teaching behaviors should lead to positive affective and cognitive learning outcomes (Scott \& Nussbaum, 1981), it is important to examine how using relevant instructor self-disclosure could have the potential to enhance effective teaching. Researchers have identified that self-disclosure relevance is correlated positively with student affect towards the instructor and course overall (Cayanus \& Heisler, 2013; Cayanus \& Martin, 2008; Goodboy et al., 2014) as well as perceptions of student learning (Goodboy et al., 2014; Hill, Ah Yun, \& Lindsey, 2008). Moreover, Sorenson (1989) examined the correlations between specific instructor self-disclosure dimensions and concluded that good teachers use positive self-disclosure that helps clarify course content for students' benefit, whereas poor teachers use negative self-disclosure that focus on their own beliefs unrelated to the lesson material. In other words, students perceived good teachers as using relevant self-disclosure and poor teachers as using irrelevant selfdisclosure.

So far, the correlational studies examining the relevance dimension have provided preliminary evidence that instructor self-disclosure may have the potential to foster student learning, but this correlational evidence relies on students' perceptions of their own learning; in other words, how much students think they learned. Moreover, there are only a few studies that have used an experimental design to examine the effects of instructor self-disclosure (e.g., Hartlep, 2001; McCarthy \& Schmeck, 1982; Stoltz, Young, \& Bryant, 2014) and the findings regarding the benefits of instructor self- 
disclosure have been mixed. The mixed findings may be due to researchers designing the experiments to examine self-disclosure versus no self-disclosure rather than specific selfdisclosure dimensions tied to learning. Since instructor self-disclosure relevance is correlated to perceived cognitive learning (e.g., Goodboy et al., 2014), it is important to examine this specific dimension more closely to determine its effects on student learning. Therefore, the next step would be to conduct an experimental study that manipulates instructor self-disclosure relevance in a real classroom to determine if different types of instructor self-disclosure (relevant or irrelevant) actually cause students to perform better (or worse) on a test of cognitive learning.

Therefore, the goal of this dissertation is twofold. First, the researcher will examine how the relevance (i.e., relevant or irrelevant) of instructor self-disclosure creates or diminishes students' affect toward the instructor. Second, the researcher will propose a model that analyzes how instructor self-disclosure relevance (i.e., relevant and irrelevant) may enhance lesson coherence, and in turn, foster students' cognitive learning. To accomplish these two goals, the researcher will review the current definition, the early history, and the dimensions of instructor self-disclosure.

\section{Instructor Self-disclosure}

Instructor self-disclosure is defined as "a voluntary (planned or unplanned) transmission of information not readily available to students" (Cayanus \& Martin, 2016, p. 243). Researchers have asserted that instructors can build relationships with students through the use of self-disclosure (Fusani, 1994; Galvin, 1999; Mendes, 2003) because these personal disclosures reduce perceptions of power distance inherent in the professional teacher-student relationship and allow students to see their instructors in a 
more personal light (Moreland, 2011). Personal self-disclosures also help achieve instructors' relational goals by fostering student perceptions of caring, connectedness, and liking (Kaufmann \& Frisby, 2017). Ultimately, researchers believe that instructor self-disclosure is an effective teaching-learning strategy because it has the potential to lead to positive student outcomes (Cayanus \& Martin, 2016; Nussbaum \& Scott, 1979; Wilson, 1995).

\section{Early History}

In order to fully understand why instructor self-disclosure can be an effective teaching strategy, it is important to examine the history of self-disclosure research over the past seven decades. For nearly 70 years, scholars have researched how self-disclosure influences relationships between individuals. Researchers began examining self-

disclosure in the early 1950s. Research first emerged from the psychology field where Block (1952) conceptualized self-disclosure as a process of communicating about one's self to others. This research was then embraced by a Canadian psychologist and researcher, Sidney Jourard, who discovered that individuals report a greater liking toward people who self-disclose to them (Jourard, 1958, 1959; Jourard \& Lasakow, 1958). Jourard (1964) summarized his research in his book The Transparent Self, which advocated that individuals should readily disclose about themselves to others because it reduces people's uncertainty, and in turn, leads to healthier interpersonal relationships. Moreover, Rubin (1970) identified a phenomenon he labeled disclosure reciprocity that happens in interpersonal interactions. Disclosure reciprocity occurs when one individual's disclosure encourages another individual's disclosure, which in turn, encourages the first individual to disclose more. This process ultimately leads to intimacy 
and relationship development through the reciprocal sharing of personal information (Dindia, 2002).

Throughout the 1960s and 1970s, psychology researchers continued to examine how self-disclosure functioned within social interactions. Worthy, Gary, and Kahn (1969) found that as an individual disclosed deeper personal (i.e., intimate) information about him or herself, a social partner reported increases in interpersonal attraction toward the individual. Within a therapeutic context, Jourard (1970) found that an increased number of therapist self-disclosure evoked more client self-disclosure, which suggested that selfdisclosure may be reciprocal. These findings led Jourard (1971) to posit that selfdisclosure is multidimensional; comprised of both depth (i.e., the extent to which selfdisclosures are deeply personal) and amount (i.e., the number of self-disclosures offered). Building from over 20 years of self-disclosure research, Altman and Taylor (1973) conceptualized Social Penetration Theory, which posits that interpersonal relationships develop primarily through reciprocal self-disclosure in five systematic stages. The first stage is the orientation stage by which individuals communicate with short, shallow, and inconsequential talk. The second stage is the exploratory-affective stage that occurs when individuals begin to reveal themselves by expressing personal attitudes toward general topics such as education and politics. This stage typically includes casual relationships such as friendships, co-workers, and teachers, thus many interpersonal relationships do not go beyond the exploratory-affective stage. The third stage is the affective stage that occurs when individuals start to talk about deeply private matters of their lives, which has the potential to lead to judgment and criticism because the individuals do not yet know how to react to learning new intimate private information 
about their partner. The fourth stage is the stable stage where personal information is readily shared between the two parties and the individuals can now predict the emotional reactions of one another in order to avoid arguments or criticism. The fifth stage is depenetration and may occur if one individual perceives the costs of maintaining the interpersonal relationship to outweigh the benefits. If the costs exceed the benefits, there is a lessening of personal self-disclosure that can ultimately lead to the termination of the interpersonal relationship between the two individuals (Altman \& Taylor, 1973).

Altman and Taylor (1973) used Social Penetration Theory to help describe how individuals use personal self-disclosure to uncover different layers of people's attitudes, beliefs, and values. The peripheral layers are typically impersonal attitudes and opinions, the middle layers are more personal beliefs and feelings, and the core layers are deeply held values. As individuals learn about one another using personal self-disclosure, the layers are uncovered to reveal the core of the individuals. These layers are described as having both breadth and depth. Breadth is the variety of topics disclosed about one's life. Depth is the extent of information available on any given topic, also known as the degree of disclosure intimacy. Social Penetration Theory posits that as an interpersonal relationship develops, personal disclosures move from being few and shallow (i.e., peripheral layers) to many and deeply intimate (i.e., core layers). The theory suggests that interpersonal relationships follow this pattern, and if an individual discloses too much personal information too quickly before establishing trust, it may push people away (Altman \& Taylor, 1973).

Early research in education examined general teacher classroom behaviors and discovered that educators often used personal disclosures in class. Researchers found that 
instructor self-disclosure helped to foster a positive and warm classroom climate (Aspy, 1969). Moreover, teachers who self-disclosed and used verbal immediacy behaviors (e.g., calling students by name, using “we” language) increased students' willingness to participate (Woolfolk \& Woolfolk, 1975) and likelihood to reciprocate self-disclosure (Woolfolk, Garlinsky, \& Nicolich, 1977). However, given that these studies examined both instructor self-disclosure and verbal immediacy behaviors together, the unique effects of instructor self-disclosure on student participation and reciprocal self-disclosure were not isolated.

Within the communication studies discipline, self-disclosure research began to gain traction in the 1970s. Wheeless and Grotz (1976) were the first to conceptualize and operationalize self-disclosure within a teaching and learning context. Shortly thereafter, self-disclosure was recognized as an important facet of a teacher's communicator style and central aspect of effective teaching (Norton, 1977). Students exposed to dramatic instructors who often shared personal disclosures rated these instructors as highly effective on a teacher effectiveness scale that included aspects of student motivation, instructor clarity, and interest in lesson material. Instructor self-disclosure was also associated positively with affective learning and behavioral intention to engage in communication practices suggested in a lesson (Nussbaum \& Scott, 1979). Overall, these early researchers discovered that instructors who self-disclosed in class had students that reported higher ratings for teacher effectiveness, greater liking for the course content, and increased likelihood to engage in suggested classroom behaviors.

Even with these initial studies, instructor self-disclosure research was only studied by a handful of researchers who felt that more work was required to better understand the 
teaching behavior. Scott and Nussbaum (1981) stated that research studies "specifically targeted at the classroom consequences of a teacher's self-disclosure are a rarity in the instructional literature" (p. 46) and suggested that more research be conducted on instructor self-disclosure. Nussbaum and his colleagues decided to continue this research by exploring what instructors were disclosing in the classroom and how students perceived these disclosures. Nussbaum, Comadena, and Holladay (1987) found that novice instructors most often disclosed about their personal beliefs, favorite leisure activities, personal problems, and friends and family, whereas award-winning instructors regularly self-disclosed about religion, taxes, politics, and ideas directly related to course content. Regardless of the topic, instructional researchers concluded that instructor selfdisclosure is a teaching behavior that has the potential to help clarify course material (Downs et al., 1988; Nussbaum et al., 1987).

Research on instructor self-disclosure continued in the late 1980s with an important study conducted by Sorensen (1989), who defined it as, "teacher statements in the classroom about the self that may or may not be related to the subject content, but reveal information about the teacher that students are unlikely to learn from other sources" (p. 260). Sorensen's study identified the types of self-disclosures shared by good and poor teachers. The most common type of instructor self-disclosure (shared by both good and poor teachers) was "commonly held beliefs," which included self-disclosures such as "I believe in the human rights movement" and "You can be great, no matter what you do" (p. 266). The researcher found that good teachers are those who share highly positive, honest, and intentional disclosures that help increase student liking toward the instructor, whereas poor teachers share highly negative disclosures that reduce 
perceptions of instructor liking.

In the early 1990 s, researchers continued to examine self-disclosure as a pedagogical strategy. Nussbaum (1992) suggested that self-disclosure was an effective teaching behavior because it could lead to positive teacher evaluations and positive student outcomes such as clarification of course content, enhanced perceptions of interpersonal solidarity, and increased reports of affective learning. However, subsequent researchers found both benefits and drawbacks related to instructor self-disclosure in the classroom. One benefit of instructor self-disclosure is that it may allow students to feel more comfortable in sharing personal details about themselves, leading to greater classroom participation (Goldstein \& Benassi, 1994). Another benefit is that many students enjoy instructor self-disclosure because they wish to get to know their instructors on a more personal level (Deiro, 1997; Martin, Myers, \& Mottet, 1999). Conversely, Kearney, Plax, Hays, and Ivey (1991) found that some students perceive instructors as misbehaving when they disclose too much and/or stray from the class subject when sharing personal disclosures. Given the evidence of both benefits and drawbacks, the effectiveness of instructor self-disclosure may depend on the quality of the self-disclosure and how researchers are measuring students' perceptions of instructor self-disclosure in the classroom. Therefore, it is important to examine the different dimensions of selfdisclosure that researchers have considered.

\section{Self-disclosure Dimensions}

Self-disclosure is not a unidimensional construct (Altman \& Taylor, 1973; Wheeless \& Grotz, 1976). Researchers have identified and measured many different dimensions of self-disclosure. In total, researchers have identified 10 dimensions of self- 
disclosure that may impact effectiveness in a classroom context: amount, depth, intent, honesty, breadth, topic, timing, appropriateness, valence, and relevance (Altman \& Taylor, 1973; Cayanus \& Martin, 2008; Wheeless \& Grotz, 1976; Zhang, 2007). To date, there are no published studies that have measured all 10 dimensions in a single study. This section reviews the relevant research for each of these dimensions.

\section{Amount}

Amount is defined as "how often a teacher uses self-disclosure" (Cayanus \& Martin, 2016, p. 251). It is the most studied dimension of self-disclosure and describes how some instructors may disclose more frequently than others. Historically, researchers of interpersonal self-disclosure have identified both a positive relationship (Halverson \& Shore, 1969) and a curvilinear relationship (Cozby, 1972) between self-disclosure and liking. Thus, it may be that moderate to high amounts of instructor self-disclosure could be the best method to increasing how much students like an instructor. Conversely, Sorensen (1989) found that good teachers were perceived as disclosing significantly less compared to poor teachers, even though the amount of disclosure was the same in both conditions. Likewise, researchers suggests that instructors have the potential to disclose too often and are then perceived as misbehaving in the classroom context (Kearney et al., 1991; Sidelinger \& Bolen, 2015).

How much self-disclosure should instructors use during instruction to increase student liking? To answer this question, instructional communication researchers first needed to determine if instructor self-disclosure functioned similarly to interpersonal selfdisclosure. After conducting a meta-analysis to further examine the relationship between interpersonal self-disclosure and liking, Collin and Miller (1994) posited the "disclosure- 
liking hypothesis," which suggests that when an individual discloses more to an interpersonal partner, the partner will report greater liking for the disclosing individual. Lannutti and Strauman (2006) then conducted a study testing the "disclosure-liking hypothesis" in the classroom context. They found when instructors used self-disclosure that were perceived by students to be honest, intentional, and positively valenced, the instructors received better teaching evaluations. However, higher amounts of instructor self-disclosure did not lead to more positive teaching evaluations.

Even though the amount of instructor self-disclosure may not be related to student liking, amount has been associated with other positive student outcomes. Cayanus and Martin (2002a, 2002b, 2004) created and validated the 18-item unidimensional Instructor Self-disclosure Scale that measured the amount of self-disclosure that an instructor used when teaching. The researchers found that instructor self-disclosure use is positively related to instructor assertiveness, instructor responsiveness, and student trust (Cayanus \& Martin, 2002b). Moreover, greater amounts of instructor self-disclosure were also associated positively with out-of-classroom communication (Cayanus \& Martin, 2004) and students' participation in classroom discussions (Cayanus, Martin, \& Weber, 2003). Overall, instructors who self-disclose often when teaching have students who report feeling comfortable communicating with their instructor. It may be that when an instructor discloses frequently, students may feel obligated to respond in kind due to the reciprocal nature of self-disclosure (Cozby, 1973). Taken together, instructors who selfdisclose more are seen as open and willing to engage to a greater extent about the course content in an interpersonal manner, which allows students to feel more comfortable communicating with the instructor in and out of the classroom. 
Instructors who often disclose personal information create a climate where students feel that the instructor is approachable (Hosek \& Presley, 2018). The amount of self-disclosure is associated positively with relational (i.e., develop an interpersonal relationship with the instructor), participatory (i.e., demonstrate knowledge of course content), sycophantic (i.e., leave a favorable impression on the instructor) and excusemaking (i.e., describe why assignments are late and/or incomplete) student motives to communicate with their instructor (Cayanus \& Martin, 2004; Cayanus, Martin, \& Goodboy, 2009). Frequent instructor self-disclosure also allows students to feel more comfortable gaining information about the class. Cayanus, Martin, and Myers (2008) found that instructor self-disclosure amount was positively related to overt (i.e., directly approaching the instructor), third-party (i.e., gain information from a fellow classmate), and observing (i.e., acquire information by watching) information-seeking strategies. Moreover, Goodboy and his colleagues (2014) have found that the more an instructor self-discloses in class, the less likely students are to engage in expressive dissent (i.e., students vent to fellow classmates for cathartic purposes).Given these findings, higher amounts of instructor self-disclosure may create a classroom climate that allows student to feel comfortable communicating with their instructor, seeking information about the course, and refraining from complaining about course issues to their classmates.

However, one study provided evidence that too much instructor self-disclosure may have the potential to lead to student incivility in the classroom because it may "flatten the classroom hierarchy" to the point where students feel able to act out in ways that they would outside of a professional classroom environment (Trad et al., 2012, p. 51). Thus, Cayanus (2004) suggested that instructors be aware of the amount of self- 
disclosure used during instruction by gathering feedback from students and gauging whether or not the personal disclosures are assisting with students' learning.

Higher amounts of instructor self-disclosure also have positive outcomes for student learning. Instructors who self-disclosed frequently had students reporting higher ratings of teacher clarity (Cayanus \& Martin, 2008) and reduced levels of receiver apprehension (Goodboy et al., 2014). It may be that instructor self-disclosure clarifies course content to help students better understand complex classroom concepts as earlier research has shown (Downs et al., 1988). Students also reported more state motivation (Cayanus \& Heisler, 2013; Goodboy et al., 2014), motivation to attend class (Cayanus \& Martin, 2008), and interest (i.e., meaningfulness and impact dimensions; Cayanus \& Martin, 2004, 2008) when instructors disclosed often in the classroom. Frequent instructor self-disclosure might help students understand why a classroom task is valuable (i.e., meaningfulness) and how completing this task can make a difference in their lives (i.e., impact), which may lead to higher reports of interest and motivation to complete classroom objectives. Instructor self-disclosure amount is associated positively with student affective learning (Cayanus \& Martin, 2008; Goodboy et al., 2014) and perceived cognitive learning (Goodboy et al., 2014), although some researchers have found no relationship between self-disclosure amount and students' reports of affective learning (Cayanus \& Heisler, 2013; Walker, 1999). Self-disclosure amount is also related positively to students' intentions of taking another class of similar content in the future (Walker, 1999). Instructors who self-disclose have students reporting greater liking toward the course content, the course instructor, and a better understanding of the lesson material. However, given that the overall findings of self-disclosure amount are mixed 
and do not specifically identify how often, per class, an instructor should self-disclose, it is important to further examine other dimensions of instructor self-disclosure.

\section{Depth}

Self-disclosure depth is defined as "the level of intimacy or privacy that information reveals" (Cayanus \& Martin, 2016, p. 246). Depth was one of the first selfdisclosure components identified in Social Penetration Theory (Altman \& Taylor, 1973). Although researchers have identified depth as being important for fostering liking (Collin \& Miller, 1994; Jourard \& Lasakow, 1958) and interpersonal attraction (Worthy et al., 1969), it is less important for instructor self-disclosure in the classroom because researchers assert that instructor self-disclosure should be "more illustrative than revealing" (Lannutti \& Strauman, 2006, p. 66). Sorensen (1989) found that disclosure depth did not differ between perceptions of good and poor teacher profiles. Depth was also not associated with student perceptions of teacher expertness, trustworthiness, and social attractiveness (McCarthy \& Schmeck, 1982). Lannutti and Strauman (2006) posited that greater depth of instructor self-disclosure would lead to more positive teacher evaluations, but found that disclosure depth was unrelated to teaching evaluations. Bell (2003) identified a small positive correlation between the depth of instructor selfdisclosure and students' intention in taking another course with similar content. Therefore, instructor self-disclosure depth may help students like the course content more, but further research is needed to support this claim.

Woolfolk (1979) found that students actually preferred an instructor who shared low to moderately intimate disclosures rather than an instructor who shared highly intimate disclosures. Researchers outside of instructional communication have found that 
moderately intimate personal disclosures from higher-powered figures (e.g., counselors or supervisors) produce more favorable evaluations than highly intimate personal disclosures (Curran \& Loganbill, 1983; Curtis, 1981; Kleinke \& Kahn, 1980; Loeb \& Curtis, 1984). Conducting an experiment, Clark (1978) found that an instructor who selfdisclosed at moderately intimate levels was perceived more positively by students than an instructor who disclosed at highly intimate levels who was ultimately perceived more negatively. However, instructors' personal disclosures about another person (e.g., friend) were rated most positive at higher intimacy levels and least positively at moderate levels of intimacy (Clark, 1978). Students may prefer instructors who use low intimacy selfdisclosure because of the professionalism of the classroom context (Cayanus \& Martin, 2016). Instructor self-disclosure may help to establish immediacy at low levels of intimacy, but may have the potential to "muddy the professional boundary between instructor and student" at high levels of intimacy (Lannutti \& Strauman, 2006, p. 96). It may be that too much in-depth instructor self-disclosure may blur the lines between perceiving the instructor as an authority figure and instructor as a friend (Moreland, 2011). Because researchers have asserted that instructor self-disclosure should be primarily used to illustrate complex course content rather than reveal inner aspects of an instructor's personal life (Lannutti \& Strauman, 2006), self-disclosure depth appears to be less important in the classroom context.

\section{Intent}

When disclosing in the classroom, instructors may intentionally or unintentionally reveal personal information to students (Nussbaum \& Scott, 1979). Intent is defined as "the conscious willingness of an individual to reveal information about him or herself" 
(Zhang, 2007, p. 15). In other words, the intent dimension examines the extent to which an instructor is perceived as being aware that they are disclosing personal information. It is important to note that it is the students' perception -- not the instructor's intent -- that ultimately determines how students will react to an instructor's personal disclosures (Cayanus \& Martin, 2016). Wheeless and Grotz (1976) first identified the intent dimension when they constructed the Reported Self-disclosure Scale. Since then, research on the intent dimension has been limited. Sorensen (1989) found that students perceived that good teachers are more intentional with their self-disclosure compared to poor teachers. Punyanunt-Carter (2006) replicated Sorensen's (1989) study, but found no significant differences for intent between good and poor teacher profiles. Other researchers found that perceptions of more intentional instructor self-disclosure led to more positive teaching evaluations (Lannutti \& Strauman, 2006). The researchers reasoned that students perceived the instructor self-disclosure as more intentional because the disclosures were relevant to the lesson and helped clarify course content compared with less intentional personal disclosures that seemed out-of-place and unrelated to the lesson (Lannutti \& Strauman, 2006). Given the little evidence, it seems as though the perception of self-disclosure intent may be beneficial to how students perceive a teacher's personal disclosure. However, it may be better to examine self-disclosure relevance instead because the relevance dimension seems to be more closely tied to students' understanding of the lesson content as suggested by Lannutti and Strauman (2006).

\section{Honesty}

Honesty is another dimension of instructor self-disclosure not often examined in instructional communication research. Honesty is defined as the extent to which students 
perceive an instructor's personal disclosures as being sincere, authentic, and accurately depicting the teacher's true feelings, emotions, and experiences (Wheeless \& Grotz, 1976). When students perceive instructors as being honest with their personal disclosures, it may make disclosures more effective. For example, Nussbaum and Scott (1979) found that the perceived honesty of instructor self-disclosure had a positive relationship with student affective learning (toward the subject matter) and behavioral learning (intent to engage in the communication practices suggested in the course). Moreover, good teachers are perceived as being more honest than poor teachers (Sorensen, 1989) and more honest teachers received more positive teaching evaluations (Lannutti \& Strauman, 2006). Given these findings, it may be important that instructors are seen as being sincere with their self-disclosures. However, it is difficult to understand how students determine if instructor's personal disclosures are actually true and if being honest would have a significant impact on student learning outcomes in the classroom.

\section{Breadth}

Breadth was one of the first self-disclosure components recognized in Altman and Taylor's (1973) Social Penetration Theory. Breadth is defined as "the number of different topic areas in which the teacher discloses personal experiences or opinions" (Cayanus \& Martin, 2016, p. 246). Researchers have not examined how the range of topics may impact student perceptions because instructors may discuss a plethora of different topics depending on the course subject. Some researchers have described breadth in terms of self-disclosure amount (Sorensen, 1989; Zhang, 2007). However, amount is different from breadth in that an instructor can self-disclose frequently (i.e., amount) without disclosing about a wide array of topics (i.e., breadth). Instructional communication 
researchers have been less interested in the breadth of instructor self-disclosure topics and more interested in the topics themselves.

\section{Topic}

When it comes to instructor self-disclosure, topic is defined as what the instructor is generally disclosing about when teaching (Cayanus \& Martin, 2016). There are two categories of self-disclosure topics: descriptive self-disclosure and evaluative selfdisclosure. Descriptive self-disclosure involves personal facts about the discloser (e.g., personal habits, family, favorite hobbies), whereas evaluative self-disclosure involves sharing personal feelings, opinions, and/or judgments of others (Derlega, Metts, Petronio, \& Margulis, 1993). Holladay (1984) analyzed instructor self-disclosure topics and found that the most reported general topics comprised the instructors' beliefs and opinions, followed by the instructors' experiences and education. Other researchers detailed similar findings that instructors often share personal disclosures about their family and friends, favorite leisure activities, and personal problems (Downs et al., 1988; Javidi \& Long, 1989). McBride and Wahl (2005) asked instructors about the topics they typically revealed to their students. The researchers identified several topical categories that instructors typically reveal (most frequently to least frequently): family, personal feeling/opinions, daily activities, personal history, personal characteristics, personal scholarship, friend stories, and general life events. Gregory (2005) asked students to list any topics that instructors should disclose in class and students reported the following: teacher education, personal experiences, professional experiences, family/friends, and general background information. These findings fit with Zhang, Shi, and Hao's (2009) "common topics" dimension, which includes instructor self-disclosure about personal 
experiences, family and friends, interests, hobbies, and opinions.

However, there are some topics that instructors rarely share, if at all, in the classroom. McBride and Wahl (2005) also asked instructors to identify topics they typically conceal from students. The categories are as follows (most frequently to least frequently): deeply personal information, negative personal relationships, sexual activity, negative aspects of character, off-topic information, negative feelings about students, and religion. Gregory (2005) asked students about which instructor self-disclosure topics should never be disclosed in the classroom; students reported that sexuality, religious beliefs/practices, deep personal problems, political beliefs, and drug/alcohol abuse disclosures were not suitable for the classroom. The "uncommon topics" dimension of the Appropriateness of Instructor Self-disclosure Scale describes some of these topics (e.g., politics, religion, intimate relationships) that students report hearing less from instructors (Zhang et al., 2009). Cayanus and Heisler (2013) replicated some of these qualitative findings when they asked students which topics they felt were inappropriate for an instructor to disclose in class. Specifically, details about sex life, information about things unrelated to class, and negative opinions regarding religion and politics were deemed inappropriate for the classroom context. Other researchers have also found that the topic of instructor sexual activity is viewed by students to be highly negative and inappropriate (Clark, 1978; Hosek \& Presley, 2018). Moreover, Borzea and Goodboy (2016) found that instructor self-disclosure about educational background and family was deemed suitable for the classroom context, whereas instructor self-disclosure about religion and risky behaviors (e.g., drinking, smoking, drug use) was seen as misbehaviors that could potentially interfere with student learning. For the most part, instructors and 
students have similar perspectives as to which topics are suitable (and unsuitable) for the professional classroom context.

Some self-disclosure topics, such as sex life, may always be unsuitable for a professional classroom context. Nonetheless, in some cases it may depend upon how the instructor discloses about the topic during instruction. For example, students react negatively when instructors discuss their personal alcohol drinking behaviors and perceive it as an inappropriate topic for classroom discussion (Borzea \& Goodboy, 2016; Brophy, 2018) to the point where self-disclosing about the topic of alcohol consumption can damage instructor credibility (Hosek \& Thompson, 2009). However, it is important to consider how an instructor discusses topics such as drinking because instructors who advocate for safe drinking behaviors during instruction had students that reported higher ratings of rapport, homophily, and instructor credibility compared to an instructor who disclosed about their personal drinking behaviors (Brophy, 2018). Future research in instructor self-disclosure topics must not simply examine "what" the topic is about, but also "how" the instructor is discussing the topic in the classroom. Therefore, simply examining different self-disclosure topics may not be the most effective way to identify the best methods for how instructors should use personal disclosures.

\section{Timing}

Timing is defined as "knowing when to disclose personal information" (Myers et al., 2009). Timing is not a designated dimension of self-disclosure, nor does it have an instrument to measure it. Nonetheless, there are instructional communication researchers who assert that self-disclosure timing is important during classroom instruction. Cayanus (2004) suggested that instructors be mindful of when they choose to disclose to illustrate 
a point because it can impact the effectiveness of the personal disclosure on student learning. The researcher suggested that a well-timed self-disclosure can be used to catch students' attention, hold students' interest, and solidify students' understanding of a lesson concept (Cayanus, 2004). Other researchers have suggested that timing is important because instructors who know the best time to employ self-disclosure are able to balance these disclosures with lesson material and increase students' perceptions of credibility (Myers et al., 2009). Given the lack of research on timing, it may be better to focus more on another dimension related to timing: relevance. Timing may be related to relevance because an instructor self-disclosure would likely be relevant if it were disclosed at the most suitable time to help clarify the lesson content.

\section{Appropriateness}

An important component of effective self-disclosure is appropriateness (Cooper \& Simonds, 2003). Instructors who use appropriate self-disclosure connect better with their students (Deiro, 1997). Appropriateness of instructor self-disclosure is defined as the extent to which the self-discloser relates the disclosure topic to overarching, agreed upon social norms in a given context (Gregory, 2005). Generally, students perceive instructor self-disclosure as an appropriate classroom behavior (Klinger-Vartabedian \& O'Flaherty, 1989).

However, appropriateness depends upon knowing how to act and speak in specific social situations (Canary \& Spitzberg, 1987). Instructors who disclose personal information about themselves may or may not be perceived as appropriate given the parameters of the social and cultural norms of a particular context. Instructor selfdisclosure that violates norms associated with this context may be perceived as 
inappropriate. For example, students have reported that highly intimate instructor disclosures (e.g., religion, political views) are not appropriate behavior for the classroom (Woolfolk, 1979). However, positive instructor disclosures (e.g., sharing reasons why a person is proud of themselves) are viewed as more appropriate than negative selfdisclosure (e.g., statements that have hurt my feelings; Caltabiano \& Smithson, 1983). Researchers have found it difficult to clarify what is appropriate and inappropriate because instructor self-disclosure appropriateness seems to relate to other factors such as disclosure topic (Hosek \& Thompson, 2009), instructor credibility (Schrodt, 2013), cultural influences (Myers, Zhong, \& Guan, 1998; Zhang \& Oetzel, 2006), and relevance to classroom material (Paluckaite \& Zardeckaite-Matulaitiene, 2015; Zhang, 2010). It is important to better understand appropriateness because it could affect how students reciprocate self-disclosure in class. An instructor that uses inappropriate self-disclosure may unknowingly elicit similar personal disclosures from students because the students now feel that such behaviors are now appropriate for the classroom context (Frisby \& Sidelinger, 2013).

Zhang (2007) created a measurement instrument that focused on the appropriateness of instructor self-disclosure in the classroom. The Appropriateness of Instructor Self-disclosure Scale was comprised of three general domains: topics of selfdisclosure (i.e., the breadth of self-disclosure topics), purposes of self-disclosure (i.e., offering personal disclosures to catch attention, clarify content, and foster instructorstudent rapport), and considerations for students (i.e., the extent to which the disclosures relate to students' grade level, cultural background, and emotional state; Zhang, 2007). After conducting an exploratory factor analysis, Zhang (2007) identified five dimensions: 
common topics (e.g., personal opinions, unique interests), uncommon topics (e.g., religious beliefs, political views, intimate relationship information), common purposes (e.g., offer real-world example, foster positive classroom climate), uncommon purposes (e.g., entertain students, disclose to please themselves), and consideration of students (e.g., student gender, student feelings). While this scale addresses some novel aspects of self-disclosure not previously investigated in research (such as how the instructor considers the students with their personal disclosures), the dimensions suffer from poor reliability. Nonetheless, Zhang's measurement instrument was one of the first attempts to operationalize appropriateness and examine its influence on student perceptions of instructor self-disclosure in the classroom.

In the 2010s, more researchers focused on the extent to which students found it appropriate for instructors to self-disclose in class. Cayanus and Heisler (2013) aimed to expand Cayanus and Martin's (2008) Teacher Self-disclosure Scale -- comprised of the amount, relevance, and negativity instructor self-disclosure dimensions -- by adding appropriateness as a fourth dimension. Initially, the researchers wanted to identify instructor self-disclosure topics that students felt were inappropriate in the classroom. Results of a content analysis found that instructor self-disclosure about sex life, negative opinions about religion and politics, and topics unrelated to class were perceived as inappropriate for the classroom context. These findings were included as items in an exploratory factor analysis, however, none of the items addressing these topics were retained due to weak factor loadings.

Thus, using items from Cayanus and Martin's (2008) Teacher Self-disclosure Scale and Canary and Spitzberg's (1987) modified Social Appropriateness Scale, 
Cayanus and Heisler (2013) sought to create a Revised Teacher Self-disclosure Scale. The exploratory factor analysis led the researchers to retain only two items from the Canary and Spitzberg (1987) scale. The appropriateness dimension comprised the following two items: "My instructor's disclosures are appropriate in class" and "My instructor's disclosures are suitable for the classroom." Cayanus and Heisler (2013) found that appropriateness was correlated positively with affective learning and student motivation to attend class. They concluded that the appropriateness dimension is an important aspect of instructor self-disclosure, but suggested that more research was required to improve the scale since only two items were retained for the newly added appropriateness dimension.

However, it is important to note that Cayanus and Youngquist (2016) conducted a qualitative study to determine whether self-disclosure appropriateness or relevance was more important to students. The researchers concluded that students place more value on how relevant the self-disclosure is to lesson content rather than the social appropriateness of the self-disclosure topic. Therefore, self-disclosure relevance may be the more suitable dimension for future instructor self-disclosure research.

\section{Valence}

Valence is defined as "the perceived positive or negative effects of the selfdisclosure" (Cayanus \& Martin, 2016, p. 251). Wheeless and Grotz (1976) identified that self-disclosure tends to have a general tone that is either positive or negative and included valence as a dimension in their Reported Self-disclosure Scale. Within an interpersonal context, researchers have found that individuals who disclose negative information are perceived as less favorable than those who share positive information (Dalto, Ajzen, \& 
Kaplan, 1979). Other researchers in psychology found that positive self-disclosure elicits more favorable evaluations (e.g., more credible, attractive, and appropriate) than negative self-disclosure (Andersen \& Anderson, 1985; Remer, Roffey, \& Buckholtz, 1983). Instructional communication researchers have reported similar findings for instructor self-disclosure. For example, Sorensen (1989) created profiles for good and poor teachers that included a list of personal disclosures for each teacher profile. Good instructor selfdisclosures were positive and altruistic (e.g., "I'll go out of my way to avoid hurting someone"), whereas poor instructor self-disclosures were negative and cynical ("I suspect people's motives when they compliment me").

As aforementioned, Cayanus and Martin (2008) integrated valence into their measure of instructor self-disclosure with the negativity dimension (since the original positivity items did not factor well during scale construction). Negativity involves disclosing bad, immoral, and undesirable information to students during instruction (Cayanus \& Martin, 2008). The researchers believed that adding the concept of selfdisclosure valence was important because studies by Sorensen (1989) and Lannutti and Strauman (2006) found that students gave instructors more positive teaching evaluations when they shared positive self-disclosure compared with negative self-disclosure. Therefore, the degree of negativity in instructor self-disclosure must play a role in how students perceive their instructors in the classroom.

Instructional communication researchers have found that negative self-disclosure is related to many detrimental student outcomes such as decreased student interest (Cayanus \& Martin, 2008), reduced state motivation (Cayanus \& Heisler, 2013; Goodboy et al., 2014), decreased perceptions of affective learning (Walker, 1999), and less 
motivation to attend class (Cayanus \& Martin, 2008). Moreover, negativity is related inversely to student perceptions of teacher clarity (Cayanus \& Martin, 2008) and associated positively with receiver apprehension (Goodboy et al., 2014). Cayanus and Martin (2016) suggested that negative instructor self-disclosure causes heightened student anxiety, which may interfere with the processing of lesson material. Negative instructor self-disclosure is also correlated positively with increased ratings of expressive and vengeful dissent (Goodboy et al., 2014). If instructors feel that the classroom is an appropriate place to air their personal grievances, students may reciprocate by complaining about the instructor and trying to hurt the instructor's reputation when they perceive classroom injustices. Ultimately, it seems that negative instructor self-disclosure is not in the instructors' or students' best interests.

Conversely, many researchers have identified that positive instructor selfdisclosure is well-received by students. Instructors who share highly positive personal disclosures had students that reported more favorable teaching evaluations (Lannutti \& Strauman, 2006), greater teacher liking (Hill, Ah Yun, \& Lindsey, 2008), and higher ratings of affective learning (Cayanus, 2005; Cayanus \& Martin, 2008; Goodboy et al., 2014; Walker, 1999). Additionally, students report greater intentions of taking another class with the same instructors when they perceive those instructors as sharing positive self-disclosure (Bell, 2003). To summarize the importance of sharing positive disclosure, Cayanus and Heisler (2013) recommended, "If teachers do not have positive information to reveal about them that is relevant to their courses, these teachers should probably stick to the content of the course and decrease or eliminate personal statements" (p. 8).

However, there are arguments that negative instructor self-disclosure may not 
always be perceived as unfavorable. Negative self-disclosure has the potential to make an instructor appear more human and more approachable if they are perceived as being open by disclosing both positive and negative information about their lives (Cayanus, 2007; Cayanus \& Martin, 2008). Instructors that only reveal positive information about themselves may encounter negative consequences such as making their students feel inferior or coming off as narcissistic (Cayanus, Martin, \& Goodboy, 2009). An instructor who shares both positive and negative aspects of their lives may avoid these potential problems. Negativity is also associated positively with the relational, participatory, excuse-making, and sycophantic motives to communicate (Cayanus et al., 2009). Even though an instructor may share some darker aspects of their lives, some students still feel comfortable communicating with them for both interpersonal and classroom-related reasons. Moreover, the valence of instructor self-disclosure may not necessarily influence student learning. Goodboy and his colleagues (2014) did not find a relationship between self-disclosure valence and perceptions of cognitive learning. Cayanus and Martin (2016) argue that more researchers should examine self-disclosure valence because it may lead to a comprehensive understanding of how students perceive instructor self-disclosure in the classroom. More importantly, the same scholars suggest that future self-disclosure research should focus on the relevance dimension because it may have the greatest potential to influence students' cognitive learning (Cayanus \& Martin, 2016).

\section{Relevance}

Deiro (1997) suggested that instructor self-disclosure should always be pertinent to the learning content. When it comes to instructor self-disclosure, relevance is defined as "how the disclosure relates to class material" (Cayanus \& Martin, 2016, p. 251). 
Relevance is argued to be "the most significant dimension which has to be considered before disclosing to the classroom" (Paluckaite \& Zardeckaite-Matulaitiene, 2015, p. 21). The relevance dimension was originally identified in Wheeless and Grotz's (1976) Reported Self-disclosure Scale, however, future researchers using this scale did not include this dimension in their self-disclosure studies (e.g., Cayanus \& Martin, 2004; Lannutti \& Strauman, 2006; Punyanunt-Carter, 2006; Sorensen, 1989; Wambach \& Brothen, 1997). When Cayanus and Martin (2008) added the relevance dimension to the Teacher Self-disclosure Scale, it became an integral aspect of instructor self-disclosure for current research.

Cayanus and Martin (2008) expanded their original Instructor Self-disclosure Scale, which only measured amount, to develop the multidimensional Teacher Selfdisclosure Scale. Rather than solely focusing on the amount of instructor self-disclosure, the expanded scale added two new dimensions: relevance (i.e., the extent that selfdisclosure relates to the course material) and negativity (i.e., the extent to which selfdisclosure is generally more negative than positive). Cayanus and Martin believed it was important to add the relevance dimension because previous researchers had found that many instructors used personal disclosures to clarify lesson material (Downs et al., 1988; Javidi \& Long, 1989; Wambach \& Brothen, 1997). If instructor self-disclosure clarifies material, it must be highly relevant to the course content in order to do so. Cayanus and Martin (2008) created a 14-item, three dimension measure for instructor self-disclosure and found that self-disclosure relevance was correlated positively with instructor clarity, student interest, student affect toward the instructor, and student motivation to attend class. These findings added support for how relevant instructor self-disclosure may help 
clarify lesson material with its relationship to instructor clarity. Cayanus and Martin (2008) concluded that relevance was an important dimension of instructor self-disclosure that may be related to effective teaching.

It is important that instructors clearly relate the relevance of their personal disclosures to the course material in order to be perceived as an effective teacher (Andersen, Norton, \& Nussbaum, 1981). Instructor self-disclosure is different from selfdisclosure in personal relationships because instructor self-disclosure should be "more illustrative than revealing" (Lannutti \& Strauman, 2006, p. 96). Therefore, Lannutti and Strauman (2006) concluded that instructor self-disclosure should be used to help clearly demonstrate course content rather than to express deeply intimate aspects of the instructor's personal life. In doing so, instructors that use relevant self-disclosure may also establish a better classroom communication climate.

Instructors who share relevant self-disclosures may improve instructor-student communication in the classroom. Researchers have found that relevant instructor selfdisclosure is associated positively with the functional motive to communicate, in which students are more motivated to communicate with their instructor to learn more about the lesson material (Cayanus et al., 2009). Moreover, students report feeling more comfortable using overt, third-party, and observation information-seeking strategies when their instructors use relevant self-disclosure in the classroom (Cayanus et al., 2008). Researchers have also found that relevant instructor self-disclosure is related negatively to students' expressive and vengeful dissent (Goodboy et al., 2014). In other words, students are less likely to vent to other students about the instructor (i.e., expressive dissent) or to attempt to sabotage the instructor's credibility (i.e., vengeful dissent) when 
their instructor shares self-disclosure that is highly related to class content. Ultimately, when instructors share relevant self-disclosure during instruction, students feel more comfortable gaining course information from their instructor and their peers, and feel less inclined to complain about the instructor to others. Because relevant instructor selfdisclosure helps clarify content and allows students to feel comfortable communicating in the classroom, these personal disclosures also have positive effects on outcomes related to student learning.

The use of relevant instructor self-disclosure is associated with positive student outcomes. Researchers have identified positive relationships between relevant selfdisclosure and student state motivation (Cayanus \& Heisler, 2013; Cayanus \& Martin, 2008; Goodboy et al., 2014). Cayanus and Martin (2008) have also found that relevant instructor self-disclosure is related positively to student interest within the meaningfulness and competence dimensions. Relevant instructor self-disclosure helps link the course material to the students' own lives (Cayanus \& Martin, 2016), and therefore may increase students' motivation and interest to learn the material because the content has been clearly related to the students' personal experiences. Researchers have also found that relevant self-disclosure is related negatively to student receiver apprehension (Goodboy et al., 2014). If students perceive that instructor self-disclosure is relevant to the lesson material, the personal disclosures may assist students in understanding the content and reduce anxieties when processing the new information. Moreover, students report greater affect toward their instructors (Cayanus \& Heisler, 2013; Cayanus \& Martin, 2008; Goodboy et al., 2014) and higher ratings of perceived cognitive learning (Goodboy et al., 2014) when their instructors share relevant personal 
disclosure. Overall, relevance is an important dimension of instructor self-disclosure that merits further research because relevant instructor self-disclosure may have the potential to foster student learning as well as other positive student outcomes (Cayanus \& Martin, 2016).

\section{Outcomes of Instructor Self-disclosure}

Researchers have identified many classroom outcomes related to instructor selfdisclosure in the classroom. This section will examine three instructor self-disclosure outcomes: affect, clarity, and cognitive learning. While other instructor self-disclosure outcomes have been investigated such as motivation (Cayanus \& Martin, 2004), participation (Goldstein \& Benassi, 1994), classroom climate (Mazer, Murphy, \& Simonds, 2007), and instructor credibility (Schrodt, 2013), this dissertation will examine affect, clarity, and cognitive learning. Affect will be examined because of its relationship to student cognitive learning. Allen, Witt, and Wheeless (2006) conducted a metaanalysis on the relationship between affective learning (i.e., affect) and cognitive learning (i.e., performed cognitive learning). The researchers found a positive average correlation between student affect and performed cognitive learning. In other words, on average (across eight different studies), students who reported greater affect toward the course and the instructor tended to score higher on a test of retention. Clarity will be examined because there is evidence to suggest that instructor self-disclosure may foster student cognitive learning through clarity (using findings on lesson coherence; Bolkan, 2017; Mayer \& Moreno, 2003). Therefore, the goals of this dissertation are to better understand how instructor self-disclosure relevance impacts students' affect towards the instructor as well as how instructor self-disclosure relevance influences perceptions of lesson 
coherence, and in turn, fosters student cognitive learning.

Affect

Affect is an important student outcome that instructional communication researchers have examined for decades. Traditionally, instructional communication scholars have conceptualized "affect" as "affective learning," which is defined as positive attitudes that students perceive toward the instructor, course content, and/or the behaviors recommended in the course (Andersen, 1979; McCroskey, Richmond, Plax, \& Kearney, 1985). Unfortunately, this is a misinterpretation of Krathwohl, Bloom, and Masia's (1964) original conceptualization of affective learning that focuses on a hierarchical taxonomy (i.e., attending, responding, valuing, organization, characterization) that describes how students ultimately learn to internalize the value of lesson content. More recently, scholars have transitioned to using the definition of positive student attitudes toward the instructor, course content, and recommended course behaviors to describe student "affect" (or "affective experience;" Bolkan, 2015) rather than student "affective learning" (see Myers \& Goodboy, 2015 for a review). Even though instructional communication scholars may have been inadvertently measuring affect rather than affective learning, Bolkan (2015) argued that affect is still an important mediating factor linking instructor behaviors to student outcomes such as motivation (Pekrun, Goetz, Frenzel, Barchfield, \& Perry, 2011) and perceived cognitive learning (Rodriguez, Plax, \& Kearney, 1996).

Self-disclosure is a relational instructor behavior that plays an integral role in the development of the teacher-student relationship through increasing student affect (Sorensen, 1989). Many instructors use self-disclosure because they feel it helps them 
connect to their students on a more personal level (Katadae, 2005). Students perceive instructors as sharing personal disclosures in order to make a personal connection with them and increase perceptions of affect toward the instructor and the course in general (Gregory, 2005). From the perspectives of both instructors and students, instructor selfdisclosure is an important relational communication behavior in the college classroom. Many researchers have found positive relationships between instructors' use of self-disclosure and student affect toward the course instructor (Cayanus, 2005; Cayanus \& Heisler, 2013; Cayanus \& Martin, 2008; Goodboy et al., 2014; Kennedy, 2005; Mazer et al., 2007; O’Sullivan, Hunt, \& Lippert, 2004; Sorensen, 1989; Walker, 1999), the course content (Cayanus, 2005; Cayanus \& Heisler, 2013; Cayanus \& Martin, 2008; Goodboy et al., 2014; Gorham, 1988; Nussbaum \& Scott, 1979; O’Sullivan et al., 2004; Sorensen, 1989; Walker, 1999), and students' intentions to engage in the behaviors recommended in the course (Goodboy et al., 2014; Gorham, 1988; Nussbaum \& Scott, 1979; O’Sullivan et al., 2004; Walker, 1999). Some researchers have also found a positive association between instructor self-disclosure and their likelihood of taking a future course with the same instructor (Mazer et al., 2007; Walker, 1999), whereas other researchers have found that too much instructor self-disclosure would dissuade them from taking another class with the same instructor (Kennedy, 2005). In accordance with affect, Zajac (2011) found that students appreciate when their instructors share personal disclosures to relate to lesson content because it demonstrates how material is applicable to students and helps them "learn in ways that a textbook cannot provide" (p. 121). Ultimately, when instructors self-disclose in the classroom, it has the potential to increase students' positive attitudes toward both the instructor and the course material. 


\section{Clarity}

It is important that instructors are clear when teaching so that students can adequately understand the lesson material. Clarity is defined as "students' perceptions of teachers' communication-related behaviors that assist in selecting, understanding, and remembering information" (Titsworth \& Mazer, 2016, p. 105). Early research on instructor clarity suggested that it had a strong connection to student learning (Rosenshine \& Furst, 1971). Recent research has supported those findings using multiple meta-analyses, which suggest that there is a moderate-to-strong relationship between clarity and student reports of affective learning and cognitive learning (Titsworth, Mazer, Goodboy, Bolkan, \& Myers, 2015).

There are five general areas of instructor clarity: pre-instructional clarity (i.e., how the instructor aligns learning objectives and assessments), organizational clarity (i.e., how the instructor uses verbal, nonverbal, and visual cues to organize lesson information), explanatory clarity (i.e., how the instructor expands upon lesson details to provide practical understand), language clarity (i.e., how the instructor uses syntax, semantics, and fluency to communicate lesson information), and adaptive clarity (i.e., how the instructor responds to students' needs during classroom information exchange; Titsworth \& Mazer, 2016). The five general areas are meant to help researchers more accurately examine how instructor communication behaviors influence students' perceptions of clarity.

The general area of explanatory clarity details how instructors give substance to the structure of their lectures. When instructors are providing information in class, their main goal is to assist students in acquiring and remembering knowledge. In order to carry 
out this goal, instructors share knowledge in three forms: declarative knowledge, procedural knowledge, and conditional knowledge (Alexander, Schallert, \& Hare, 1991). Declarative knowledge is the facts related to new information such as definitions and terminologies. Procedural knowledge describes how students can use the information to perform specific tasks. Conditional knowledge assists students in understanding the practical application of the new information in real life situations. Together, these three forms of knowledge make the substance of an instructor's lecture and explanatory clarity "involves the ways in which teachers make such knowledge available to students" (Titsworth \& Mazer, 2016, p. 120).

Instructor self-disclosure likely functions as an explanatory clarity behavior as it can help students understand conditional knowledge. If instructors offer personal disclosures from their real life experiences in order to clarify course content to students (Downs et al., 1988; Javidi, Downs, \& Nussbaum, 1988; Javidi \& Long, 1989), then they are likely providing conditional knowledge so that students can better understand the practical application of the declarative and procedural knowledge within a lesson. The potential for instructor self-disclosure to clarify course material may help explain why Wambach and Brothen (1997) found a positive relationship between instructor selfdisclosure and instructor clarity. When Cayanus and Martin (2008) created the Teacher Self-disclosure Scale, they identified a positive correlation between students' perceptions of instructor clarity and instructor self-disclosure amount and relevance. They also found that clarity was inversely associated with self-disclosure negativity. Other researchers have not found a relationship between instructor self-disclosure and perceptions of clarity (Cayanus \& Martin, 2004). It may be that the relationship between instructor self- 
disclosure and clarity may ultimately depend on how an instructor's personal disclosures are relevant to the lesson material, which aids students' understanding of the content.

\section{Cognitive Learning}

Cognitive learning has been defined as "the acquisition of knowledge and the ability to understand and use knowledge" (Hosek, Crawford, \& Vogl-Bauer, 2018, p. 210). Bloom (1956) created a hierarchical taxonomy of six levels to describe how students acquire knowledge in order of lower-order thinking to higher-order thinking: knowledge, comprehension, application, analysis, synthesis, and evaluation. More recently, Anderson and Krathwohl (2001) revised Bloom's taxonomy of cognitive learning by rewording the terms and reordering the hierarchy, so that it is now as follows: remember, understand, apply, analyze, evaluate, and create. Instructional communication scholars use these taxonomies to better understand how instructors can apply communicative strategies to improve cognitive learning so that students are able to convert lecture information to useful knowledge. Self-disclosure may be one communicative behavior that instructors can use to enhance cognitive learning because of preliminary studies that suggest it can clarify course content (Downs et al., 1988; Javidi et al., 1988; Javidi \& Long, 1989).

Educators believe that instructor self-disclosure has the potential to increase student cognitive learning. Instructors believe that when they "present their own life experiences with lecture ideas, it is a way to successfully merge objectivity with subjectivity for learning" (Scheer, 1999, p. 156). Instructors often use self-disclosure because they believe it enriches students' learning (Katadae, 2005) and helps to reinforce a particular concept being taught (Galvin, 1999). For example, Zajac (2011) interviewed 
instructors and asked them why they disclosed personal information in class in relation to course material. One instructor stated, “A higher level of learning is going on. It isn't just learning what you are going to learn about the test and never think of it again. It is learning that is going to stay with you" (Zajac, 2011, p. 118). Even though instructors believe that self-disclosure is an effective way to increase cognitive learning, it is more important to examine if students feel the same way and perform better in the classroom as a result.

Over the years, researchers have used different methods to measure the effects of instructor self-disclosure on students' cognitive learning. Some researchers have used the Learning Loss Scale (Richmond, Gorham, \& McCroskey, 1987), whereas others have used Frymier and Houser's (1999) Revised Learning Indicators Scale to measure students' perceived cognitive learning. Using the Learning Loss Scale, researchers have found that students report increased ratings of perceived cognitive learning when instructors use self-disclosure when teaching (Cayanus et al., 2003; Gorham, 1988). Using the Revised Learning Indicators Scale, Goodboy and his colleagues (2014) identified a positive correlation between instructor self-disclosure and perceived cognitive learning. Ultimately, students believe that instructor self-disclosure helps their classroom learning experience. While these findings are important, scholars have questioned the usefulness of perceived cognitive learning scales because they do not truly evaluate students' knowledge of the lesson content (Smythe \& Hess, 2005). Even though perceived cognitive learning measures may not illustrate if students have really learned more from instructor self-disclosure, actual class quizzes can test to see if this is true.

Other researchers have implemented tests of retention in order to examine how 
instructor self-disclosure may help (or hinder) students' performed cognitive learning (e.g., test score, final class grade). McCarthy and Schmeck (1982) conducted an experiment that compared a male instructor disclosing personal information during instruction (condition one) to the same male instructor who did not self-disclose during the same lesson (condition two). The researchers found that male students performed significantly better on a test of retention when the instructor self-disclosed. There were no differences in the test scores for female students between the two conditions. The researchers posited that instructor self-disclosure may encourage self-reference by which "male students are more able to identify with, and accept, the self-disclosures of a male teacher who is providing personal examples from his own experiences" (McCarthy \& Schmeck, 1982, p. 11). The researchers concluded that self-reference may act as a mediator to enhance students' memory and learning for the lesson content. Other researchers have found that students performed better on recalling definitional quiz questions in a disclosure condition compared to a non-disclosure condition (Stoltz, Young, \& Bryant, 2012; Stoltz, Young, \& Bryant, 2014; Youells, 1981). Moreover, Hartlep (2001) found that lectures with instructor self-disclosure (compared to lectures without instructor self-disclosure) led to improved exam performance. Students may be able to remember more lecture material and perform better on a test of retention because the instructor relates the lesson content to personal examples from their own lives, and in doing so, reinforces the practical applicability of the material (Strangeways \& Papatraianou, 2016).

Conversely, some researchers have provided evidence that self-disclosure may hinder cognitive learning. Nussbaum and Scott (1979) found that the more that students 
reported instructor self-disclosure, the worse the students performed on a test of retention. Moreover, Naumann (1988) found in an experimental study that "the absence of selfdisclosure aided student performance on a quiz over lecture content” (p. 105). Given these findings, instructor self-disclosure may have the potential to be distracting and detract from student learning.

In other cases, instructor self-disclosure did not lead to any changes in students' learning. Gregory (2005) and Minger (2004) did not find any significant relationships between instructor self-disclosure and perceived cognitive learning using the Learning Loss Scale. Moreover, there were no significant differences in students' final class grades between a three condition experiment (i.e., high, low, and no disclosure) of online instructor self-disclosure (Ivy, 2016). Whether an instructor discloses personal information or not in a face-to-face setting, an experimental study did not find any differences in students' performance as evident by their final class grade (Aubry, 2009). Since the findings have been mixed, Stoltz et al. (2014) concluded that "the connection between cognitive learning and self-disclosure is not clear" (p. 170). In summary, the relationship between instructor self-disclosure and cognitive learning is inconclusive. Correlational studies only provide students' perceptions of increased learning as a result of instructor self-disclosure and the experimental studies do not test any specific selfdisclosure dimension that may be influencing students' cognitive learning. Thus, future research needs to experimentally test the unique effects of specific instructor selfdisclosure dimensions to determine how self-disclosure impacts students' performed cognitive learning in the college classroom.

\section{Rationale}


The purpose of this dissertation is to determine how instructor self-disclosure relevance influences student affect and performed cognitive learning in an experimental setting. To achieve this purpose, the researcher offers two hypotheses. First, the researcher proposes that students will report greater affect toward an instructor who uses relevant self-disclosure as opposed to an instructor who uses irrelevant self-disclosure. Second, the researcher proposes a comprehensive mediation model suggesting that instructor self-disclosure relevance (i.e., relevant/irrelevant) influences lesson coherence, which in turn, impacts students' performance on a test of cognitive learning (see Figure $1)$.

The first hypothesis will determine if relevant instructor self-disclosure will foster more student affect compared to irrelevant instructor self-disclosure. As previously mentioned, affect is defined as students' positive attitudes toward the instructor, the course content, and/or the behaviors recommended in the course (Andersen, 1979). Researchers have conducted several correlational studies to identity a positive relationship between instructor self-disclosure relevance and student affect (Cayanus \& Heisler, 2013; Cayanus \& Martin, 2008; Goodboy et al., 2014). Cayanus and Martin (2008) found that relevant self-disclosure is associated positively with increased affect toward the instructor. Other researchers have found that students liked both the instructor and course content more when instructor self-disclosure was relevant to the lesson (Cayanus \& Heisler, 2013). Furthermore, Goodboy and his colleagues (2014) found that students reported increased affect toward the instructor, the course, and the behaviors recommended in the course when instructors used relevant self-disclosure. Generally, students like instructors who disclose personal information that is relevant to the lesson. 
Conversely, students may report lower levels of affect toward instructors who use irrelevant self-disclosure. Students perceive their instructors as misbehaving when they share personal disclosures that are irrelevant and stray from the lesson topic (Goodboy \& Myers, 2015; Kearney et al., 1991). Moreover, instructors have reported attempts to avoid irrelevant personal disclosures during instruction because they feel it may lead students to express frustration and reduce liking (McBride \& Wahl, 2005). Thus, both students and instructors feel that instructor self-disclosure should be relevant in order to avoid the potential to reduce feelings of affect toward the instructor.

Overall, previous correlational research suggests that using relevant instructor self-disclosure is associated with increased student affect toward the instructor, likelihood of enrolling in a course with the same instructor in the future, and the course overall (Cayanus \& Heisler, 2013; Cayanus \& Martin, 2008; Goodboy et al., 2014). However, this positive relationship has not been tested in a live lecture teaching experiment to determine if student will report greater affect toward instructors who use relevant selfdisclosure compared to irrelevant self-disclosure. Therefore, it is hypothesized that an instructor who uses relevant self-disclosure (compared to irrelevant self-disclosure) should have students report increased scores of affect toward the instructor. Therefore, the first hypothesis is offered:

H1: Compared to a lesson with irrelevant instructor self-disclosure, relevant instructor self-disclosure will create more student affect toward the instructor.

The second hypothesis will explore how instructor self-disclosure relevance affects lesson clarity (i.e., lesson coherence), and in turn, students' performed cognitive 
learning. As aforementioned, self-disclosure relevance is the degree to which an instructor's personal disclosures relate to the lesson content (Cayanus \& Martin, 2016). Students perceive relevant instructor self-disclosure as personal disclosures that are short, quick, and executed at the appropriate time during a lecture to help clarify content (Myers et al., 2009). Moreover, students report higher levels of instructor clarity when instructors use relevant self-disclosure while teaching (Cayanus \& Martin, 2008; Wambach \& Brothen, 1997). However, within these studies, the specific reason why relevant instructor disclosure is related to students' perceptions of instructor clarity is unclear. Therefore, it is important to examine the distinct aspects of instructor clarity to better understand how relevant instructor self-disclosure may impact how students process lesson content.

It is important to examine how instructor self-disclosure may be related to specific aspects of instructor clarity. When developing the Clarity Indicator Scale, Bolkan (2017) identified five dimensions of instructor clarity: disfluency (i.e., struggling to articulate thoughts), working memory overload (i.e., overwhelming students with information), interaction (i.e., assessing students' understanding during instruction), structure (i.e., organizing lectures into manageable portions), and coherence (i.e., supplying unnecessary information in the lectures). Specifically, coherence involves the extent to which instructors avoid providing superfluous information that is not essential to learning the lesson content. When instructors self-disclose when teaching, they are providing supplemental personal information that may be deemed necessary or unnecessary to understanding the lesson depending on whether students perceive this information as relevant or irrelevant for their learning. 
Students may perceive relevant instructor self-disclosure as necessary to learning the lesson content because it provides important conditional knowledge. When instructors regularly describe their own personal experiences in relation to class content, students report that this practice highlights concepts and promotes understanding of the material within a particular context (Downs et al., 1988). This enhanced understanding may occur because relevant instructor self-disclosure conveys the conditional knowledge of the lesson content. As previously mentioned, conditional knowledge is defined as information that an instructor provides to help students understand when and where new declarative knowledge (e.g., facts, terminologies) would be applicable in certain contexts (Alexander et al., 1991). In other words, the inclusion of conditional knowledge provides a rationale for why lesson content is important (Paris, Lipson, \& Wixson, 1983). When an instructor provides a relevant personal disclosure that helps students understand when, where, and why to use new declarative knowledge, students may perceive this supplemental information as essential to learning course concepts, and in turn, enhance the coherence of the lesson. Ultimately, relevant instructor self-disclosure may clarify the usefulness of learning new lesson content and allow them to easily see how this new information applies to real life situations.

Relevant instructor self-disclosure may also help increase lesson coherence because it highlights the most important aspects of the lesson. When teaching, instructors may share optional, but related information to reiterate important lesson ideas. This practice is called redundancy and it has the potential to increase perceptions of clarity because the extra information helps students understand what is most important to focus on about a class concept (Mayer \& Moreno, 2003). If instructor self-disclosure is relevant 
to the lesson content, the personal disclosures may act as a form of redundancy, which may lead to a more coherent lecture, reinforce important ideas, and ultimately clarify content for students. To that point, researchers have found that award-winning instructors regularly self-disclose ideas directly related to course content (Nussbaum et al., 1987). Students perceived instructor self-disclosure from award-winning instructors as having a "content-oriented function" because these disclosures helped students understand the most important aspects of the lesson material (Nussbaum et al., 1987, p. 78). Several other researchers have reached the same conclusion and suggest that the main purpose of using instructor self-disclosure is to clarify course content through the reiteration of important lesson ideas in a personalized manner (Downs et al., 1988; Javidi et al., 1988; Javidi \& Long, 1989).

Irrelevant instructor self-disclosure should have the opposite effect on lesson coherence. At times, instructors may share irrelevant personal disclosures that are perceived as unnecessary to learning the lesson material. When instructors share superfluous information, they may reduce student perceptions of clarity because this unnecessary information can direct students' attention to unimportant aspects of the lesson content (Land, 1979). Moreover, irrelevant instructor self-disclosure may have the potential to tax students' limited memory workload. Students may perceive irrelevant instructor self-disclosure as extraneous cognitive load. Extraneous cognitive load is defined as superfluous information not required to understand important course concepts (Ayres \& Paas, 2012). Irrelevant instructor self-disclosure may reduce perceptions of lesson coherence because students perceive these disclosures as off-topic instructor tangents unrelated to the lesson. These instructor tangents may provide an extraneous 
cognitive load upon the students when they are trying to actively process important lesson material. Researchers have also found that students experience more student receiver apprehension when instructors share irrelevant self-disclosure (Goodboy et al., 2014). The lack of relevant information in personal disclosures might lead students to feel anxious about not clearly understanding important concepts in the lecture, which may impede students' ability to learn the course content. Ultimately, irrelevant instructor selfdisclosure should reduce lesson coherence because it directs attention toward unimportant aspects of the lesson, provides extraneous cognitive load, and increases receiver apprehension. This reduction in lesson coherence reflects an overall lack of instructor clarity, which may lead students to become confused about the most important aspects of the lesson.

Overall, prior studies have provided evidence suggesting that instructors who use relevant self-disclosure should have students report increased lesson coherence and that instructors who use irrelevant self-disclosure should have students report decreased lesson coherence. The next step is to examine the relationship between lesson coherence and performed cognitive learning. If students report increased lesson coherence from instructors who use relevant self-disclosure (compared to irrelevant self-disclosure), students should also perform better on a cognitive learning test. As aforementioned, lesson coherence is a dimension of instructor clarity (Bolkan, 2017). Instructional communication researchers have conducted studies that have determined a positive relationship between instructor clarity and student cognitive learning test performance (e.g., Chesebro, 2003; Comadena, Hunt, \& Simonds, 2007). Moreover, Titsworth et al. (2015) offered two meta-analyses; meta-analysis two (Goodboy, Bolkan, \& Myers) 
provided clear evidence for a moderate positive relationship $(r=.42)$ between instructor clarity and performed cognitive learning. In other words, students taught by a clear instructor tended to score higher on a test of cognitive learning. Because lesson coherence is an integral dimension of clarity, it is expected that lesson coherence will be related positively to students' performance on a test.

Ultimately, it is posited that instructor self-disclosure relevance affects lesson coherence, which in turn, may influence students' performed cognitive learning. If relevant instructor self-disclosure helps clarify course content, then relevant selfdisclosure should foster cognitive learning. When instructors share relevant selfdisclosure, they are perceived to be more clear (Cayanus \& Martin, 2008). When students perceive their instructors as clear (as opposed to unclear), students perform better on tests of cognitive learning (Chesebro, 2003, Titsworth et al., 2015). Therefore, instructors that share personal disclosures that are relevant to the lesson should increase lesson coherence and ultimately increase students' performance on a cognitive learning test. Conversely, irrelevant instructor self-disclosure should make it harder for students to learn the course content because it directs students'attention to unimportant aspects of the lesson (Land, 1979) and increases student receiver apprehension (Goodboy et al., 2014). Therefore, irrelevant instructor self-disclosure should make it more difficult for students to follow along with a lecture, reduce perceptions of lesson coherence, and in turn, hinder students' performance on a cognitive learning test (see Figure 1). Therefore, the second hypothesis is offered:

$\mathrm{H} 2$ : $\quad$ Students will score higher on a test of the material when they attend a lesson with an instructor who uses relevant self-disclosure (compared to 
an instructor who uses irrelevant self-disclosure) because of increased lesson coherence.

When examining the effects of instructor self-disclosure relevance, it is important to consider other variables that may influence the results. These variables include students' comfort with instructor self-disclosure, perceptions of instructor credibility, grade point average (GPA), lesson familiarity, and perceived difficulty of the lesson. These five variables will be controlled for when examining how instructor self-disclosure relevance influences student affect, lesson coherence, and performed cognitive learning.

Students' own level of comfort with receiving personal information must be considered when examining how students will perceive a self-disclosing instructor. According to Communication Privacy Management Theory (Petronio, 1991), individuals have different rules as to what is private information and what is not. If their personal privacy rules are broken, individuals may experience boundary turbulence by which he or she feels discomfort in receiving another person's private information (Petronio, 2002). In other words, students may "resist being treated as involuntary, captive recipients" of an instructor's disclosure of private information (Schrodt, 2013, p. 358), regardless of the relevance of the self-disclosure. If students feel discomfort receiving an instructor's personal information, they may report less affect toward the instructor.

Students' comfort with instructor self-disclosure may also impact lesson coherence when it comes to relevant and irrelevant personal disclosures. If students have a low tolerance of comfortability toward instructor self-disclosure, they may perceive the personal disclosures as irrelevant to a lesson because they simply want the instructor to teach the necessary content without expressing private details of their lives (Schrodt, 
2013). Students uncomfortable with these disclosures may find them irrelevant and less clear to the lesson, even though other students -- who are content with hearing personal details about their instructors -- may find the disclosures to be relevant and helpful in clarifying the material. Therefore, it is important to control for students' comfort with receiving instructor self-disclosure when examining how instructor self-disclosure influences students' perceptions of both affect and lesson coherence.

Students' perception of instructor credibility will also be controlled for when examining the effects of relevant instructor self-disclosure. Instructor credibility is conceptualized as the degree to which students perceive their instructors to be believable (McCroskey, Valencic, \& Richmond, 2004). Consisting of three dimensions (i.e., competence, character, and caring; McCroskey \& Teven, 1999), instructor credibility is associated with instructor self-disclosure use. Evidence from prior studies suggest that the personal information that instructors choose to disclose may either enhance credibility (Myers et al., 2009) or damage credibility (McBride \& Wahl, 2005) depending on how relevant the personal disclosures are to the course lesson (Schrodt, 2013). In a metaanalytical review of instructor credibility, Finn and her colleagues (2009) suggested that instructor credibility is a potential mediator of instructor behaviors and student learning outcomes. Specifically, instructor credibility has the potential to influence affect because students report greater affect toward instructors that they perceive as highly credible compared to less credible instructors (Pogue \& AhYun, 2006). Moreover, students report that clear instructor are more credible compared to unclear instructors (Carbone, 1975). Titsworth and Mazer (2016) suggest that if students do not find their instructors credible they may spend mental resources questioning "the relevance or validity of the 
information their instructors present," and ultimately reduce student perceptions of instructor clarity (p. 189). Thus, instructor credibility may influence students' perceptions of lesson coherence as well. Given the evidence, it is important that instructor credibility is held constant when examining the effects of relevant (and irrelevant) instructor selfdisclosure on affect and lesson coherence.

Three other important variables must be controlled for because they may affect students' performance on test of cognitive learning. Some students may have prior knowledge of the lesson material. Lesson familiarity has the potential to influence students' scores on a short-term recall test (Bolkan, Goodboy, \& Myers, 2017). Similarly, students' test performance has been found to be influenced by perceived difficulty of material (Bolkan, Goodboy, \& Kelsey, 2016) and students' GPA (Bolkan \& Goodboy, 2019) in prior teaching experiments. Therefore, it is important to control for these three variables when examining the specific effects of relevant instructor self-disclosure on students' test performance (see Figure 1). 
Figure 1

Hypothesized Conceptual Model of Hypothesis 2

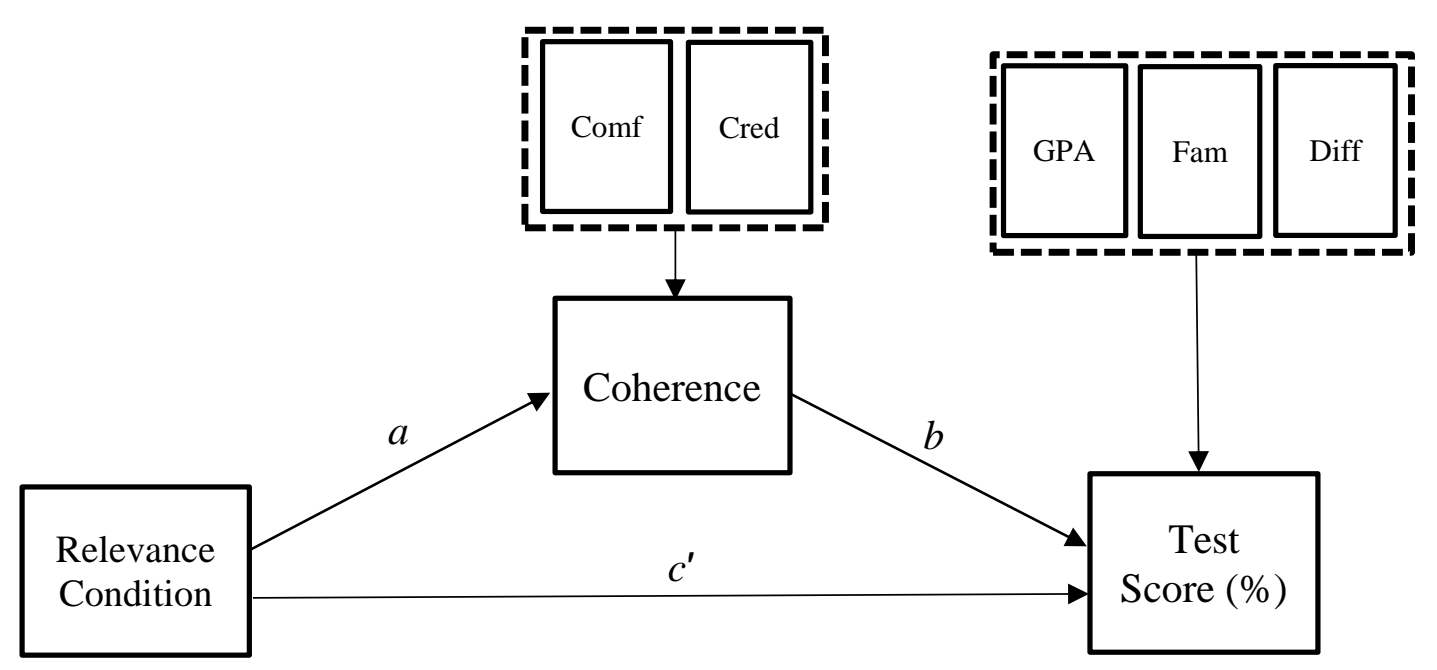

Note: Relevance condition represents the lecture conditions that will be indicator coded $(0=$ irrelevant self-disclosure condition, 1 = relevant self-disclosure condition). The following covariates are included in the model: student comfort with instructor self disclosure (Comf) and instructor credibility (Cred) on Coherence, and grade point average (GPA), familiarity of lesson material (Fam), and perceived difficulty of lesson material (Diff) on Test Score percentage.

\section{Summary}

This chapter reviewed the current definition, the history, and the 10 dimensions of instructor self-disclosure. Using prior research on the instructor self-disclosure relevance dimension, the researcher hypothesized that students exposed to an instructor who used relevant self-disclosure (as opposed to irrelevant self-disclosure) would report increased affect toward the instructor. Moreover, the researcher proposed a mediation model suggesting that instructor self-disclosure relevance would influence lesson coherence, which in turn, would impact students' performance on a test (see Figure 1). Ultimately, it was hypothesized that students will score higher on a cognitive learning test when an instructor uses relevant self-disclosure compared to irrelevant self-disclosure because of 
causal increases in lesson coherence. While testing the hypotheses, students' comfort with instructor self-disclosure, instructor credibility, grade point average, familiarity of lesson material, and perceived difficulty of lesson material will be controlled for during analyses. 


\section{CHAPTER II \\ METHODOLOGY}

\section{Pilot Study}

\section{Participants}

The researcher conducted a pilot test to assess the relevant and irrelevant instructor self-disclosures that would be used in the primary study. The pilot study consisted of 55 undergraduate students enrolled in upper-level communication studies courses at a large Mid-Atlantic university. Participants were not asked to provide any demographic information.

\section{Procedures}

To examine the effects of instructor self-disclosure in the classroom, the researcher created instructor self-disclosures that were used in the live lecture teaching experiment (i.e., the primary study). Instructor self-disclosures that vary in general lesson relevance (i.e., relevant/irrelevant) were developed using previous instructor selfdisclosure research as a guide (Cayanus \& Martin, 2008; Downs et al., 1988; Hosek \& Presley, 2018). For example, Cayanus and Martin’s (2008) relevance dimension description and scale items were used to create instructor self-disclosures that were relevant and irrelevant to the lesson topic. The development of the self-disclosures resulted in two instructor self-disclosure conditions: relevant instructor self-disclosure and irrelevant instructor self-disclosure. Overall, this pilot study prepared the manipulations for the primary study, which was a two condition equivalent groups pretest/posttest experiment that manipulated instructor self-disclosure relevance (i.e., relevant/irrelevant) during a live lecture. 
A 15-minute lesson script was developed for the two conditions. Within the lesson script, the instructor shared 11 personal self-disclosures because Downs and her colleagues (1988) found that instructors, on average, share 10 self-disclosures per 50minute classroom lecture. The quantity of instructor self-disclosures was the same for both conditions. Depending on the condition, the instructor self-disclosure offered in the lesson scripts were relevant (see Appendix A) or irrelevant (see Appendix B).

The researcher then created a lesson script for the live lecture teaching experiment. The topic of the lesson was affectionate communication, which covers the definition of affection, Affection Exchange Theory, and the outcomes of receiving and expressing affection (Floyd, 2006). In the lesson script, the instructor first explained the ways that people express affection through verbal statements, direct nonverbal gestures, and social support behaviors. Second, the instructor introduced Affection Exchange Theory and covered how the theory proposes how affectionate feelings and expressions are distinct, affection contributes to human survival, and affection can be physiologically aversive. Third, the instructor concluded the lesson by discussing the physical and mental health benefits related to affection such as higher self-esteem, increased relationship satisfaction, and reduced risk of depression (Floyd, Hess, \& Generous, 2018). This topic was chosen because affectionate communication and Affection Exchange Theory are unique subtopics that were not emphasized in undergraduate-level classes in West Virginia University's communication studies department. The lesson content and PowerPoint slides (see Appendix C) remained exactly the same between the two conditions. The only difference between the conditions was the manipulation of instructor self-disclosure. The scripts were used to pilot test the instructor self-disclosure 
manipulations for the primary experimental study.

After receiving approval from the Institutional Review Board, the researcher visited several upper-level communication studies courses (i.e., one section of "Business and Professional Communication" and two sections of "Capstone") to pilot test the relevance and perceived realism of the instructor self-disclosure manipulations for the two lesson scripts. There were 30 students in the relevant self-disclosure condition pilot test and 25 students in the irrelevant self-disclosure condition pilot test. The undergraduate students were blind to the purposes of the pilot study. Students listened to audio samples from the two audio-recorded instructor self-disclosure lesson scripts (i.e., relevant and irrelevant). Students were provided a pilot study cover letter that explained how the study was voluntary and that they would not receive any type of compensation for their participation (see Appendix D). If a student had already completed the study in a previous class, they were asked to not complete the study a second time. Students were also given the pilot study instructions (see Appendix E) and pilot study questionnaire (see Appendix F). The researcher told the students they would listen to several instructor selfdisclosure audio samples from a lesson on affectionate communication. Students were asked to listen carefully to each instructor self-disclosure in the same manner as they would for one of their current college instructors. The students were asked to listen to each instructor self-disclosure audio sample one at a time. After each sample played, the researcher stopped the playback so that students could rate the instructor self-disclosure on the pilot study questionnaire.

To measure the relevance and perceived realism of the instructor self-disclosures, students were initially provided with the definitions for these instructor self-disclosure 
characteristics at the beginning of the pilot study questionnaire. Using the description and scale items from Cayanus and Martin's (2008) relevance subscale, the following instructor self-disclosure relevance definition were provided: "The extent to which the instructor's self-disclosure relates back to the course material and helps you understand the importance of the content. In other words, how relevant was the self-disclosure to the lesson." Adapting the perceived realism description from Kromka and Goodboy (2019), students were provided the following definition for perceived realism: "The extent to which the ideas in the instructor self-disclosure are very similar to ideas that one would encounter in a real classroom. In other words, how realistic was the self-disclosure." Students then responded to two 7-point semantic differential scales (i.e., "irrelevant/relevant," "unrealistic/realistic") for each instructor self-disclosure audio sample (see Appendix F). After students had assessed all of the instructor self-disclosure audio samples, the pilot study was complete. The researcher then thanked the undergraduate students for their time and effort in completing the pilot study.

\section{Pilot Study Results}

After completing the pilot study for the two lesson scripts, the researcher analyzed the data to assess the quality of each instructor self-disclosure in terms of relevance and perceived realism. The researcher examined the instructor self-disclosure manipulations to be sure that each one fit appropriately in their respective condition (i.e., relevant or irrelevant) and that students found each instructor self-disclosure to be realistic. The means and standard deviations are provided for the relevant instructor self-disclosures (see Table 1) and the irrelevant instructor self-disclosures (see Table 2). 
Table 1

Pilot Study Descriptive Information for Relevant Instructor Self-disclosures $(n=30)$

Instructor Self-disclosure

$M$

$S D$

SD 1: "When I first met my wife Emma"

Relevance

5.53

1.13

Realism

5.70

1.17

SD 2: "I prefer a lot of affection in my life"

Relevance

5.07

1.43

Realism

5.13

1.30

SD 3: "My life would be empty if I never met Emma"

Relevance

5.40

1.32

Realism

5.37

1.69

SD 4: "Friends and I give each other big bear hugs"

Relevance

5.17

1.28

Realism

5.30

1.46

SD 5: "I was there for Jason after his bad break-up"

Relevance

6.00

1.20

Realism

6.20

0.99

SD 6: "I provide the resource of food to my family"

Relevance

5.43

Realism

SD 7: "My buddies and I like to go to Big Bear Lake"

Relevance

5.13

1.45

Realism

5.30

1.51

SD 8: "First official date with Emma"

Relevance

5.50

1.48

Realism

5.77

1.61

SD 9: "I received my degree at Eastern Michigan University"

Relevance

5.90

1.15

Realism

5.83

1.28

SD 10: "I express affection to my wife Emma"

Relevance

5.33

1.70

Realism

5.20

1.80 
SD 11: "I keep in mind live, laugh, love"

Relevance

5.30

1.74

Realism

4.90

1.82

Note. The relevance scale and the realism scale both ranged from 1(irrelevant; unrealistic) to 7 (relevant; realistic). See Appendix A to see each relevant instructor self-disclosure indicated by a number (1-11) in the lesson script.

Table 2

Pilot Study Descriptive Information for Irrelevant Instructor Self-disclosures $(n=25)$

Instructor Self-disclosure

$M$

$S D$

SD 1: "First met my wife Emma"

Relevance

3.72

1.76

Realism

5.76

0.97

SD 2: "I prefer a lot of affection in my life"

Relevance

3.60

1.78

Realism

5.36

1.52

SD 3: "My life would be empty if I never met Emma"

Relevance

3.08

1.60

Realism

5.04

1.54

SD 4: "Friends and I give each other big bear hugs"

Relevance

Realism

6.12

1.13

SD 5: "I was there for Jason after his bad break-up"

Relevance

Realism

4.64

SD 6: "I provide the resource of food to my family"

Relevance

1.50

Realism

5.16

1.17

SD 7: "My buddies and I like to go to Big Bear Lake"

Relevance

Realism

SD 8: "First official date with Emma"

Relevance

Realism 
SD 9: "I received my degree at Eastern Michigan University"

Relevance

SD 10: "I express affection to my wife Emma"

Relevance

SD 11: "I keep in mind live, laugh, love"

Relevance

Realism

Note. The relevance scale and the realism scale both ranged from 1 (irrelevant; unrealistic) to 7 (relevant; realistic). See Appendix B to see each irrelevant instructor self-disclosure indicated by a number (1-11) in the lesson script.

An independent samples Welch's t-test was used to examine the differences between the relevant and irrelevant instructor self-disclosure ratings for each of the 11 disclosures (rather than Student's t-test, Welch's t-test was used because it performs better when sample sizes and variances are not equal between groups, and provides the same result as a Student's t-test when sample sizes and variances are equal; see Delacre, Lakens, \& Leys, 2017). Significant differences emerged in the relevance means for all 11 instructor self-disclosures (see Table 3 for the Welch's t-test results between the relevant and irrelevant instructor self-disclosures). On average, the 11 relevant instructor selfdisclosures were perceived as significantly more relevant compared to the irrelevant instructor self-disclosures with Cohen's $d$ effect sizes ranging from .89 to 3.13. Thus, the relevance manipulation for each of the eleven instructor self-disclosures was successful. 
Table 3

Pilot Study Independent Samples Welch's t-test between Relevant and Irrelevant Selfdisclosure Conditions for Relevance $(N=55)$

\begin{tabular}{|c|c|c|c|c|c|c|c|c|}
\hline $\begin{array}{c}\text { Self- } \\
\text { disclosure }\end{array}$ & $d f$ & $t$ & $p$ & \multicolumn{2}{|c|}{$\begin{array}{c}95 \% \text { CI } \\
{[\mathrm{LL}, \mathrm{UL}]}\end{array}$} & $d$ & $\begin{array}{l}\mathrm{U}_{3} \\
(\%)\end{array}$ & $\begin{array}{c}\text { Mean } \\
\text { Difference }\end{array}$ \\
\hline SD 1 & 39.49 & -4.42 & $<.001$ & -2.60 & -0.98 & 1.21 & 88.70 & -1.81 \\
\hline SD 2 & 45.93 & -3.31 & .002 & -2.35 & -0.57 & 0.90 & 81.80 & -1.46 \\
\hline SD 3 & 46.64 & -5.76 & $<.001$ & -3.13 & -1.52 & 1.57 & 94.20 & -2.32 \\
\hline $\mathrm{SD} 4$ & 42.25 & -2.79 & .008 & -2.07 & -0.33 & 0.97 & 83.60 & -1.20 \\
\hline SD 5 & 52.03 & -11.59 & $<.001$ & -4.31 & -3.04 & 3.13 & 99.90 & -3.68 \\
\hline SD 6 & 49.47 & -6.20 & $<.001$ & -3.22 & -1.64 & 1.68 & 95.40 & -2.43 \\
\hline SD 7 & 52.60 & -7.40 & $<.001$ & -3.52 & -2.02 & 1.99 & 97.70 & -2.77 \\
\hline SD 8 & 51.07 & -7.00 & $<.001$ & -3.62 & -2.01 & 1.89 & 97.10 & -2.82 \\
\hline SD 9 & 37.41 & -5.00 & $<.001$ & -3.11 & -1.32 & 1.38 & 91.70 & -2.22 \\
\hline SD 10 & 51.80 & -3.63 & .001 & -2.56 & -0.74 & 0.98 & 83.70 & -1.65 \\
\hline SD 11 & 47.54 & -3.28 & .002 & -2.74 & -0.65 & 0.89 & 81.50 & -1.70 \\
\hline
\end{tabular}

Note. Mean Difference represents the Relevant Self-disclosure Condition mean subtracted by the Irrelevant Self-disclosure Condition mean.

To test instructor self-disclosure perceived realism, two one-sample t-tests were conducted to examine the difference between the conditions and a set test value of moderate realism. The test value was set at 4 because this value reflects a moderately realistic middle score on the 7-point semantic differential scale for perceived realism. For the relevant instructor self-disclosures, the results of a one-sample t-test revealed significant mean differences (ranging from .90 to 2.20) between the test value (4) and all 11 of the relevant instructor self-disclosures (see Table 4 for the results for each of the 
relevant instructor self-disclosures). In summary, students rated the 11 relevant instructor self-disclosures as significantly more realistic compared to the moderately realistic middle scale test value of 4 .

Table 4

Pilot Study One-Sample t-test Examining the Difference between Relevant Selfdisclosures and Moderate Perceived Realism $(n=30)$

\begin{tabular}{|c|c|c|c|c|c|c|}
\hline $\begin{array}{c}\text { Self- } \\
\text { disclosure } \\
\text { Number }\end{array}$ & $d f$ & $t$ & $p$ & \multicolumn{2}{|c|}{$\begin{array}{l}95 \% \text { CI } \\
{[\mathrm{LL}, \mathrm{UL}]}\end{array}$} & $\begin{array}{c}\text { Mean } \\
\text { Difference }\end{array}$ \\
\hline SD 1 & 29 & 7.89 & $<.001$ & 1.26 & 2.14 & 1.70 \\
\hline SD 2 & 29 & 4.75 & $<.001$ & 0.65 & 1.62 & 1.13 \\
\hline SD 3 & 29 & 4.42 & $<.001$ & 0.74 & 2.00 & 1.36 \\
\hline $\mathrm{SD} 4$ & 29 & 4.85 & $<.001$ & 0.75 & 1.85 & 1.30 \\
\hline SD 5 & 29 & 12.09 & $<.001$ & 1.83 & 2.57 & 2.20 \\
\hline SD 6 & 29 & 4.85 & $<.001$ & 0.79 & 1.94 & 1.36 \\
\hline SD 7 & 29 & 4.70 & $<.001$ & 0.74 & 1.86 & 1.30 \\
\hline SD 8 & 29 & 6.00 & $<.001$ & 1.16 & 2.37 & 1.76 \\
\hline SD 9 & 29 & 7.79 & $<.001$ & 1.35 & 2.31 & 1.83 \\
\hline SD 10 & 29 & 3.63 & .001 & 0.52 & 1.88 & 1.20 \\
\hline SD 11 & 29 & 2.70 & .011 & 0.22 & 1.58 & 0.90 \\
\hline
\end{tabular}

Note. The test value was set at 4 because this value represents self-disclosures that are moderately realistic. All of the relevant self-disclosures were above 4 on the perceived realism scale.

For the irrelevant instructor self-disclosures, the results of a one-sample t-test revealed significant mean differences (ranging from 0.64 to 2.12) between the test value (4) and 10 of the irrelevant instructor self-disclosures. Table 5 includes the results for 
each of the irrelevant instructor self-disclosures. Irrelevant instructor self-disclosure number 7 was the only instructor self-disclosure that did not reflect a significant mean difference from the test value. Because this single instructor self-disclosure was still perceived above moderately realistic $(M=4.64)$, it was deemed acceptable for this study.

Table 5

Pilot Study One-Sample t-test Examining the Difference between Irrelevant Selfdisclosures and Moderate Perceived Realism $(n=25)$

\begin{tabular}{|c|c|c|c|c|c|c|}
\hline $\begin{array}{c}\text { Self- } \\
\text { disclosure } \\
\text { Number }\end{array}$ & $d f$ & $t$ & $p$ & \multicolumn{2}{|c|}{$\begin{array}{c}95 \% \text { CI } \\
{[\mathrm{LL}, \mathrm{UL}]}\end{array}$} & $\begin{array}{c}\text { Mean } \\
\text { Difference }\end{array}$ \\
\hline SD 1 & 24 & 9.07 & $<.001$ & 1.36 & 2.16 & 1.76 \\
\hline SD 2 & 24 & 4.46 & $<.001$ & 0.73 & 1.99 & 1.36 \\
\hline SD 3 & 24 & 3.37 & .003 & 0.40 & 1.68 & 1.04 \\
\hline $\mathrm{SD} 4$ & 24 & 9.38 & $<.001$ & 1.65 & 2.59 & 2.12 \\
\hline SD 5 & 24 & 2.62 & .015 & 0.14 & 1.14 & 0.64 \\
\hline SD 6 & 24 & 4.91 & $<.001$ & 0.67 & 1.65 & 1.16 \\
\hline SD 7 & 24 & 1.82 & .080 & -0.08 & 1.36 & 0.64 \\
\hline SD 8 & 24 & 3.90 & .001 & 0.51 & 1.65 & 1.08 \\
\hline SD 9 & 24 & 7.60 & $<.001$ & 1.37 & 2.39 & 1.88 \\
\hline SD 10 & 24 & 4.90 & $<.001$ & 0.76 & 1.88 & 1.32 \\
\hline SD 11 & 24 & 6.07 & $<.001$ & 1.08 & 2.20 & 1.64 \\
\hline
\end{tabular}

Note. The test value was set at 4 because this value represents self-disclosures that are moderately realistic. All of the irrelevant self-disclosures were above 4 on the perceived realism scale.

Overall, students, on average, perceived the relevant instructor self-disclosures as significantly more relevant compared to the irrelevant instructor self-disclosures. 
Moreover, students perceived both the relevant and irrelevant instructor self-disclosures to be at least moderately realistic, and therefore, similar to the personal instructor disclosures that they would hear in a real classroom. Thus, the pilot study was successful and the researcher moved forward to the primary study.

\section{Primary Study}

\section{Participants}

For the primary study, participants were undergraduate students enrolled in largelecture introductory communication courses at a large Mid-Atlantic university. The researcher recruited a total of 288 participants for the primary study. The participants were asked to provide the following demographic information: sex, age, class rank, cultural background, and current GPA (see Appendix G for the demographic information questionnaire). The age of the participants ranged from 18 to 28 years $(M=19.82, S D=$ 1.62). The participants consisted of 132 men, 154 women, and two students who selected "Prefer not to Answer" when asked to report their sex. For class rank, 113 participants were first year students, 64 participants were sophomores, 65 participants were juniors, 45 participants were seniors, and one participant reported "other." There were 205 participants who identified as Caucasian, 35 participants who identified as Middle Eastern, 21 participants who identified as Black/African-American, 16 participants who identified as Asian/Asian-American, six participants who identified as Hispanic, and five participants who identified as mixed race. The current GPA of the participants ranged from 1.00 to $4.00(M=3.17, S D=1.32)$.

The researcher recruited a total of 288 participants, however, there were a total of 23 participants omitted. Seven participants were excluded because the researcher was 
unable to pair the unique identification code from the part one online survey responses with the code from the part two live lecture feedback questionnaire. Moreover, five students were excluded because they reported having previous experience with the instructor Miles Payne. Another 10 students were excluded because they reported participating in the pilot study. One participant was excluded because the student reported both having previous experience with the instructor Miles Payne and participating in the pilot study. Therefore, the final sample size for the primary study was 265 participants (i.e., 138 students in the relevant instructor self-disclosure condition and 127 students in the irrelevant instructor self-disclosure condition).

\section{Procedures}

To prepare for the live lecture teaching experiment, the researcher recruited an instructor to teach the lecture for the two conditions. The instructor was a 25 year old Caucasian man dressed in business-casual attire. This instructor was chosen because he had two years of college teaching experience in both small and large lecture classroom settings. The instructor also had over three years of acting experience, which would help him to be perceived as authentic when sharing various types of self-disclosure in the two conditions. The researcher scheduled four rehearsals with the instructor to practice the lesson scripts. The first rehearsal had the instructor simply read through the scripts. The remaining three rehearsals took place in the actual classroom that the primary experiment would be conducted. During these in situ rehearsals, the researcher directed the instructor to maintain the same pace and delivery when teaching the lesson material. The practice rehearsals helped the instructor deliver the lesson content and self-disclosures in the same manner for both lecture conditions. 
After receiving Institutional Review Board (IRB) approval for the primary study, students were recruited from large-lecture communication courses to participate in the two-part research study (part one: online sign-up survey, part two: live lecture lesson). Participants were recruited using three types of recruitment scripts: an e-mail recruitment script, a pre-class announcement recruitment script, and a printed bulletin board "mach form" recruitment script. First, the researcher asked seven instructors of large-lecture communication courses to e-mail their students an IRB-approved e-mail announcement for the current study (see Appendix H). Second, the researcher provided pre-class verbal announcements at the beginning of eight undergraduate communication courses. After receiving permission from the course instructor to announce the study, the researcher read from an IRB-approved recruitment script to explain the details of the study (see Appendix I). Third, a "mach form" was posted on the communication studies department physical bulletin board located in front of the main office on the first floor of Armstrong Hall as well as the electronic research board posted on the communication studies department website (see Appendix J). Each of these recruitment scripts provided the study's description, dates, times, inclusion criteria, and directions for how to sign up.

If interested in the study, students were instructed to follow an online Qualtrics link (provided in all recruitment scripts) to the part one sign-up survey (see Appendix K). In this online survey, students were shown a cover letter that provided the details and instructions for how to complete the two-part study. To participate, participants had to meet the following inclusion criteria: (a) be a student at West Virginia University, (b) be currently enrolled in a communication studies course, (c) be at least 18 years of age, and (d) be available to attend a live lecture lesson on the provided dates and times (the dates 
and times were listed on the recruitment scripts and the part one sign-up survey cover letter).

If students met the inclusion criteria and agreed to participate, they were asked to complete the Student Comfort with Instructor Self-disclosure Scale (Schrodt, 2013), provide demographic information, and create a unique alpha-numeric identification code. Students then were randomly assigned to one of four scheduled live lecture lesson conditions: two live lectures with relevant instructor self-disclosure and two lectures with irrelevant self-disclosure (completing two lectures for each condition helped ensure a sufficient sample size for the study). The unique alpha-numeric identification code required participants to provide the first three letters of their favorite color followed by the last four digits of their phone number (e.g., BLU5888). The unique identification code was used to match participants' online survey responses (part one) with their feedback questionnaire responses from the live lecture lesson (part two). At the end of the part one online survey, participants were randomly assigned a date, time, and location of a live lecture lesson that they would attend in order to participate in part two of the study. Students were also told that they could only attend their assigned live lecture lesson and could not attend any other lesson date. Students were sent two reminders via Qualtrics: a reminder email for the week of the study (see Appendix L) and a reminder email for the day of the study (see Appendix M).

On the date of their assigned lesson, participants attended the live lecture in a classroom. All of the lectures were recorded with a video camera placed in the back of the classroom. The camera was positioned to not record the participants. Recorded video footage was examined by the researcher for internal validity purposes to make sure that 
the instructor maintained consistency in his delivery between the lesson conditions. When it was time to begin, the researcher first provided participants with the feedback questionnaire (see Appendix N) and an envelope. The researcher then introduced himself, explained the details of the study using an introduction script (see Appendix O) about how the professor is interested in pursuing a career in teaching, and asked student for their honest feedback on the professor's teaching. The feedback questionnaire included a blank page in case students would like to take notes. Participants were asked to wait until the professor had completed his lesson and the researcher had made an announcement before completing the feedback questionnaire. The researcher introduced the professor and informed the students that he would teach a 15-minute lesson on affectionate communication. The instructor used a PowerPoint presentation that included the main headings of the lesson material and personal photos of the instructor (see Appendix C). The title of the lesson was "Communicating Affection." The instructor then began his lesson.

Immediately after the lesson, the instructor left the room and the researcher remained in the classroom to provide directions to students using a pre-feedback questionnaire script (see Appendix P). Students were asked to complete the feedback questionnaire, which included scales measuring instructor self-disclosure relevance (Cayanus \& Martin, 2008), student affect (McCroskey, 1994), lesson coherence (Bolkan, 2017), lesson topic familiarity (Bolkan et al., 2016), lesson difficulty (created for this study), instructor credibility (McCroskey \& Teven, 1999) as well as two exclusion criteria questions addressing participants' potential prior experiences with the instructor and/or prior exposure to the pilot study. The feedback questionnaire also asked 
participants to provide their unique identification code that they created in the part one online sign-up survey. The questionnaire concluded with a 15-item test on the lesson material. The participants were given 15 minutes to complete the feedback questionnaire. After completing the questionnaire, participants were instructed to place their completed questionnaire in the envelope and seal it. After the 15 minute time period, the participants were dismissed all at once. Participants were told to place their sealed envelope in a closed box at the front of the classroom. After the envelope had been placed in the specified box, the researcher provided participants with an extra credit research receipt slip that the student could use to receive a minimal amount of extra credit in their respective communication course (see Appendix Q). At this point, the study had ended and the participants were free to leave the classroom.

\section{Instrumentation}

As a manipulation check, a subscale from Cayanus and Martin's (2008) Teacher Self-disclosure Scale was used to assess the general relevance of the instructor selfdisclosures used throughout the lesson (see Appendix R). The relevance subscale is a 5item measure that included items such as "The instructor provides personal explanations that make the content relevant" and "The instructor provides personal examples which help me understand the importance of the content." Students responded to the items for each of these subscales using a 7-point Likert scale ranging from (1) strongly disagree to (7) strongly agree.

Student affect toward the instructor was measured using two subscales from McCroskey’s (1994) Instructional Affect Assessment Instrument (see Appendix S). The stem of the first subscale stated "My attitude about this instructor is:" and used four 7- 
point semantic differential scales (i.e., "good/bad," "valuable/worthless," "fair/unfair," "positive/negative") to measure students' attitudes toward the instructor. The stem of the second subscale stated "The likelihood of actually enrolling in another course with this instructor if my schedule would permit would be:" and used four 7-point semantic differential scales (i.e., "likely/unlikely," "possible/impossible," "probable/improbable," “would/would not”) to measure students' likelihood of enrolling in a course with the same instructor.

The coherence subscale of the Clarity Indicators Scale (Bolkan, 2017) was used to assess students' perceptions of lesson coherence (see Appendix T). The 4-item instrument asked students to respond to statements such as "The instructor went off topic when lecturing" and "In the lecture, we often received information that was not essential to learning course concepts" using a 7-point Likert type scale ranging from (1) strongly disagree to (7) strongly agree.

To assess students' short-term recall of lesson material, a 15-item multiple choice test was administered (see Appendix U). These items tested students' recall of the main points of the affectionate communication lesson such as expressing affection (i.e., verbal statements, nonverbal gestures, and social support behaviors), Affection Exchange Theory (i.e., the key propositions), and affection and health (i.e., the health benefits of receiving and expressing affection). Each multiple choice question included four possible answers (a, b, c, d). The researcher referred to Suskie's (2018) book on sufficiently assessing student learning and worked closely with a committee member (Dr. Scott Myers) to create a valid short-term recall test. Test questions were coded as (1) for correct answers and (0) for incorrect answers, and were scored to reflect a percentage of 
correct answers. The percentage mean, standard deviation, range, KR-20 reliability value, and the number of participants who received each test score are provided in Table 6 . The percentages for each test question answered correctly and incorrectly are provided in Table 7.

Covariates. The following variables were included in the model as covariates: general comfort with instructor self-disclosure, perceptions of instructor credibility (on lesson coherence), grade point average (GPA), familiarity with the lesson material, and perceived difficulty of lesson material (on test score). By including these pertinent covariates in the model, the effects of the variables were held constant, which increases the accuracy of the findings. Moreover, two exclusion criteria questions were included that asked about participants' prior experience with the instructor and the pilot study.

The Student Comfort with Instructor Self-disclosure Scale (Schrodt, 2013) asked students to indicate "in general, how comfortable you are with instructors who share personal information during class." Three items (i.e., "uncomfortable/comfortable," "restless/content," "worried/at ease") from the 18-item semantic differential instrument were included and solicited responses using a 7-point scale format (see Appendix V). Schrodt (2013) suggested that students with low comfort toward instructor self-disclosure may dislike personal disclosures and perceive instructor disclosures as irrelevant to a lesson because they simply want the instructor to teach the necessary content without expressing private details of their lives (Schrodt, 2013). Therefore, this covariate was applied during analyses on instructor affect and lesson coherence. 
Table 6

\begin{tabular}{|c|c|c|c|c|c|c|c|c|c|c|c|c|c|c|c|c|c|c|c|}
\hline \multicolumn{20}{|c|}{ Descriptive information for the 15-item Test } \\
\hline Condition & M & SD & $\begin{array}{c}\text { KR- } \\
20\end{array}$ & Range & $1 / 15$ & $2 / 15$ & $3 / 15$ & $4 / 15$ & $5 / 15$ & $6 / 15$ & $7 / 15$ & $8 / 15$ & $9 / 15$ & $10 / 15$ & $11 / 15$ & $12 / 15$ & $13 / 15$ & $14 / 15$ & $15 / 15$ \\
\hline $\begin{array}{l}\text { Relevant } \\
\text { Condition } \\
(n=137)\end{array}$ & 83.21 & 13.43 & .57 & $\begin{array}{c}46.67- \\
100\end{array}$ & 0 & 0 & 0 & 0 & 0 & 0 & 1 & 6 & 8 & 9 & 12 & 25 & 27 & 25 & 24 \\
\hline $\begin{array}{l}\text { Irrelevant } \\
\text { Condition } \\
(n=128)\end{array}$ & 74.06 & 16.37 & .64 & $\begin{array}{l}20- \\
100\end{array}$ & 0 & 0 & 2 & 0 & 3 & 3 & 1 & 6 & 14 & 13 & 25 & 20 & 24 & 10 & 7 \\
\hline
\end{tabular}

Note. The last 15 columns reflect the number of participants who received each test score (e.g., 12/15 means that the student got 12 questions correct out of 15 test questions).

Table 7

\begin{tabular}{|c|c|c|c|c|c|c|c|c|c|c|c|c|c|c|c|}
\hline \multicolumn{16}{|c|}{ Questions answered correctly and incorrectly on the 15-item Test } \\
\hline Condition & Q1 & Q2 & Q3 & Q4 & Q5 & Q6 & Q7 & Q8 & Q9 & Q10 & Q11 & Q12 & Q13 & Q14 & Q15 \\
\hline \multicolumn{16}{|l|}{$\begin{array}{l}\text { Relevant } \\
\text { Condition } \\
(n=137)\end{array}$} \\
\hline Correct & 92.7 & 88.3 & 94.9 & 97.8 & 67.9 & 91.2 & 70.8 & 92.7 & 86.9 & 82.5 & 52.6 & 81.0 & 84.7 & 81.0 & 83.2 \\
\hline Incorrect & 7.3 & 11.7 & 5.1 & 2.2 & 32.1 & 8.8 & 29.2 & 7.3 & 13.1 & 17.5 & 47.4 & 19.0 & 15.3 & 19.0 & 16.8 \\
\hline \multicolumn{16}{|l|}{$\begin{array}{l}\text { Irrelevant } \\
\text { Condition } \\
(n=128)\end{array}$} \\
\hline Correct & 87.5 & 78.9 & 93.0 & 92.2 & 50.0 & 85.2 & 64.1 & 88.3 & 82.8 & 70.3 & 25.0 & 64.1 & 79.7 & 74.2 & 75.8 \\
\hline Incorrect & 12.5 & 21.1 & 7.0 & 7.8 & 50.0 & 14.8 & 35.9 & 11.7 & 17.2 & 29.7 & 75.0 & 35.9 & 20.3 & 25.8 & 24.2 \\
\hline
\end{tabular}

Note. Correct and Incorrect reflect the percentage test score for each question. 
A shortened version of the Measure of Source Credibility Scale (McCroskey \& Teven, 1999) asked students to report their perceptions on each of the three dimensions of instructor credibility: competence, character, and caring. Three items (i.e., competence: "competent/incompetent," character: "honest/dishonest," caring: "cares about me/doesn't care about me") from the original 18-item semantic differential instrument were included and solicited responses using a 7-point scale format (see Appendix W). Instructor credibility was included as a covariate on instructor affect and lesson coherence because previous correlational research suggests credibility has an influence on students' perceptions of affect (Pogue \& AhYun, 2006) and clarity (Carbone, 1975).

Three covariates were applied to students' test scores. The first covariate that was included was students' GPA. Prior teaching experiments found that students' GPA could influence performance on a test (e.g., Bolkan, 2019; Bolkan \& Goodboy, 2019).

Therefore, participants were asked to provide their current GPA (see Appendix G). It was also possible that students could be familiar with the lesson material. Students' familiarity with the lesson material has the potential to influence scores on a short-term recall test (Bolkan et al., 2017), and therefore was the second covariate included during analyses on test score. The 3-item Perceived Familiarity Scale (Bolkan et al., 2016) was used to measure students' familiarity with the lesson material (see Appendix X). The scale used a 5-point Likert type format and included items such as "How familiar were you with the topic before today?" and "How much did you already know about this topic before today?" Responses ranged from (1) not at all to (5) very much. Perceived level of difficulty was the third covariate included on test score because it has the potential to 
influence students' performance on short-term recall tests (Bolkan et al., 2016). A oneitem question was created for this study to measure the perceived difficulty of the lesson. The question asked students to report "How difficult was the material to understand?" Response options ranged from (1) very low to (9) very high with higher values representing greater difficulty (see Appendix Y).

The researcher also included two exclusion criteria questions (see Appendix N). The first question addressed students' prior experiences with the instructor. It is possible that some students may have had the instructor in class before since he currently teaches courses at the university in which this study took place. Therefore, the feedback questionnaire included a 1-item question that asked students "Have you ever had Miles Payne as an instructor before?" with the option to select "yes" or "no." Participants who selected "yes" were excluded from the study. For this reason, five participants were excluded from the study. The second question addressed the possibility that the students may have participated in the preceding audio-recorded pilot study lesson, which may have influenced their responses on the feedback questionnaire. Therefore, the feedback questionnaire included a 1-item question that asked students "Have you ever heard this lesson before from a previous research study?" with the option to select "yes" or "no." Participants who selected "yes" were excluded from the study. For this reason, ten participants were excluded from the study.

\section{Data Analysis}

Power Analysis. To achieve sufficient statistical power of $80 \%(.80)$ with a .05 alpha level for the parameters in the model, Fritz and MacKinnon (2007) estimated a total sample size of 162 to detect a "small to medium" mediated effect ( $a$ path $=.26, b$ path $=$ 
.26). Therefore, the researcher aimed to recruit at least 81 participants for both experimental conditions. As previously mentioned, the final sample size for the primary study was 265 participants (i.e., 138 students in the relevant instructor self-disclosure condition and 127 students in the irrelevant instructor self-disclosure condition). This final sample size was deemed acceptable to conduct the analyses for the current study.

Confirmatory factor analyses. Using Mplus Version 8.4 statistical software with the updated user's guide (Muthén \& Muthén, 2017), confirmatory factor analyses (CFAs) with robust maximum likelihood estimation was used to assess the dimensionality of the scales implemented in this study. Robust maximum likelihood estimation was chosen because it corrects for violations of multivariate normality and accounts for nonnormality by correcting model fit statistics and providing robust standard errors (Kline, 2016). A CFA was not conducted on the student comfort with self-disclosure scale, the instructor credibility scale, the familiarity scale, and the perceived difficulty scale due to insufficient degrees of freedom. CFA analyses were conducted on the self-disclosure relevance subscale, affect toward instructor subscale, affect in likelihood to enroll with the instructor subscale, and the lesson coherence subscale.

Confirmatory factor analyses were conducted before testing the two hypotheses. A CFA is a deductive statistical tool used to assess the suitability of a scale's predetermined factor structure by examining the extent to which the scale items (i.e., observed variables) represent factors (i.e., latent variables) to ultimately obtain support for measurement validity (Bandalos, 2018). When conducting the CFAs, the researcher followed Kline's (2016) guidelines for global fit and factor loadings. Referring to Kline's (2016) recommendations for global fit, a CFA model should meet the following four 
criteria in order to be retained. First, the model should demonstrate a non-significant Yuan-Bentler residual-based chi-square (Y-B $\chi^{2}$; Yuan \& Bentler, 2000). Second, the model should have a root mean square error of approximation (RMSEA) value of .08 or less with a $90 \%$ confidence interval with an upper limit not exceeding .10 . Third, the model should demonstrate a comparative fit index (CFI) value of .95 or above. Fourth, the model should have a standardized root mean squared residual (SRMR) value of .08 or less. As an additional indicator of model fit, Kline (2016) recommends that the standardized factor loadings should be at .70 or above (i.e., $49 \%$ of an item's variance is explained by that factor) to provide further evidence for a good fitting CFA model for each of the instruments examined. For local fit, Bandalos's (2018) rule of thumb for assessing local fit is that normalized residuals should not exceed $|2.0|$ because these values are "taken to be large and indicative of possible misfit" between the model and the data (p. 383).

There were two issues with global fit for the CFA models (see Table 8). First, the Yuan-Bentler residual-based chi-square was significant for all CFA models. However, Bandalos (2018) and Kline (2016) suggested that because the chi-square test is overly rigorous and highly dependent on sample size, multiple indices should be used to assess model fit such as RMSEA, CFI, and SRMR. Second, the RMSEA value for all of the scales exceeded the cutoff value of .08 and the $90 \%$ confidence interval upper limit of .10. However, researchers have found that the RMSEA often falsely produces a poor fitting model in models of small sample size and degrees of freedom (Kenny, Kaniskan, \& Betsy McCoach, 2015). Because the sample size $(N=265)$ and degrees of freedom (ranging from 2 to 5) were relatively small for these models, less attention was paid to the 
high RMSEA values when assessing model fit. The CFI values were acceptable for nearly all models (with the exception of the .85 value for the affect toward the instructor subscale). The SRMR values were all well below the .08 cutoff and were deemed acceptable. Furthermore, all but one of the standardized factor loadings were above the .70 threshold (see Table 9). Moreover, there were no issues with local fit after examining the normalized residual matrices (see Table 10).

Table 8

Confirmatory Factor Analysis Goodness of Fit for Predicted Model Variables

\begin{tabular}{lccccc}
\hline \multicolumn{1}{c}{ Model } & $\chi^{2}(d f)$ & RMSEA & $\begin{array}{c}\text { RMSEA } \\
90 \% \text { CI } \\
{[\text { LL, UL] }}\end{array}$ & CFI & SRMR \\
\hline $\begin{array}{l}\text { 1. Self-disclosure Relevance } \\
\text { Manipulation Check }\end{array}$ & $28.79(5)^{\wedge}$ & .13 & {$[.08, .18]$} & .95 & .02 \\
2. Affect toward Instructor & $15.78(2)^{\wedge}$ & .16 & {$[.09, .23]$} & .85 & .03 \\
3. Affect Enroll with Instructor & $6.57(2)^{*}$ & .09 & {$[.01, .17]$} & .98 & .02 \\
4. Coherence & $15.97(2)^{\wedge}$ & .16 & {$[.09, .24]$} & .95 & .02
\end{tabular}

Note. ${ }^{*} p<.05 .{ }^{\wedge} p<.001$.

Table 9

Factor Loadings and Variance Estimates for Scales

Scale \& Items $\quad$ Standardized Loadings (SE) $\quad R^{2}(\mathrm{SE})$

\section{Self-disclosure Relevance}

Rel_1

Rel_2 $.929(.020)^{\wedge}$

$.863(.038)$

$.917(.022)^{\wedge}$

$.840(.041)$ 

Rel_3
$.934(.017)^{\wedge}$
$.872(.032)$
Rel_4
$.922(.022)^{\wedge}$
$.851(.040)$
Rel_5
$.869(.025)^{\wedge}$
$.755(.044)$

Affect toward Instructor

Aff_1

Aff_2

Aff_3

Aff_4

Affect Enroll with Instructor

AffL_1

AffL_2

AffL 3

AffL_4

Coherence

Coh_1

Coh_2

Coh_3

Coh_4 $.741(.084)^{\wedge}$

$.532(.087)^{\wedge}$

$.753(.067)^{\wedge}$

$.815(.073)^{\wedge}$

$.888(.026)^{\wedge}$

$.860(.023)^{\wedge}$

$.861(.034)^{\wedge}$

$.907(.026)^{\wedge}$

$.549(.124)$

$.283(.093)$

$.567(.101)$

$.664(.119)$

$789(.047)$

$.740(.039)$

$.741(.059)$

$.822(.047)$

$.868(.036)^{\wedge}$

$.754(.062)$

$.888(.028)^{\wedge}$

$.788(.050)$

$.912(.024)^{\wedge}$

$.833(.044)$

$.885(.028)^{\wedge}$

$.783(.050)$

Note. ${ }^{*} p<.01 .{ }^{\wedge} p<.001$. 
Table 10

Normalized Residual Matrices for Scales

Scale \& Items

Self-disclosure Relevance

$\begin{array}{lrrrrr} & \text { Rel_1 } & \text { Rel_2 } & \text { Rel_3 } & \text { Rel_4 } & \text { Rel_5 } \\ \text { Rel_1 } & .000 & & & & \\ \text { Rel_2 } & .820 & .000 & & & \\ \text { Rel_3 } & -.140 & -.206 & .000 & & \\ \text { Rel_4 } & -.403 & -.320 & .264 & .000 & \\ \text { Rel_5 } & -.341 & -.557 & .134 & .721 & .000\end{array}$

Affect toward Instructor

$\begin{array}{lrrrr} & \text { Aff_1 } & \text { Aff_2 } & \text { Aff_3 } & \text { Aff_4 } \\ \text { Aff_1 } & .000 & & & \\ \text { Aff_2 } & 1.044 & .000 & & \\ \text { Aff_3 } & -.436 & .093 & -.001 & \\ \text { Aff_4 } & .018 & -.858 & .202 & .000\end{array}$

Affect Enroll with Instructor

$\begin{array}{lcrrr} & \text { AffL_1 } & \text { AffL_2 } & \text { AffL_3 } & \text { AffL_4 } \\ \text { AffL_1 } & .000 & & & \\ \text { AffL_2 } & -.423 & -.002 & & \\ \text { AffL_3 } & -.065 & .553 & .000 & \\ \text { AffL_4 } & .272 & -.052 & -.351 & .002\end{array}$

\section{Coherence}

\begin{tabular}{lrrrr} 
& Coh_1 & Coh_2 & Coh_3 & Coh_4 \\
Coh_1 & .000 & & & \\
Coh_2 & .818 & .000 & & \\
Coh_3 & -.287 & -.318 & .000 & \\
Coh_4 & -.519 & -.300 & .568 & .000 \\
\hline Note. $* p<.01{ }^{\wedge} p<<.001$. & & &
\end{tabular}

Hypothesis Testing. Hypothesis one was tested using SPSS Version 26 statistical software. For hypothesis one, a one-way Analysis of Covariance (ANCOVA) was conducted to examine the mean differences on students' affect toward the instructor and 
affect in student likelihood to enroll with the same instructor in a future course between the instructor self-disclosure conditions (i.e., relevant/irrelevant). The two conditions were indicator coded as 0 for the irrelevant condition and 1 for the relevant condition. The two covariates (i.e., student comfort with instructor self-disclosure and instructor credibility) were controlled for in the models. Before running the ANCOVAs, the researcher tested for normality by inspecting the Kolmogorov-Smirnov test, the ShapiroWilk test, skewness, kurtosis, normal Q-Q plots, and detrended normal Q-Q plots. The researcher also tested for homogeneity of variance by examining Levene's statistic.

Hayes's (2018) PROCESS version 3.0 macro was used to test hypothesis two using ordinary least squares path-analysis. The conceptual diagram model (see Figure 1) is best described as a simple mediation model. A simple mediation model specifies a causal sequence in which the independent variable influences the dependent variable indirectly through the mediator (Preacher \& Hayes, 2008). In other words, using a simple mediation model allows the researcher to examine the inferred causal sequence of the instructor relevant (versus irrelevant) self-disclosure conditions $(X)$ on students' test performance $(Y)$ indirectly through the unique indirect effect of instructor lesson coherence $(M)$. Furthermore, when examining the model, students' comfort with instructor self-disclosure, familiarity with the lesson material, perceived difficulty of the lesson material, GPA, and perception of instructor credibility were included as covariates to control for confounding effects. Using PROCESS, the researcher estimated the indirect effect using $95 \%$ percentile confidence intervals with the number of bootstrap resamples set to 10,000 , and reported the partially standardized indirect effect as a mediation effect size (Hayes, 2018). 


\section{Summary}

This chapter explained the methodological procedures that were used to test the two hypotheses. A pilot study was conducted to test the relevance and perceived realism of the instructor self-disclosure manipulations created for this study. The researcher trained an instructor to teach a live lecture lesson on affectionate communication. The researcher then recruited undergraduate students who were randomly assigned to attend one of two live lecture lessons (four sessions) that varied in instructor self-disclosure relevance (i.e., relevant or irrelevant). The researcher also provided an overview of the participants, instruments, and data analysis procedures that were involved in this dissertation in order to sufficiently test the two hypotheses. 


\section{Chapter III}

\section{Results}

Table 11 provides a correlation matrix of all variables included in the study. The table also includes the means, standard deviations, and McDonald's Omega $(\omega)$ reliability coefficients (McDonald, 1999) with 95\% confidence intervals.

\section{Instructor Self-Disclosure Relevance Manipulation Check}

To determine whether students perceived differences in instructor self-disclosure relevance between the two lecture conditions, students were asked to complete Cayanus and Martin's (2008) self-disclosure relevance subscale. The results from a Welch's independent samples t-test revealed that there were significant differences between the relevant and irrelevant instructor self-disclosure lecture conditions, $t(140)=12.97, p=$ $<.001, d=1.61, \mathrm{U} 3=94.60 \%$, with a mean difference of $2.76,95 \%$ CI $[2.34,3.18]$ between the two conditions. Students in the relevant condition $(M=6.63, S D=.55)$ rated the instructor's self-disclosure as more relevant than students in the irrelevant condition $(M=3.87, S D=2.34)$. Therefore, the manipulation check was deemed successful for the purposes of the study.

\section{Hypothesis Testing}

Hypothesis one predicted that a lesson with relevant instructor self-disclosure would create more student affect toward the instructor compared to a lesson with irrelevant instructor self-disclosure. When examining this hypothesis, the researcher controlled for student comfort with instructor self-disclosure and student perceptions of instructor credibility. 
Table 11

\section{Correlation Matrix}

\begin{tabular}{|c|c|c|c|c|c|c|c|c|c|c|c|c|c|}
\hline Variables & M & SD & $\begin{array}{c}\omega \\
{[\mathrm{LL}, \mathrm{UL}]}\end{array}$ & 1 & 2 & 3 & 4 & 5 & 6 & 7 & 8 & 9 & 10 \\
\hline 1. Self-disclosure Comfort & 5.67 & 1.34 & $\begin{array}{c}.92 \\
{[.89, .94]}\end{array}$ & -- & & & & & & & & & \\
\hline 2. Self-disclosure Relevance & 5.30 & 2.17 & $\begin{array}{c}.96 \\
{[.95, .97]}\end{array}$ & -.10 & -- & & & & & & & & \\
\hline 3. Affect toward Instructor & 6.26 & .93 & $\begin{array}{c}.78 \\
{[.71, .85]}\end{array}$ & $.14 *$ & -.01 & -- & & & & & & & \\
\hline 4. Affect Enroll with Instructor & 5.71 & 1.35 & $\begin{array}{c}.93 \\
{[.90, .95]}\end{array}$ & .01 & .11 & $.65^{\wedge}$ & -- & & & & & & \\
\hline 5. Coherence & 5.44 & 1.88 & $\begin{array}{c}.93 \\
{[.91, .95]}\end{array}$ & .00 & $.42^{\wedge}$ & $.24^{\wedge}$ & $.31^{\wedge}$ & -- & & & & & \\
\hline 6. Instructor Credibility & 6.13 & .84 & $\begin{array}{c}.61 \\
{[.51, .71]}\end{array}$ & .11 & .01 & $.52^{\wedge}$ & $.52^{\wedge}$ & $.22^{\wedge}$ & -- & & & & \\
\hline 7. GPA & 3.17 & .58 & -- & $.15^{*}$ & -.09 & $.18^{*}$ & .11 & -.04 & .09 & -- & & & \\
\hline 8. Familiarity & 2.85 & .93 & $\begin{array}{c}.86 \\
{[.82, .89]}\end{array}$ & .00 & -.06 & -.02 & .01 & -.01 & .00 & -.07 & -- & & \\
\hline 9. Difficulty & 2.13 & 1.31 & -- & $-.12 *$ & .00 & -.09 & -.10 & -.10 & -.14 & -.05 & -.10 & -- & \\
\hline 10. Test Percentage & 78.79 & 15.58 & -- & $.13^{*}$ & $.20 * *$ & $.17 * *$ & .11 & $.16^{* *}$ & .11 & $.21 * *$ & $-.23^{\wedge}$ & $-.15^{*}$ & -- \\
\hline
\end{tabular}

Note. ${ }^{*} p<.05 . * * p<.01 .{ }^{\wedge} p<.001$. 
Before conducting a one-way analysis of covariance (ANCOVA), the researcher tested for normality between the relevant and irrelevant instructor self-disclosure groups for the ratings of affect toward the instructor. The Kolmogorov-Smirnov test $(p<.001)$ and the Shapiro-Wilk test $(p<.001)$ were both significant, which suggested that affect toward the instructor was not normally distributed. Although skewness value $(z=-1.633)$ was below the $|1.96| z$ score cutoff significance value, the kurtosis value $(z=2.619)$ was well above the cutoff value. Very few points were near the line for the normal Q-Q plot and the ends of the plot were not similar in shape in the detrended normal Q-Q plot, providing additional evidence that normality was not assumed. Levene's statistic was not significant $(p=.986)$ suggesting that equal variances between groups were assumed.

The researcher then tested for normality between instructor self-disclosure groups for the rating of student affect in likelihood to enroll in a future course with the same instructor. The Kolmogorov-Smirnov test $(p<.001)$ and the Shapiro-Wilk test $(p<.001)$ were both significant, which suggested that the ratings were not normally distributed. The skewness value $(z=-1.109)$ and the kurtosis value $(z=.787)$ were below the $|1.96| z$ score cutoff significance value, suggesting that normality was not assumed. Few points were near the line for the normal Q-Q plot and the ends of the plot did not have a similar shape in the detrended normal Q-Q plot, both of which suggested that normality was not assumed. For homogeneity of variance, Levene's statistic was significant $(p=.003)$, suggesting that equal variances were not assumed.

The results of a one-way analysis of covariance revealed that there were no significant differences in student affect toward the instructor based on self-disclosure condition, $F(1,258)=.370, p=.544, \eta_{\mathrm{p}}{ }^{2}=.001$, controlling for student comfort with 
self-disclosure and instructor credibility. Based on estimated marginal means, students in the relevant instructor self-disclosure condition $(M=6.304)$ compared to students in the irrelevant instructor self-disclosure condition $(M=6.245)$ did not report significantly higher ratings of affect toward the instructor.

The results of a one-way analysis of covariance revealed that there were significant differences in affect in likelihood to enroll in a future course with the same instructor based on self-disclosure condition, $F(1,259)=7.191, p=.008, \eta_{\mathrm{p}}^{2}=.027$, controlling for student comfort with self-disclosure and instructor credibility. Based on estimated marginal means, students in the relevant instructor self-disclosure condition $(M$ $=5.900)$ compared to students in the irrelevant instructor self-disclosure condition $(M=$ 5.519) reported significantly higher ratings of likelihood to enroll in a future course with the same instructor (if their course schedule would permit it). Thus, hypothesis one was partially supported.

Hypothesis two posited that relevant instructor self-disclosure (compared to irrelevant self-disclosure) would increase students' test scores, indirectly through lesson coherence. To test this hypothesis, the researcher used a simple mediation model (Model 4; Hayes, 2018), which included the five covariates. The results uncovered a direct effect of self-disclosure relevance on students' test performance $\left(c^{\prime}=8.707, c_{p s}^{\prime}=.558, \mathrm{CI}\right.$ : 4.493, 12.920). Moreover, there was not an indirect effect ( $a b=-.072$, CI: $-2.654,2.351$, $\left.a b_{p s}=-.004, \mathrm{CI}:-.172, .150\right)$ of relevant instructor self-disclosure on students' test score through lesson coherence. See Table 12 for unstandardized model estimates and Figure 2 for the final mediation model including paths, covariates, and confidence intervals. Hypothesis two was not supported. 
Table 12

Unstandardized Model Estimates for Hypothesis 2

H2 - Self-disclosure Relevance

$\underline{\text { Consequent }}$

$a b=-.072$, CI: $-2.654,2.351$

$\mathrm{F}(3,261)=43.23, p=<.001, R^{2}=.33 \quad \mathrm{~F}(5,259)=12.85, p=<.001, R^{2}=.19$

$c^{\prime}=8.707, p=<.001$

Coherence

$\underline{\text { Test Percentage }}$

\begin{tabular}{lcccccc} 
Antecedent & Estimate & $S E$ & $p$ & Estimate & $S E$ & $p$ \\
\hline SD Relevance Condition & $\mathbf{2 . 1 6 7}$ & $\mathbf{. 1 9 1}$ & $<.001$ & $\mathbf{8 . 7 0 7}$ & $\mathbf{2 . 1 3 9}$ & $<.001$ \\
Coherence & --- & --- & --- & -.033 & .567 & .952 \\
$\quad$ SD Comfort & -.021 & .014 & .143 & --- & --- & --- \\
Credibility & .001 & .014 & .925 & --- & --- & --- \\
GPA & --- & --- & --- & $\mathbf{5 . 0 6 9}$ & $\mathbf{1 . 5 0 2}$ & $<.001$ \\
Familiarity & --- & --- & --- & $\mathbf{- 3 . 5 2 7}$ & $\mathbf{. 9 4 4}$ & $<.001$ \\
$\quad$ Difficulty & --- & --- & --- & $\mathbf{- 2 . 0 8 6}$ & $\mathbf{. 6 7 1}$ & $\mathbf{. 0 0 2}$ \\
\hline
\end{tabular}

Note. Estimates in bold represent significant unstandardized regression slopes.

Figure 2

Final Mediation Model

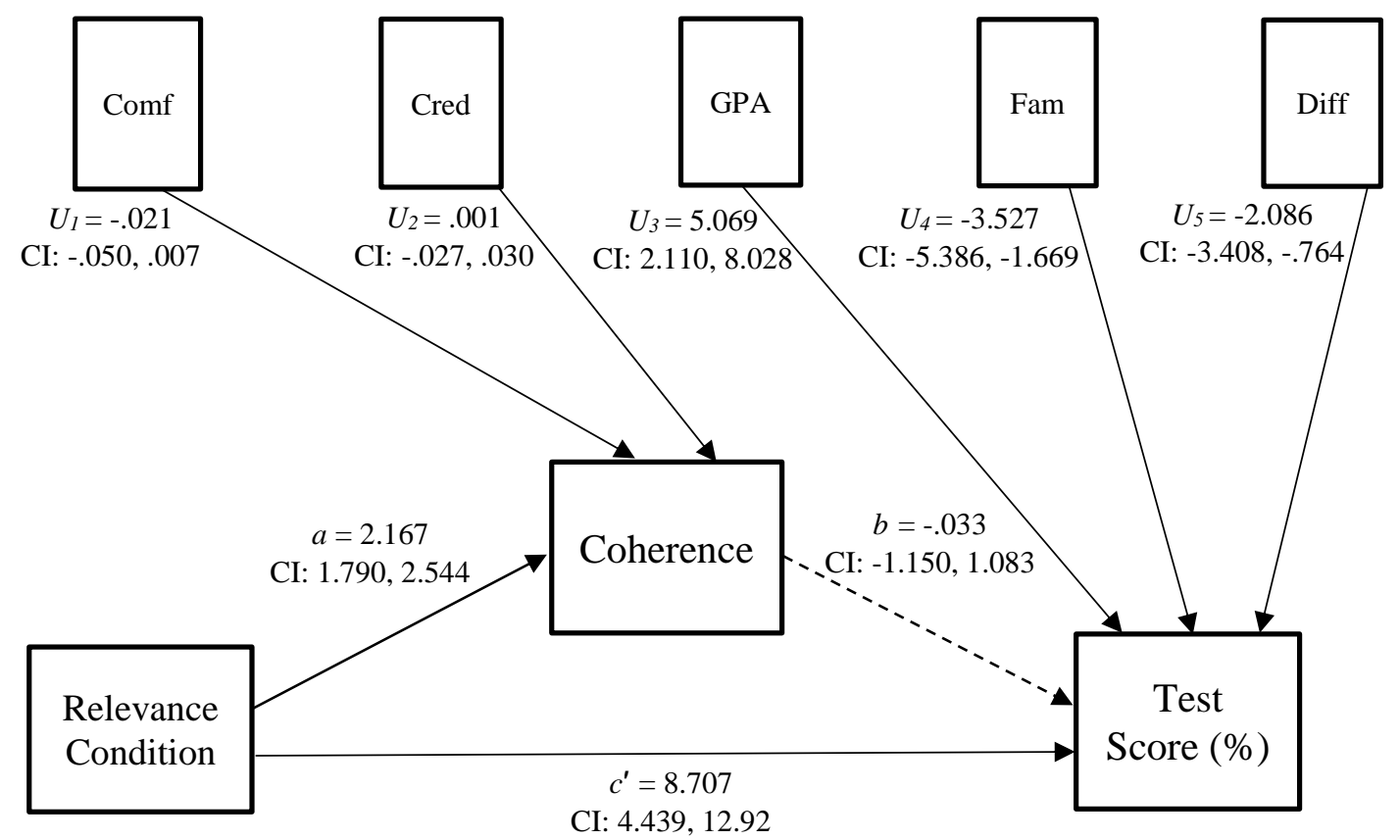

Note. Relevance condition represents the lecture conditions that were indicator coded $(0=$ irrelevant self-disclosure condition, $1=$ relevant self-disclosure condition). The following covariates were included in the model: student comfort with instructor self disclosure $\left(U_{l}=\right.$ Comf) and instructor credibility $\left(U_{2}=\right.$ Cred) controlling for Coherence, and grade point average $\left(U_{3}=\right.$ GPA $)$, familiarity with lesson material $\left(U_{4}=\right.$ Fam $)$, and perceived difficulty of lesson material $\left(U_{5}=\right.$ Diff $)$ controlling for Test Score. 


\section{Summary}

The results suggest that instructor self-disclosure has an influence on student affect and performance on a test, but not in the ways predicted in the two hypotheses. The results revealed that student affect toward the instructor did not significantly differ between the relevant and irrelevant instructor self-disclosure conditions after controlling for student comfort with self-disclosure and perceptions of instructor credibility. However, there were significant differences between the relevant and irrelevant instructor self-disclosure conditions for student affect in their likelihood to enroll in a future course with the same instructor after controlling for student comfort with self-disclosure and perceptions of instructor credibility. Students reported a greater likelihood of enrolling in a future course with the same instructor when the instructor shared relevant selfdisclosures compared with irrelevant self-disclosures. Moreover, the relevance condition (i.e., relevant self-disclosure versus irrelevant self-disclosure) did not indirectly (through lesson coherence) influence student test scores due to a lack of lesson coherence contributing to student test scores (i.e., the $b$ path in the mediation model; see Figure 2). However, the use of relevant instructor self-disclosure (as compared to the use of irrelevant instructor self-disclosure) produced a direct effect on student test scores. 


\section{Chapter IV}

\section{Discussion}

There were two main goals of this dissertation. The first goal was to examine how the relevance (i.e., relevant or irrelevant) of instructor self-disclosure influenced students' affect toward the instructor in a live lecture lesson. The second goal was to investigate how relevant and irrelevant instructor self-disclosures during teaching created lesson coherence, and in turn, caused students to perform better on a short-term recall test. To achieve these goals, the researcher used a live lecture teaching experiment to examine the causal influences of relevant and irrelevant instructor self-disclosure on student affect and cognitive learning. Interestingly, students reported similar ratings of affect toward the instructor in both the relevant and irrelevant instructor self-disclosure conditions. However, students reported greater affect in their intentions to enroll in a future course with the same instructor when he used relevant self-disclosure rather than irrelevant selfdisclosure. Moreover, self-disclosure relevance did not indirectly influence students' test scores through lesson coherence. Instead, there was a direct effect of relevant selfdisclosure (compared to irrelevant self-disclosure); students in the relevant instructor selfdisclosure condition earned an $8.70 \%$ higher grade on the test despite their affect for the instructor. Based on these findings, it is important that instructors make sure that their personal disclosures are relevant to the lesson material or else it may cause significant reductions in student learning. This chapter discusses these findings, offers implications for theory and teaching, and identifies limitations and future directions.

\section{Hypothesis One: Instructor Self-disclosure Relevance and Student Affect}

Whether the instructor used relevant self-disclosure, students reported high levels 
of affect toward the instructor. These results may be explained by the disclosure-liking hypothesis, which suggests that a person will like an individual more when he or she chooses to self-disclose (Collin \& Miller, 1994). In Collin and Miller's (1994) metaanalysis on the disclosure-liking hypothesis, the researchers revealed that the relationship between self-disclosure and liking operates through the information-processing model of attraction. The information-processing model of attraction posits that liking is determined by positive attitudes toward an individual (Ajzen, 1977). The more positive the attitudes are toward an individual, the greater the reports of liking are toward that individual (Berg \& Derlega, 1987; Dalto, Ajzen, \& Kaplan, 1979). In this study, the instructor's personal disclosures were equally positive (e.g., how much he loves his wife, how he likes to make his daughter's favorite food, etc.) in both the relevant and irrelevant conditions so that the effects of self-disclosure valence would not confound the effects of self-disclosure relevance on students' reported affect toward the instructor. Whether instructor selfdisclosure was relevant to the lesson, then, students might have reported high affect because offering positive self-disclosures helped students to form a positive attitude toward the instructor as predicted by the information-processing model of attraction. It is important to note that Lannutti and Strauman (2006) tested the disclosureliking hypothesis in the classroom context and found that instructor self-disclosure was not related to positive teaching evaluations (i.e., how much students liked the instructor). The reason that the disclosure-liking hypothesis may not have worked in their study may have been due to the study's recall design. Lannutti and Strauman (2006) asked female students to complete a survey about a female instructor they once had in class. Because of this recall design, students may not have been able to easily remember any specific 
instructor self-disclosures that would have fostered positive attitudes and led to increased reports of student affect. In the current experimental study, participants listened to the same positive self-disclosing instructor and then immediately reported on the instructor after the lesson was taught. When the instructor shared positive personal disclosures during the lesson, the students likely perceived positive attitudes toward the instructor and reported high levels of affect toward the instructor in the moment (whether the disclosures were relevant or irrelevant to the lesson content), confirming the disclosureliking hypothesis. Similar to previous experiments that demonstrated that self-disclosure causes liking (Jones \& Archer, 1976; Kleinke \& Kahn, 1980), this dissertation experiment provides support for the disclosure-liking hypothesis in the classroom context.

Regardless of self-disclosure relevance, students reported similar levels of affect toward the instructor in the moment when he was teaching his lesson, but that was not the case for their affect in their likelihood to enroll with the same instructor in another course. Compared to students in the irrelevant instructor self-disclosure condition, students in the relevant instructor self-disclosure condition reported significantly higher ratings of affect in their likelihood to enroll in a future course with the same instructor (if their course schedule would permit it). These findings align with previous research that suggests that students report a greater likelihood to take another class with the same instructor when the instructor stays on task and incorporates personal disclosures that are relevant to the lesson (Goodboy et al., 2014; Mazer et al., 2007; Orbash, 2008). Students may have appreciated the instructor more because the relevant self-disclosure clarified course content and made it easier for them to understand the main points of the lesson 
(Downs et al., 1988). Because the relevant self-disclosure made course content clearer to understand, students may have liked the instructor for aiding their learning and were more interested in enrolling with the instructor again.

The results provided some evidence as to how irrelevant instructor self-disclosure may cause a reduction in affect when students are prompted to think about future classes with the same instructor. Students report that instructors misbehave when they use irrelevant personal disclosures that stray from the main purpose of the lesson (Goodboy \& Myers, 2015; Kearney et al., 1991; Zhang, 2007). That is, instructors that generally get off topic throughout the course are perceived as misbehaving and are less liked by students. When students in the current experiment were asked to rate their affect in the likelihood to enroll in a future class with the same irrelevant self-disclosing instructor, they may have imagined how this irrelevant self-disclosure could interfere with their learning and perceived it as a misbehavior. Furthermore, McBride and Wahl (2005) suggested that irrelevant instructor self-disclosure may lead to student frustration and reduced liking because the off topic disclosures waste students' time and distract from the important aspects of the lesson. In this dissertation, students may have considered how the instructor's irrelevant disclosures could have become frustrating over the course of a semester, which ultimately led them to report lower affect in their likelihood to enroll with the instructor again. While this experimental study was not longitudinal, these results provide preliminary evidence that irrelevant instructor self-disclosure could have deleterious effects on affect if students imagine that the instructor will continue to share off topic personal disclosures over the course of a semester. Irrelevant instructor selfdisclosure may not be detrimental to instructor affect in a single lesson (like in this 
study), but could have potential negative effects if students perceive that an instructor will continue to go off topic in future classes. Overall, students may like an instructor in the moment when he or she chooses to use self-disclosure regardless of its relevance to the lesson. However, when students are prompted to think about enrolling in future classes with the instructor, they like the instructor who uses relevant self-disclosure more than the instructor who uses irrelevant self-disclosure.

\section{Hypothesis Two: Self-disclosure Relevance Directly Causes Student Learning}

Instructor self-disclosure relevance did not operate indirectly through lesson coherence to influence student test scores. Instead, there was a significant direct effect of relevance condition (i.e., relevant versus irrelevant instructor self-disclosure) on student test scores. Given the findings, at first glance, it might be concluded that clarity (i.e., lesson coherence) did not play a role in student learning. Upon further investigation, clarity likely played an important role, but not in the way that was predicted.

These findings may be explained by positioning relevance as another form of instructor clarity, whereby the effect of clarity through instructor self-disclosure relevance had a more powerful effect on student learning compared to the effect of clarity through lesson coherence. Recall that instructor self-disclosure relevance is the extent to which an instructor's personal examples help students "understand the importance of the content" (Cayanus \& Martin, 2008, p. 352). This is similar to how instructor clarity is defined as communication behaviors that assist students in "selecting, understanding, and remembering information" (Titsworth \& Mazer, 2016, p. 105). Moreover, self-disclosure relevance has a moderate positive correlation with instructor clarity (Cayanus \& Martin, 2008). Given this evidence, self-disclosure relevance likely operates as its own form of 
clarity because it is a communication behavior that assists students in understanding and remembering important lesson information.

As for lesson coherence clarity, recall that lesson coherence refers to the extent that instructors avoid providing superfluous information that is not essential to learning the lesson content (Mayer \& Moreno, 2010). On the lesson coherence scale, students responded to items such as "our teacher goes off topic when lecturing" and "there is a lot of unnecessary information in our lectures" (Bolkan, 2017, p. 28). In the current study, students in both conditions (relevant and irrelevant) reported that the instructor's lecture was coherent, and thus, clear. This current experiment involved two forms of clarity: selfdisclosure relevance, which possibly served as a clear teaching behavior, and lesson coherence clarity. If relevant self-disclosure is just another type of clarity, it is possible that self-disclosure relevance functioned as one form of clarity while holding lesson coherence clarity constant in the mediation model. Put simply, the choice of mediator may have resulted in testing a model in which clarity controls for clarity. To test a direct effect in a mediation model $\left(c^{\prime}\right)$, the effect of the antecedent $(X)$ on the consequence $(Y)$ must control for the mediator $(M)$ and partial out variance explained by it by the mediated process (Hayes, 2018). Even though lesson coherence clarity was positively correlated with student test scores, in the mediation model, the effect ( $b$ path) became nonsignificant after controlling for the relevant self-disclosure manipulation $(X)$.

Another reason why lesson coherence did not act as a mediator between relevance condition and student test scores may have been the topic of affectionate communication. The chosen topic of affectionate communication was conducive to personal selfdisclosure. Students may have perceived all instructor self-disclosure as coherent (i.e., on 
topic and necessary to learning the lesson content), whether the instructor related his personal disclosures back to the lesson content. In both the relevant and irrelevant selfdisclosure conditions, the instructor was sharing personal information about showing affection toward his family and friends. Students likely perceived that any instructor selfdisclosure about sharing affection to others was on topic for the lesson, even though the instructor may not have clearly related it back to the important lesson material. For example, in the irrelevant condition the instructor disclosed that he and his wife had "the same favorite movie: Titanic. We watch it together at least once a month. We love that movie so much that we often refer to each other as Jack and Rose. I guess we are just a couple of hopeless romantics." While this information was considered irrelevant because it did not directly relate back to the lesson topic being discussed (i.e., verbal statements of affection), the compassionate nature of the self-disclosure may have caused students to perceive this as relevant to the overall lesson on affectionate communication. If the instructor provided the same disclosure during a lesson on supermassive black holes, students would have likely seen the personal disclosure as unnecessary information for learning the course content and reported less coherence. Ultimately, the affectionate communication lesson topic may have influenced ratings on lesson coherence, which makes this a limitation of the study.

The direct effect of relevance condition (i.e., relevant versus irrelevant selfdisclosure) on student test scores may have occurred because self-disclosure relevance operated as a form of clarity that reinforced the lesson content through examples. That is, relevant self-disclosures may serve as reinforcing examples to the lecture content. An example is defined as an instance of the lesson concept encountered in practical 
circumstances (LeFevre \& Dixon, 1986). Examples are important because they provide concrete information that helps students learn abstract lesson material (Sadoski, 2001). Concrete information evokes mental imagery that contextualizes abstract concepts into applied and "perceptually rich" situations (Goldstone \& Son, 2005, p. 70). The concrete information present in examples helps students learn lesson material (Elio \& Anderson, 1981).

In the current study, the concrete information within the instructor's relevant personal disclosures may be why students scored higher on a test in the relevant selfdisclosure condition. In the relevant self-disclosure condition of the experiment, the instructor taught an abstract lesson concept (e.g., "affectionate feelings and expressions are different"), then used a relevant self-disclosure as an example (e.g., "For my first official date with Emma, I took her to the botanical gardens at the Phipps Conservatory in Pittsburgh. After several more fun and romantic dates, I felt genuine affection towards Emma."), and finally related the relevant self-disclosure example back to the abstract lesson concept (e.g., "However, I didn't immediately express my affection out of fear of being rejected by her. So for a short time, I felt affection toward Emma but I did not express my affection, which highlights how affectionate feelings and expressions are different."). The instructor reinforced the abstract lesson concepts with a relevant selfdisclosure, which functioned as a concrete example to evoke mental imagery of the abstract information. Ultimately, relevant instructor self-disclosure provided concrete information that clarified abstract lesson material through mental imagery and contextualization to make lesson content more memorable and increase student learning.

Conversely, irrelevant instructor self-disclosure might not have reinforced the 
abstract lesson concepts in meaningful ways. Even though the irrelevant self-disclosures provided concrete information to evoke mental imagery, the imagery did not directly help students connect the concrete information to the abstract information in the lesson. Thus, students may have had trouble relating the concrete information in the self-disclosures back to the important lesson content. Moreover, the instructor's relevant self-disclosure examples likely helped students understand how the important lesson concepts functioned in practical circumstances, which may have promoted meaningful learning. Meaningful learning is reflected in students' ability to apply lesson content to new situations (Mayer \& Wittrock, 1996). When the instructor shared a relevant self-disclosure, he provided a concrete personal example that helped students see how an important lesson concept directly applied to a real-life situation that the instructor experienced. In doing so, the instructor's relevant personal disclosures helped make the content more meaningful to students, which in turn, caused students to perform better on the test.

In this dissertation, self-disclosure relevance functioned as a form of clarity to directly influence student test performance. In the irrelevant instructor self-disclosure condition, students may have perceived the instructor as unclear because he provided an overwhelming amount of unrelated information about a plethora of topics that diverted from the lesson, which ultimately hindered students' ability to learn. This may be explained by cognitive load theory (Chandler \& Sweller, 1991). Cognitive load theory posits that students have a finite amount of working memory workload in terms of mental capacity when learning new information (Sweller \& Chandler, 1994). Cognitive load is considered another aspect of instructor clarity (Bolkan, 2017). There are three forms of cognitive load: intrinsic, germane, and extraneous (Sweller, van Merrienboer, \& Paas, 
1998). Intrinsic load refers to the inherent complexity of the lesson content and cannot be altered by instructional design. Germane load is the effort that students put into comprehending lesson content. It is the students' mental resources they have available to deeply process new information. Extraneous load refers to the load imposed through instructor behaviors that contribute to learning important lesson content. Extraneous load burdens students with additional cognitive effort "required to process poorly designed instruction" (Sweller et al., 1998, p. 259). Instructional behaviors that present extraneous load reduce students' ability to deeply process new information (i.e., germane load; Ayres, 2006; Bolkan, 2016).

Irrelevant instructor self-disclosure likely functioned as an extraneous load in the current experimental study. In the irrelevant self-disclosure condition, the instructor taught the lesson concept (e.g., "affectionate feelings and expression are different"), then used a self-disclosure (e.g., "For my first official date with Emma, I took her to the botanical gardens at the Phipps Conservatory in Pittsburgh. After several more fun and romantic dates, I felt genuine affection towards Emma."), and then continued off on a tangent that was not related back to the lesson concept (e.g., "I took Emma to the conservatory because she loves flowers. When we were there, we also saw a bunch of miniature Bonsai trees that are grown to mimic the shape and scale off full size trees. I think that those little Bonsai trees are so interesting. I plan to get one for myself."). The irrelevant tangent (i.e., Bonsai trees) likely burdened students with extraneous cognitive load that took away from their germane load (i.e., ability to deeply process the concept that affectionate feelings and expressions are different). Cognitive load theory explains how irrelevant instructor self-disclosure may have overloaded students' working memory 
with extraneous information, reduced their ability remember the most important lesson concepts, and led them to perform worse on the test.

\section{Implications for Theory and Teaching}

One theoretical implication that can be drawn from this dissertation is the important causal effect of instructor self-disclosure relevance on student learning. Previous experiments examining the effects of instructor self-disclosure on student learning have resulted in mixed findings. Several researchers have reported that instructor self-disclosure increases cognitive learning (Cayanus, Martin, \& Weber, 2003; Goodboy et al., 2014; Gorham, 1988; Hartlep, 2001; McCarthy \& Schmeck, 1982; Stoltz, Young, \& Bryant, 2014; Youells, 1981), whereas other researchers have suggested that instructor self-disclosure decreases student cognitive learning (Naumann, 1988; Nussbaum \& Scott, 1979). Moreover, other researchers have reported that instructor self-disclosure did not have any significant impact on students' final class grade (Aubry, 2009; Ivy, 2016). Given these mixed findings, this dissertation provides preliminary causal evidence of how the self-disclosure dimension of relevance promotes student learning. The result of the direct effect of self-disclosure relevance on student test scores prompts instructional researchers to further examine how instructors use relevant self-disclosure as a form of clarity to help students understand and remember important lesson content. Given the findings of this experimental study, future research should primarily examine the relevance dimension when investigating how instructor self-disclosure causes increases in student learning.

Another theoretical implication is that instructor self-disclosure may be both a rhetorical and relational behavior. Mottet, Frymier, and Beebe (2006) conceptualized 
rhetorical and relational goals of instruction theory (RRGT) that posits instructors have both rhetorical and relational goals. When seeking to meet rhetorical goals, instructors "focus on influencing students to learn and understand the content presented by the teacher" (Mottet et al., 2006, p. 267). When striving to meet relational goals, instructors are "seeking a closer relationship with students" and "view learning as something the teacher and students do together" (Mottet et al., 2006, p. 267). Mottet and his colleagues (2006) suggested that instructors should meet both goals in order to fulfill students' classroom expectations and facilitate effective instruction. Even though earlier research has proposed that instructor self-disclosure is solely a relational behaviors (Cayanus, 2004), self-disclosure may be able to meet both rhetorical and relational goals. Using RRGT to frame their study, Kaufmann and Frisby (2017) found support that instructor self-disclosure can meet both rhetorical goals (via perceived content relevance) and relational goals (via perceived caring) in the classroom. Moreover, Cayanus and Martin (2016) suggested that instructor self-disclosure is "one communication strategy that teachers may use to attain these goals" (p. 244). As a relational behavior, instructors may use relevant self-disclosure to maintain affect and build interpersonal connectedness with their students because it demonstrates that they are willing offer personal information from their lives to help students learn important lesson concepts. Instructors may also be able to use self-disclosure as a rhetorical behavior by using relevant personal disclosures to reinforce important lesson concepts, and in turn, help students better remember content for a test. Future research should continue to examine instructor self-disclosure as not only a relational behavior to increase student liking, but also as a rhetorical behavior that can increase student learning. 
Several practical implications can be offered for how instructors should use selfdisclosure in the college classroom. First, instructors should present relevant selfdisclosures after abstract lesson content. As accomplished in the relevant self-disclosure condition in this study, instructors should first explain an important lesson concept (e.g., expressing affection reduces likelihood of depression), then use a relevant self-disclosure ("I constantly show affection to those people that mean the most to me in my life. This could be how I give my daughter Lily a kiss on the cheek each time I tuck her in for bed. This could be how I help my wife with her paperwork whenever I can.”), and then explicitly relate the self-disclosure back to the important lesson concept ("Therefore, I am buffered from the effects of depression when I get the chance to express my affection to my family in these simple ways.”). This sequence follows recent research that suggests abstract lesson content should precede concrete practical examples to optimize student learning (Bolkan \& Goodboy, 2019). Providing abstract information before concrete information allows students to form a basic idea of the lesson concept, which is then easily transferred to a wide variety of different content-specific situations (Bassok \& Holyoak, 1989). Instructors who provide concrete information before abstract information run the risk of tying students' understanding to a specific content, which may make it harder for them to transfer the concrete information to other practical situations (Goldstone \& Sakamoto, 2003). Providing abstract information first acts as a signaling device that prepares students to organize an incoming concrete example, which ultimately reduces the extraneous load burden on students' cognitive resources (Bolkan \& Goodboy, 2019). The suggested format incorporates a concrete example (i.e., relevant selfdisclosure) that reinforces the lesson content by evoking mental imagery for abstract 
lesson concepts (Goldstone \& Son, 2005). By following this suggested sequence, instructors may be able to use relevant self-disclosure to reinforce abstract lesson content and optimize student learning.

Second, instructors should explicitly relate the relevant self-disclosures back to the lesson content because not all students may perceive the relevance of the instructor's personal disclosures. When testing the relevant instructor self-disclosures in the pilot study, students perceived some of the relevant self-disclosures as more relevant than other relevant self-disclosures. In other words, an instructor may be providing selfdisclosure that is highly relevant to the lesson content, but students may not perceive the relevance to be as strong as the intended manipulation. This difference in relevance ratings between the self-disclosures suggests that there is a relevance gray area as to what students perceive as relevant, which may ultimately depend on their individual backgrounds and prior experiences. For this reason, instructors might provide a logical connective phrase to connect the relevant self-disclosures to important lesson content. A logical connective phrase is an explicit verbal statement that instructors use to "clarify connections between subordinate concepts" (Mautone \& Mayer, 2001, p. 378). Providing a logical connective phrase might act as a signal that reduces ambiguity about how abstract lesson content and relevant self-disclosures relate to one another. Loman and Mayer (1983) asserted that it is important for instructors to use logical connective phrases to reduce the number of inferences that students must make to understand a lesson. By providing a logical connective phrase between abstract lesson content and relevant selfdisclosure examples, instructors may be able to reduce the relevance gray area and assist students in understanding the connection between subordinate concepts. 
Third, instructors may not need to be concerned about the effects on student affect if they share irrelevant personal disclosures during instruction. For this dissertation, students liked the instructor despite whether his personal disclosures were relevant or irrelevant to the lesson material. Student affect may decrease slightly if students perceive the instructor as potentially sharing irrelevant self-disclosures in the future, but students still, on average, liked the instructor overall in both conditions. Previous correlational studies have identified a moderate positive relationship between self-disclosure relevance and student affect toward the instructor (Cayanus \& Martin, 2008; Goodboy et al., 2014). Given these findings, students like instructors who use self-disclosure that relate to the lesson. However, instructors that use off-topic self-disclosures may not greatly reduce student liking. Overall, instructors may be able to use self-disclosure to maintain student affect (on average) whether they share relevant or irrelevant personal disclosures.

Fourth, instructors should make sure that their personal disclosures are positive because self-disclosure valence may be the primary influence on student affect. In this study, the instructor's self-disclosures were overall positive and consistent between the relevant and irrelevant conditions. Several researchers found that instructors who use positive self-disclosure (as opposed to negative self-disclosure) have students report increased teacher liking (Hill, Ah Yun, \& Lindsey, 2008), greater intentions of taking another class with the same instructor (Bell, 2003) and higher ratings of general affect (Cayanus, 2005; Cayanus \& Martin, 2008; Goodboy et al., 2014; Walker, 1999). Even though this study did not examine self-disclosure valence (i.e., positive versus negative), the positive self-disclosures used in this study (for both the relevant and irrelevant conditions) might have fostered positive student attitudes toward the instructor and led 
students to report high levels of affect toward the instructor (on average). Using RRGT, future research should examine how self-disclosure valence (i.e., positive or negative) may be important for meeting relational goals (e.g., interpersonal connectedness), whereas self-disclosure relevance (i.e., relevant or irrelevant) may be important for meeting rhetorical goals (i.e., increased test performance). More research is required on self-disclosure valence and relevance together because instructors who share a relevant/negative self-disclosure may reinforce the lesson material but may also cause students to dislike them. If students dislike their instructor, it has the potential to reduce student learning (Goodboy, Bolkan, \& Baker, 2018). Until more research is conducted on self-disclosure valence and relevance, instructors might follow Cayanus and Heisler's (2013) recommendation that, "If teachers do not have positive information to reveal about them that is relevant to their courses, these teachers should probably stick to the content of the course and decrease or eliminate personal statements" (p. 8).

Although it may be an obvious pedagogical take-away, instructors should avoid self-disclosure that is irrelevant to the lesson content. Most instructors already intuitively know not to share off topic personal information during instruction, but some instructors may not, according to instructor misbehavior research (Goodboy \& Myers, 2015; Vallade \& Kaufmann, 2018; Vallade \& Malachowski, 2015). In this dissertation, irrelevant instructor self-disclosure interfered with learning and made it harder for students to focus on the important lesson content that they needed to remember for the test. Compared to the relevant instructor self-disclosure condition, students in the irrelevant self-disclosure condition performed significantly worse on the test $(-8.70 \%)$, which is nearly a full letter grade deduction. Although this dissertation was only one lesson with a simple 15-item 
multiple-choice test, the use of irrelevant instructor self-disclosure over the course of a semester may potentially compound the detrimental effects on student learning and further reduce students' ability to perform well on tests of retention. Therefore, irrelevant instructor self-disclosure should be avoided so it does not hinder student learning.

Finally, several recommendations are offered about how an educator might train new trainee instructors to use self-disclosure in the college classroom. An educator may begin by asking trainees to recall a time when a teacher used a self-disclosure during instruction. What was the topic of the self-disclosure? Did the self-disclosure reveal positive or negative information about the teacher? Did the self-disclosure help you better understand the lesson content? If so, how? The educator should generate discussion because it will help trainees begin to think about the different aspects of instructor selfdisclosure (e.g., relevance, valence). Next, an educator may ask trainees to list personal information about themselves that they would feel comfortable disclosing in class. This may include information about personal hobbies, educational background, prior experiences, friends, and/or family. These personal disclosures should be generally positive and avoid highly negative topics that reveal bad, undesirable, or unflattering information. Trainees should be asked to keep this "bank" of positive self-disclosures to utilize later in the training session. An educator should then provide examples of an instructor effectively using relevant self-disclosure during an actual classroom lesson. For example, an educator may choose to play the recorded lecture of the relevant selfdisclosing instructor from this dissertation. The educator would highlight how the instructor teaches the lesson content ("expressing affection to others leads to reduced levels of stress and lower vulnerability to stress"), shares a relevant self-disclosure ("I 
appreciate a high level of affection in my family, especially with my wife Emma. While there are obvious benefits to receiving affection from my wife Emma, it's also beneficial for me to express affection back to her, such as when I told my wife the night before our wedding, I can't wait to be married to you."), and then explicitly relates the selfdisclosure back to course material to reinforce the important lesson concepts ("Expressing affection at stressful times like right before my wedding has the potential to reduce my stress and lower my vulnerability for stressing out more in the future"). The educator should then ask the trainees to insert their own relevant self-disclosures (from their self-disclosure "bank") into the lesson content from the video example. The trainees should incorporate their own relevant self-disclosure examples into the lesson content to reinforce important concepts using the suggested sequence (i.e., teach content, share relevant self-disclosure, relate self-disclosure back to lesson content). The educator might also choose to play the recorded lecture footage of the irrelevant self-disclosing instructor so that the trainees learn to avoid sharing off-topic tangents that can potentially distract student attention from the lesson subject. The educator may then ask each trainee to teach a short lesson that incorporates their own self-disclosures. After each lesson, the educator and other trainees can provide constructive feedback about how the self-disclosure helped (or hindered) the trainees' understanding of the important lesson content. Ultimately, the educator should emphasize that effective self-disclosure occurs when instructors use their personal information as relevant examples to help students better imagine how abstract lesson content is functioning in easily imagined circumstances.

\section{Limitations and Future Directions}

The first limitation was that the dissertation used only a white heterosexual male 
instructor to teach the live lecture lessons. Previous studies have suggested that instructor ethnicity, sex, and sexual orientation may influence student perceptions of instructor selfdisclosure. Referring to ethnicity, personal disclosures shared by instructors of color (and other minority populations) have the potential to "significantly shift the content and process of learning in many communication classrooms" (Simpson, 2010, p. 368). Thus, a person's cultural background will change how students perceive certain instructor disclosures. Instructor sex may also play a role with instructor self-disclosure because McCarthy and Schmeck (1982) found that instructor self-disclosure from a male instructor was more beneficial to student learning for male students compared to female students. However, Sorensen (1988) concluded that the relationship between instructor sex and self-disclosive behaviors were negligible, so findings are mixed. Moreover, instructor sexual orientation may impact what instructors may share in the classroom. Russ, Simonds, and Hunt (2002) found that students reported less credibility and less learning when they were taught by a gay instructor compared to a heterosexual instructor. However, Boren and McPherson (2018) replicated Russ et al.'s (2002) study and found that students did not report any differences in instructor credibility and perceived learning between a gay instructor and a heterosexual instructor. While Farr (2000) states that selfdisclosing sexual orientation to the class can be an effective teaching strategy, some instructors do not feel comfortable doing so (DiVerniero \& Hosek, 2011) and admit that they conceal this information from their students (McBride \& Wahl, 2005). Ultimately, McKenna-Buchanan, Munz, and Rudnick (2015) assert that instructor self-disclosure is "made more complicated for teachers with potentially stigmatizing private information to share, as disclosing such information might undermine the benefits traditionally 
associated with self-disclosure in the classroom" (p. 281). Given his status in American culture, the white male heterosexual instructor in this study may have been privileged to reap the benefits of the personal disclosures compared to instructors from minority populations. This limits the generalizability of the findings.

The second limitation was the validity and reliability issues associated with the measures used in this study. After following Kline's (2016) recommendations for global fit, the researcher found that each scale in this study demonstrated poor fit in some way. Even though there were nearly no issues with local fit, global fit was arguably poor for all scales examined using confirmatory factor analysis. Furthermore, scale reliability analyses using McDonald's Omega (McDonald, 1999) identified that the affect toward the instructor subscale and the shortened instructor credibility scale demonstrated relatively poor internal consistency compared to the other scales used in this study. The original 18-item Measure of Source Credibility Scale (McCroskey \& Teven, 1999) was shortened to a 3-item scale to reduce participant response fatigue. However, this choice came with the cost of reduced reliability as compared to previous studies using the 18item credibility scale that have reported Cronbach's alpha reliability coefficients ranging from .86 to .95 for the three dimensions (Ledbetter \& Finn, 2018; Myers \& Huebner, 2011; Sidelinger \& Bolen, 2016). The poor fit and low reliability issues call into question the validity of the scales. As Bandalos (2018) stated, "Validity is arguably the most important quality of a test because it has to do with the fundamental measurement issue of what our measurement instruments are really measuring" (p. 254). If a scale is not valid, it may not be measuring what a researcher is trying to measure. In other words, study results are only as good as the scales used to achieve them, and thus, the scale 
validity and reliability issues in this study suggest that the scales may not be measuring what they intend to measure, which might have ultimately influenced the findings. Instructional researchers may wish to further examine the psychometric properties of these scales to ensure proper measurement in the future.

The third limitation was that the 15-item multiple-choice test may have been too easy. Many students performed well on the test and received a high $\mathrm{C}$ grade $(M=$ $78.79 \%, S D=15.58 \%)$. The test consisted of short-term recall questions that tapped into low levels of learning (i.e., factual and conceptual knowledge; Anderson \& Krathwohl, 2001), which may not have challenged students. As previously discussed, irrelevant instructor self-disclosure likely created more of an extraneous load that took away from students' germane resources that would have allowed them to process more difficult lesson content. However, a high extraneous load during learning might not matter as much if test items are tapping into learning processes that are characterized by a low intrinsic cognitive load. Put simply, students might not be cognitively overburdened to learn to novice material assessed by low difficulty test questions. Sweller, Ayres, and Kalyuga (2011) argued that "a less than optimal instructional design associated with low intrinsic load may not interfere with learning” (p. 68). For example, students may have been able to easily answer the test question "[Direct nonverbal gestures] are ways that people can express affection through kissing, hugging, and smiling" even if the instructor's irrelevant personal disclosure provided extraneous information about "getting together for football and playing racing video games" with his high school friends. Teaching definitions likely provided a low intrinsic load for students to learn. Students may have been able to perform well on the test despite the high extraneous load of 
irrelevant instructor self-disclosure because the lesson content provided a relatively low intrinsic load on students' working memory to recall important lesson concepts. Future researchers should assess higher levels of cognitive learning including open-ended and application questions to better understand how relevant (and irrelevant) instructor selfdisclosure influences student learning.

The fourth limitation of this dissertation is that it only examined students' perceptions of the instructor in a single 15-minute lesson. For example, students reported on their perceptions of the instructor's credibility only having been taught by him for a short time. The credibility scale had students respond to three items (i.e., competence: “competent/incompetent," character: "honest/dishonest," caring: "cares about me/doesn't care about me") to measure the three dimensions of instructor credibility. After a single 15-minute lesson, students might not have felt that the instructor cared about their wellbeing because the instructor will likely never teach them again. Moreover, instructor selfdisclosure may change over the course of the semester as instructors build a rapport with their students. As the semester progresses, instructors may share more intimate and negative disclosures because they just come out naturally when they are teaching. Future researchers may wish to use a longitudinal study design that investigates how instructor self-disclosures organically manifest during instruction and simultaneously examines the effects of multiple instructor self-disclosure dimensions.

Future research should also examine the effects of instructor self-disclosure in a variety of different topics and contexts. For this dissertation, the topic of affectionate communication was chosen for three reasons: the topic would be interesting to students, the topic would be unfamiliar to students in the introductory communication classes, and 
the topic would be conducive to instructor self-disclosure. However, it is possible that the conduciveness of affectionate communication to instructor self-disclosure may have led students to perceive all instructor self-disclosures as coherent (i.e., on topic and necessary to learning the lesson content), whether the instructor related his personal disclosures back to the lesson content or not. Future research should use a different lesson topic (e.g., chemistry, physics, history) to see if there are similar benefits to student learning.

Future research should also experimentally test the influence of self-disclosure valence on student affect and cognitive learning. Researchers have found that individuals tend to like others more when they share positive information about their personal lives rather than negative, unflattering information (Dalto, Ajzen, \& Kaplan, 1979). As aforementioned previously, several correlational studies identified a positive relationship between positive instructor self-disclosure and student affect (Cayanus \& Heisler, 2013; Cayanus \& Martin, 2008). When instructors share positive self-disclosure (as opposed to negative self-disclosure), students report increased feelings of affect toward an instructor (Walker, 1999), greater intention to take another class with the same instructor (Bell, 2003; Goodboy et al., 2014), and provide more positive teaching evaluations (Lannutti \& Strauman, 2006). In this study, instructor self-disclosure was largely positive in both conditions to control for any effect that valence would have on student affect. Future research should examine if and how instructor self-disclosure relevance and valence interact to influence affect and learning. One could assume that positive/relevant instructor self-disclosure would be most effective, whereas negative/irrelevant instructor self-disclosure would be least effective. However, how would positive/irrelevant and negative/relevant instructor self-disclosure influence student affect and cognitive 
learning? Future instructional researchers would be wise to simultaneously examine multiple dimensions of instructor self-disclosure to better understand this teaching behavior.

\section{Summary}

The results of this dissertation revealed that relevant (as opposed to irrelevant) instructor self-disclosure directly caused students to perform better on a test of cognitive learning. In other words, an instructor who related personal disclosures back to lesson content helped students clarify important concepts and increased their learning. Conversely, irrelevant instructor self-disclosure detracted from student learning because the off topic tangents likely overloaded students' cognitive processes with extraneous information. In the moment, students liked self-disclosing instructors whether the disclosures were relevant to the lesson or not. However, when students were asked to report on their affect in the likelihood to enroll in a future class with the same instructor, they reported less affect toward the irrelevant self-disclosing instructor because they likely imagined how the irrelevant self-disclosure could interfere with learning and perceive it as an instructor misbehavior. Ultimately, these findings suggest that instructors should incorporate relevant personal disclosures into their lesson and avoid irrelevant disclosures at all costs because these off topic tangents could potentially lead to reduced student learning and reduced affect to enroll with the instructor again in a future class. 


\section{References}

Ajzen, I. (1977). Information processing approaches to interpersonal attraction. In S. W. Duck (Ed.), Theory and practice in interpersonal attraction (pp. 51-77). San Diego, CA: Academic Press.

Alexander, P. A., Schallert, D. L., \& Hare, V. C. (1991). Coming to terms: How researchers in learning and literacy talk about knowledge. Review of Educational Research, 61, 315-343. doi:10.3102/00346543061003315

Allen, M., Witt, P. L., \& Wheeless, L. R. (2006). The role of teacher immediacy as a motivational factor in student learning: Using meta-analysis to test a causal model. Communication Education, 55, 21-31. doi:10.1080/03634520500343368

Altman, I., \& Taylor, D. (1973). Social penetration: The development of interpersonal relationships. New York, NY: Holt, Rinehart, \& Winston.

Andersen, B., \& Anderson, W. (1985). Client perceptions of counselors using positive and negative self-involving statements. Journal of Counseling Psychology, 32, 462-465. doi:10.1037/0022-1067.32.3.462

Andersen, J. F. (1979). Teacher immediacy as a predictor of teaching effectiveness. In B. D. Ruben (Ed.), Communication yearbook (Vol. 3, pp. 534-559). New Brunswick, NJ: Transaction Books.

Andersen, J. F., Norton, R. W., \& Nussbaum, J. F. (1981). Three investigations exploring relationships between perceived teacher communication behaviors and student learning. Communication Education, 30, 377-392. doi:10.1080/03634528109378493

Anderson, L. W., \& Krathwohl, D. R. (Eds.). (2001). A taxonomy for learning, teaching, 
and assessing: A revision of Bloom's taxonomy of educational objectives. New York, NY: Addison Wesley Longman.

Aspy, D. (1969). The effects of teacher-offered conditions empathy, positive regard and congruence upon student achievement. Florida Journal of Educational Research, 2, 39-48.

Aubry, J. M. (2009). Motivation and instructor's self-disclosure using Facebook in a French online course context. Unpublished doctoral dissertation, University of South Florida, Tampa, Florida.

Ayres, P. (2006). Impact of reducing intrinsic cognitive load on learning in a mathematical domain. Applied Cognitive Psychology, 20, 287-298. doi:10.1002/acp.1245

Ayres, P., \& Paas, F. (2012). Cognitive load theory: New directions and challenges. Applied Cognitive Psychology, 26, 827-832. doi:10.1002/acp.2882

Bandalos, D. B. (2018). Measurement theory and applications for the social sciences. New York, NY: Guilford Press.

Bassok, M., \& Holyoak, K. J. (1989). Interdomain transfer between topics in algebra and physics. Journal of Experimental Psychology: Learning, Memory, and Cognition, 15, 153-166. doi:10.1037/h0090398

Bell, L. M. (2003). Instructors' message variables and students' learning orientation/grade orientation and affective learning. Unpublished master's thesis, West Virginia University, Morgantown, West Virginia.

Berg, J. H., \& Derlega, V. J. (1987). Themes in the study of self-disclosure. In V. J. Derlega \& J. H. Berg (Eds.), Self-disclosure: Theory, research, and therapy (pp. 
1-8). New York: Plenum Press.

Block, J. (1952). The assessment of communication: Role variations as a function of interactional context. Journal of Personality, 21, 272-286. doi:10.1111/j.14676494.1952.tb01133.x

Bloom, B. S. (Ed.). (1956). Taxonomy of educational objectives: Handbook I, cognitive domain. New York, NY: David Mckay.

Bolkan, S. (2015). Students' affective learning as affective experience: Significance, reconceptualization, and future directions. Communication Education, 64, 502505. doi:10.1080/03634523.2015.1058963

Bolkan, S. (2016). The importance of instructor clarity and its effect on student learning: Facilitating elaboration by reducing cognitive load. Communication Reports, 29, 152-162. doi:10.1080/08934215.1067708

Bolkan, S. (2017). Development and validation of the clarity indicators scale. Communication Education, 66, 19-36. doi:10.1080/03634523.2016.1202994

Bolkan, S. (2019) Facilitating student attention with multimedia presentations: Examining the effects of segmented PowerPoint presentation on student learning. Communication Education, 68, 61-79. doi:10.1080/03634523.2018.1517895

Bolkan, S., \& Goodboy, A. K. (2019). Examples and the facilitation of student learning: Should instructors provide examples or should students generate their own? Communication Education, 68, 287-307. doi:10.1080/03634523.2019.1602275

Bolkan, S., Goodboy, A. K., \& Kelsey, D. (2016). Instructor clarity and student motivation: Academic performance as a product of students' ability and motivation to process instructional material. Communication Education, 65, 129- 
148. doi:10.1080/03634523.2015.1079329

Bolkan, S., Goodboy, A. K., \& Myers, S. A. (2017). Conditional processes of effective instructor communication and increases in students' cognitive learning. Communication Education, 66, 129-147. doi:10.1080/03634523.2016.1241889

Boren, J. P., \& McPherson, M. B. (2018). Is coming out in the classroom still an occupational hazard? A replication of Russ, Simonds, and Hunt (2002). Communication Studies, 69, 242-250. doi:10.1080/10510974.2018.1466719

Borzea, D., \& Goodboy, A. K. (2016). When instructors self-disclose but misbehave: Conditional effects on student engagement and interest. Communication Studies, 67, 548-566. doi:10.1080/10510974.2016.1212912

Brophy, N. S. (2018). The effects of instructors discussing alcohol in the classroom on student perceptions of their instructor. Unpublished master's thesis, Illinois State University, Normal, Illinois.

Caltabiano, M. L., \& Smithson, M. (1983). Variables affecting the perception of selfdisclosure appropriateness. The Journal of Social Psychology, 120, 119-128. doi:10.1080/00224545.1983.9712017

Canary, D. J., \& Spitzberg, B. H. (1987). Appropriateness and effectiveness perceptions of conflict strategies. Human Communication Research, 14, 93-118. doi:10.1111/j.1468-2958.1987.tb00123.x

Carbone, T. (1975). Stylistic variables as related to source credibility: A content analysis approach. Speech Monographs, 42, 99-106. doi:10.1080/03637757509375884

Cayanus, J. L. (2004). Effective instructional practice: Using teacher self-disclosure as an instructional tool. Communication Teacher, 18, 6-9. 
doi:10.1080/1740462032000142095

Cayanus, J. L. (2005). Students' propensity to ask questions: Do cognitive flexibility, teacher self-disclosure, student motives to communicate, and affective learning influence question asking in the classroom? Unpublished doctoral dissertation, West Virginia University, Morgantown, West Virginia.

Cayanus, J. L. (2007, November). To ask or not to ask? An examination of student question-asking. Paper presented at the annual meeting of the National Communication Association, Chicago, IL.

Cayanus, J. L., \& Heisler, J. (2013, November). Teacher self-disclosure: Exploring a fourth dimension. Paper presented at the annual meeting of the National Communication Association, Washington, DC.

Cayanus, J. L., \& Martin, M. M. (2002a, March). The relationship between teacher selfdisclosure, student motives, student affect, and student participation. Paper presented at the annual meeting of the Eastern Communication Association, Washington, DC.

Cayanus, J. L., \& Martin, M. M. (2002b, November). Development of a teacher selfdisclosure scale. Paper presented at the annual meeting of the National Communication Association, Atlanta, GA.

Cayanus, J. L., \& Martin, M. M. (2004). An instructor self-disclosure scale. Communication Research Reports, 21, 252-263. doi:10.1080/0882409040935987

Cayanus, J. L., \& Martin, M. M. (2008). Teacher self-disclosure: Amount, relevance, and negativity. Communication Quarterly, 56, 321-341.

doi:10.1080/01463370802241492 
Cayanus, J. L., \& Martin, M. M. (2016). Teacher self-disclosure. In P. Witt (Ed.), Handbooks of communication science: Communication and learning (pp. 241258). Berlin, Germany: De Gruyter Mouton.

Cayanus, J. L., Martin, M. M., \& Goodboy, A. K. (2009). The relationship between teacher self-disclosure and student motives to communicate. Communication Research Reports, 26, 105-113. doi:10.1080/0882409090902861523

Cayanus, J. L., Martin, M. M., \& Myers, S. A. (2008). The relationship between perceived instructor self-disclosure and college student information seeking. Texas Speech Communication Journal, 33, 20-26.

Cayanus, J. L., Martin, M. M., \& Weber, K. D. (2003, April). The relationships between teacher self-disclosure with out-of-class communication, student interest, and cognitive learning. Paper presented at the annual meeting of the Southern States Communication Association, Birmingham, AL.

Cayanus, J. L., \& Youngquist, J. (2016). Examining relevance and appropriateness of teacher self-disclosure. Unpublished manuscript, Department of Communication and Journalism, Oakland University, Rochester, Michigan.

Chandler, P., \& Sweller, J. (1991). Cognitive load theory and the format of instruction. Cognition and Instruction, 8, 293-332. doi:10.1207/s1532690xci0804_2

Chesebro, J. L. (2003). Effects of teacher clarity and nonverbal immediacy on student learning, receiver apprehension, and affect. Communication Education, 52, 135147. doi:10.1080/03634520302471

Clark, J. D. (1978). The impact of teacher self-disclosure on student perceptions of the teacher. Unpublished master's thesis, University of New Hampshire, Durham, 
New Hampshire.

Collin, N. L., \& Miller, L. C. (1994). Self-disclosure and liking: A meta-analytic review. Psychological Bulletin, 116, 457-475. doi:10.1037/0033-2909.116.3.457

Comadena, M. E., Hunt, S. K., \& Simonds, C. J. (2007). The effects of teacher clarity, nonverbal immediacy, and caring on student motivation, affective and cognitive learning. Communication Research Reports, 24, 241-248.

doi:10.1080/08824090701446617

Cooper, P., \& Simonds, C. (2003). Communication for the classroom teacher. Boston, MA: Allyn \& Bacon.

Cozby, P. C. (1972). Self-disclosure, reciprocity, and liking. Sociometry, 35, 151-160.

Cozby, P. C. (1973). Self-disclosure: A literature review. Psychological Bulletin, 79, 7391. doi:10.1037/h0033950

Curran, J., \& Loganbill, C. R. (1983). Factors affecting the attractiveness of a group leader. Journal of College Student Personnel, 24, 350-355.

Curtis, J. M. (1981). Effect of therapist's self-disclosure on patients' impression of empathy, competence, and trust in an analogue of a psychotherapeutic interaction. Psychological Reports, 48, 127-136. doi:10.2466/pr0.1981.48.1.127

Dalto, C. A., Ajzen, I., \& Kaplan, K. J. (1979). Self-disclosure and attraction: Effects of intimacy and desirability on beliefs and attitudes. Journal of Research in Personality, 13, 127-138. doi:10.1016/0092-65667990025-4

Deiro, J. (1997). Teacher strategies for nurturing healthy connections with students. Journal for a Just and Caring Education, 3, 192-202.

Delacre, M., Lakens, D., \& Leys, C. (2017). Why psychologists should by default use 
Welch's t-test instead of student's t-test. International Review of Social Psychology, 30, 92-101. doi:10.5334/irsp.82

Derlega, V. J., Metts, S., Petronio, S., \& Margulis, S. T. (1993). Sage series on close relationships: Self-disclosure. Thousand Oaks, CA: Sage.

Dindia, K. (2002). Self-disclosure research: Knowledge through meta-analysis. In M. Allen, R. W. Priess, B. M. Gayle, \& N. A. Burrell (Eds.), Interpersonal communication research: Advances through meta-analysis (pp. 169-185). Mahwah, NJ: Erlbaum.

DiVerniero, R. A., \& Hosek, A. M. (2011). Students' perceptions and communicative management of instructors' online self-disclosure. Communication Quarterly, 59, 428-449. doi:10.1080/01463373.2011.597275

Downs, V. C., Javidi, M., \& Nussbaum, J. F. (1988). An analysis of teachers' verbal communication within the college classroom: Use of humor, self-disclosure, and narratives. Communication Education, 37, 127-141.

doi:10.1080/03634528809378710

Farr, M. T. (2000). "Everything I didn’t want to know I learned in lit class": Sex, sexual orientation, and student identity. International Journal of Sexuality \& Gender Studies, 5, 205-213. doi:10.1023/A:1010132914278

Finn, A. N., Schrodt, P., Witt, P. L., Elledge, N., Jernberg, K. A., \& Larson, L. M. (2009). A meta-analytic review of teacher credibility and its associations with teacher behaviors and student outcomes. Communication Education, 58, 516-537. doi:10.1080/03634520903131154

Floyd, K. (2006). Communicating affection: Interpersonal behavior and social context. 
Cambridge, England: Cambridge University Press.

Floyd, K., Hesse, C., \& Generous, M. A. (2018). Affection exchange theory: A bioevolutionary look at affectionate communication. In D. O. Braithwaite, E. A. Suter, \& K. Floyd (Eds.), Engaging theories in family communication: Multiple perspectives (2nd ed., pp. 17-26). New York, NY: Routledge.

Frisby, B. N., \& Sidelinger, R. J. (2013). Violating student expectations: Student disclosures and student reactions in the college classroom. Communication Studies, 64, 241-258. doi:10.1080/10510974.2012.755636

Fritz, M. S., \& MacKinnon, D. P. (2007). Required sample size to detect the mediated effect. Psychological Science, 18, 233-239. doi:10.1111/j.14679280.2007.01882.x

Frymier, A. B., \& Houser, M. L. (1999). The revised learning indicators scale. Communication Studies, 50, 1-12. doi:10.1080/10510979909388466

Fusani, D. S. (1994). “Extra-class” communication: Frequency, immediacy, selfdisclosure, and satisfaction in student-faculty interaction outside the classroom. Journal of Applied Communication Research, 22, 232-255. doi:10.1080/00909889409365400

Galvin, K. M. (1999). Classroom roles of the teacher. In A. L. Vangelisti, J. A. Daly, \& G. W. Friedrich (Eds.). Teaching communication theory, research, and methods (2nd ed., pp. 243-255). Malwah, NJ: Erlbaum.

Goldstein, G. S., \& Benassi, V. A. (1994). The relation between teacher self-disclosure and student classroom participation. Teaching of Psychology, 21, 212-216. doi:10.1207/s15328023top2104_2 
Goldstone, R. L., \& Sakamoto, Y. (2003). The transfer of abstract principles governing complex adaptive systems. Cognitive Psychology, 46, 414-466. doi:10.1016/S0010-0285(02)00519-4

Goldstone, R. L., \& Son, J. Y. (2005). The transfer of scientific principles using concrete and idealized simulations. Journal of the Learning Sciences, 14, 69-110. doi:10.1207/s15327809jls1401_4

Goodboy, A. K., Bolkan, S., \& Baker, J. P. (2018). Instructor misbehaviors impede students" cognitive learning: Testing the causal assumption. Communication Education, 67, 308-329. doi:10.1080/03634523.2018.1465193

Goodboy, A. K., Carton, S. T., Goldman, Z. W., Gozanski, T. A., Tyler, J. J. C., \& Johnson, N. R. (2014). Discouraging instructional dissent and facilitating student learning experience through instructor self-disclosure. Southern Communication Journal, 79, 114-129. doi:10.1080/1041794x.2013.865256

Goodboy, A. K., \& Myers, S. A. (2015). Revisiting instructor misbehaviors: A revised typology and development of a measure. Communication Education, 64, 133-153. doi:10.1080/03634523.2014.978798

Gorham, J. (1988). The relationship between verbal teacher immediacy behaviors and student learning. Communication Education, 37, 40-53. doi:10.1080/03634528809378702

Gregory, L. D. (2005). Influence in the classroom: Exploring instructor self-disclosure communication and student outcomes in higher education. Unpublished doctoral dissertation, University of Miami, Coral Gables, Florida.

Halverson, C. F., \& Shore, R. E. (1969). Self-disclosure and interpersonal functioning. 
Journal of Consulting and Clinical Psychology, 33, 213-217.

doi:10.1037/h0027158

Hartlep, K. (2001). Self-reference and instructor self-disclosure: Is gossip easier to remember? The Online Journal of Teaching and Learning in the CSU. Retrieved from http://www.exchangesjournal.org/research/self_reference_pg1.html

Hayes, A. F. (2018). Introduction to mediation, moderation, and conditional process analysis: A regression-based approach (2nd ed.). New York, NY: Guilford Press.

Hill, J., Ah Yun, K., \& Lindsey, L. (2008, November). The interaction effect of teacher self-disclosure valence and relevance on student motivation, teacher liking, and teacher immediacy. Paper presented at the annual meeting of the National Communication Association, Chicago, IL.

Holladay, S. J. (1984). Student and teacher perceptions of teacher self-disclosure. Unpublished manuscript. University of Oklahoma, Norman, Oklahoma.

Hosek, A. M., Crawford, R. P., \& Vogl-Bauer, S. (2018). Cognitive approaches in the instructional context. In M. L. Houser \& A. M. Hosek (Eds.), Handbook of instructional communication: Rhetorical and relational perspectives (2nd ed., pp. 209-222). New York, NY: Routledge.

Hosek, A. M., \& Presley, R. (2018). College student perceptions of the (in)appropriateness and functions of teacher disclosure. College Teaching, 66, 6372. doi:10.1080/87567555.2017.1385587

Hosek, A. M., \& Thompson, J. (2009). Communication privacy management and college instruction: Exploring the rules and boundaries that frame instructor private disclosures. Communication Education, 58, 327-349. 
doi:10.1080/03634520902777585

Ivy, L. D. (2016). Effect of teacher self-disclosure via Facebook on student-instructor rapport, state motivation, and academic achievement. Unpublished doctoral dissertation, University of Central Arkansas, Conway, Arkansas.

Javidi, M. M., Downs, V. C., \& Nussbaum, J. F. (1988). A comparative analysis of teachers' use of dramatic style behaviors at higher and secondary educational levels. Communication Education, 37, 278-288. doi:10.1080/03634528809378729

Javidi, M. N., \& Long, L. W. (1989). Teachers' use of humor, self-disclosure, and narrative activity as a function of experience. Communication Research Reports, 6, 47-52. doi:10.1080/08824098909359831

Jones, E. E., \& Archer, R. L. (1976). Are there special effects of personalistic selfdisclosure? Journal of Experimental Social Psychology, 12, 180-193. doi:10.1016/0022-10317690069-X

Jourard, S. M. (1958). Personal adjustment: An approach through the study of healthy personality. New York, NY: Macmillan.

Jourard, S. M. (1959). Self-disclosure and other cathexis. Journal of Abnormal and Social Psychology, 59, 428-431. doi:10.1037/h0041640

Jourard, S. M. (1964). The transparent self. Princeton, NJ: Van Nostrand.

Jourard, S. M. (1970). The beginnings of self-disclosure. Voices: The Art and Science of Psychotherapy, 6, 42-51.

Jourard, S. M. (1971). Self-disclosure: The experimental investigation of the transparent self. New York, NY: Wiley.

Jourard, S. M., \& Lasakow, P. (1958). Some factors in self-disclosure. The Journal of 
Abnormal and Social Psychology, 56, 91-98. doi:10.1037/h0043357

Katadae, A. (2005). Japanese family and consumer sciences teachers' lived experiences of self-disclosure in the classroom. Unpublished doctoral dissertation, University of Minnesota, Saint Paul, Minnesota.

Kaufmann, R., \& Frisby, B. N. (2017). Dimensions of instructor self-disclosure: Implications for rhetorical and relational goals of instruction. Communication Research Reports, 34, 221-229. doi:10.1080/08824096.2017.1286469

Kearney, P., Plax, T. G., Hays, E. R., \& Ivey, M. J. (1991). College teacher misbehaviors: What students don't like about what teachers say and do. Communication Quarterly, 39, 309-324. doi:10.1080/01463379109369808

Kennedy, A. M. (2005). A look at students' perceptions of teacher self-disclosure in communication classes at the University of Wyoming. Unpublished master's thesis, University of Wyoming, Laramie, Wyoming.

Kenny, D. A., Kaniskan, B., \& Betsy McCoach, D. (2015). The performance of RMSEA in models with small degrees of freedom. Sociological Methods \& Research, 44, 486-507. doi:10.1177/0049124114543236

Kleinke, C. L., \& Kahn, M. L. (1980). Perceptions of self-disclosers: Effects of sex and physical attractiveness. Journal of Personality, 48, 190-205. doi:10.1111/j.14676494.1980.tb00827.x

Kline, R. B. (2016). Principles and practice of structural equation modeling (4th ed.). New York, NY: Guilford Press.

Klinger-Vartabedian, L., \& O’Flaherty, K. M. (1989). Student perceptions of presenter self-disclosure in the college classroom based on perceived status differentials. 
Contemporary Educational Psychology, 14, 153-163. doi:10.1016/0361476X8990033-7

Krathwohl, D. R., Bloom, B. S., \& Masia, B. B. (1964). Taxonomy of educational objectives, the classification of educational goals: Handbook II: The affective domain. New York, NY: David McKay.

Kromka, S. M., \& Goodboy, A. K. (2019). Classroom storytelling: Using instructor narratives to increase student recall, affect, and attention. Communication Education, 68, 20-43. doi:10.1080/03634523.2018.1529330

Land, M. L. (1979). Low-inference variables of teacher clarity: Effects on student concept learning. Journal of Experimental Psychology, 71, 795-799. doi:10.1037/0022-0663.71.6.795

Lannutti, P. J., \& Strauman, E. C. (2006). Classroom communication: The influence of instructor self-disclosure on student evaluations. Communication Quarterly, 54, 89-99. doi:10.1080/01463370500270496

Ledbetter, A. M., \& Finn, A. N. (2018). Perceived teacher credibility and students' affect as a function of instructors' use of PowerPoint and email. Communication Education, 67, 31-51. doi:10.1080/03634523.2017.1385821

LeFevre, J., \& Dixon, P. (1986). Do written instructions need examples? Cognition and Instruction, 3, 1-30. doi:10.1207/s1532690xci0301_1

Loeb, R. G., \& Curtis, J. M. (1984). Effect of counselor' self-references on subjects' first impression in an experimental psychological interview. Psychological Reports, 55, 803-810. doi:10.2466/pr0.1984.55.3.803

Loman, N. L., \& Mayer, R. E. (1983). Signaling techniques that increase the 
understandability of expository prose. Journal of Educational Psychology, 75, 402-412. doi:10.1037/0022-0663.75.3.402

Martin, M. M., Myers, S. A., \& Mottet, T. P. (1999). Students' motives for communicating with their instructors. Communication Education, 48, 155-164. doi:10.1080/03634529909379163

Mautone, P. D., \& Mayer, R. E. (2001). Signaling as a cognitive guide in multimedia learning. Journal of Educational Psychology, 93, 377-389. doi:10.1037/00220663.93.2.377

Mayer, R. E., \& Moreno, R. (2003). Nine ways to reduce cognitive load in multimedia learning. Educational Psychologist, 38, 43-52. doi:10.1207/s15326985ep3801_6

Mayer, R. E., \& Moreno, R. (2010). Techniques that reduce extraneous cognitive load and manage intrinsic cognitive load during multimedia learning. In J. L. Plass, R. Moreno, \& R. Brunken (Eds.), Cognitive load theory (pp. 131-152). New York, NY: Cambridge University Press.

Mayer, R. E., \& Whittrock, M. C. (1996). Problem-solving transfer. In D. C. Berliner \& R. C. Calfee (Eds.), Handbook of educational psychology (pp. 47-62). London, England: Prentice Hall International.

Mazer, J. P., Murphy, R. E., \& Simonds, C. J. (2007). I'll see you on “Facebook": The effects of computer-mediated teacher self-disclosure on student motivation, affective learning, and classroom climate. Communication Education, 56, 1-17. doi:10.1080/03634520601009710

McBride, C. M., \& Wahl, S. T. (2005). “To say or not to say:” Teachers' management of privacy boundaries in the classroom. Texas Speech Communication Journal, 30, 
$8-22$.

McCarthy, P. R., \& Schmeck, R. R. (1982). Effects of teacher self-disclosure on student learning and perceptions of teacher. College Student Journal, 16, 45-49.

McCroskey, J. C. (1994). Assessment of affect toward communication and affect toward instruction in communication. In S. Morreale \& M. Brooks (Eds.), Assessing college student competency in communication (pp. 56-70). Annandale, VA: Speech Communication Association.

McCroskey, J. C., Richmond, V. P., Plax, T., \& Kearney, P. (1985). Power in the classroom V: Behavior alteration techniques, communication training and learning. Communication Education, 34, 125-136. 10.1080/03634528509378609

McCroskey, J. C., \& Teven, J. J. (1999). Goodwill: A reexamination of the construct and its measurement. Communication Monographs, 66, 90-103.

doi:10.1080/03637759909376464

McCroskey, J. C., Valencic, K. M., \& Richmond, V. P. (2004). Toward a general model of instructional communication. Communication Quarterly, 52, 197-210. doi:10.1080/01463370409370192

McDonald, R. P. (1999). Test theory: A unified treatment. Mahwah, NJ: Erlbaum. McKenna-Buchanan, T., Munz, S., \& Rudnick, J. (2015). To be or not to be out in the classroom: Exploring communication privacy management strategies of lesbian, gay, and queer college teachers. Communication Education, 64, 280-300. doi:10.1080/03634523.2015.1014385

Mendes, E. (2003). What empathy can do. Educational Leadership, 61, 56-59. Minger, S. R. (2004). Student empowerment and learning within the instructor-student 
relationship: Student outcomes mediated by instructor self-disclosure, perceived instructor caring, and relational solidarity. Unpublished doctoral dissertation, University of Kentucky, Lexington, Kentucky.

Moreland, E. S. (2011). Crossing the line: K-12 public school teacher negotiation of unsolicited requests for self-disclosure. Unpublished master's thesis, Colorado State University, Fort Collins, Colorado.

Mottet, T. P., Frymier, A. B., \& Beebe, S. A. (2006). Theorizing about instructional communication. In T. P. Mottet, V. P. Richmond, \& J. C. McCroskey (Eds.), Handbook of instructional communication: Rhetorical and relational perspectives (pp. 252-282). Boston, MA: Allyn \& Bacon.

Muthén, L. K., \& Muthén, B. O. (2017). Mplus user's guide (Version 8). Los Angeles, CA: Muthén \& Muthén.

Myers, S. A., Brann, M., \& Members of Comm 600. (2009). Qualitative Research Reports in Communication, 10, 9-16. doi:10.1080/17459430902751808

Myers, S. A., \& Goodboy, A. K. (2015). Reconsidering the conceptualization and operationalization of affective learning. Communication Education, 64, 493-497. doi:10.1080/03634523.2015.1058489

Myers, S. A., \& Huebner, A. D. (2011). The relationship between students' motives to communicate with their instructors and perceived instructor credibility, attractiveness, and homophily. College Student Journal, 45. 84-92.

Myers, S. A., Zhong, M., \& Guan, S. (1998). Instructor immediacy in the Chinese college classroom. Communication Studies, 49, 240-254.

doi:10.1080/10510979809368534 
Naumann, J. J. (1988). The effects of teacher expressiveness, physical attractiveness and self-disclosure on student ratings of teaching. Unpublished doctoral dissertation, Fordham University, Bronx, New York.

Norton, R. W. (1977). Teacher effectiveness as a function of communicator style. In B. Ruben (Ed.), Communication yearbook (Vol. 1, pp. 525-542). New Brunswick, NJ: Transaction Books.

Nussbaum, J. F. (1992). Effective teacher behaviors. Communication Education, 41, 167180. doi:10.1080/03634529209378878

Nussbaum, J. F., Comadena, M. E., \& Holladay, S. J. (1987). Classroom verbal behaviors of highly effective teachers. Journal of Thought, 22, 73-80. doi:42589249

Nussbaum, J. F., \& Scott, M. D. (1979). Instructor communication behaviors and their relationship to classroom learning. Annals of the International Communication Association, 3, 561-583. doi:10.1080/23808985.1979.11923783

Orbash, D. N. (2008). Perceived teacher power use and credibility as a function of teacher self-disclosure. Unpublished doctoral dissertation, Miami University, Oxford, Ohio.

O’Sullivan, P. B., Hunt, S. K., \& Lippert, L. R. (2004). Mediated immediacy: A language of affiliation in a technological age. Journal of Language and Social Psychology, 23, 464-490. doi:10.1177/0261927X04269588

Paluckaite, U., \& Zardeckaite-Matulaitiene, K. (2015). The appropriateness of the relevant and irrelevant teacher's self-disclosure: Students' and their teachers' attitudes. European Scientific Journal, 11, 18-35.

Paris, S. G., Lipson, M. Y., \& Wixson, K. K. (1983). Becoming a strategic reader. 
Contemporary Educational Psychology, 8, 293-316.

doi:10.1016/0361476x83900188.

Pekrun, R., Goetz, T., Frenzel, A. C., Barchfield, P., \& Perry, R. P. (2011). Measuring emotions in students' learning and performance: The achievement emotions questionnaire (AEQ). Contemporary Educational Psychology, 36, 36-48. doi:10.1016/j.cedpsych.2010.10.002

Petronio, S. (1991). Communication boundary management: A theoretical model of managing disclosure of private information between marital couples. Communication Theory, 1, 311-335. doi:10.1111/j.1468-2885.1991.tb00023.x

Petronio, S. (2002). Boundaries of privacy: Dialectics of disclosure. Albany, NY: State University of New York Press.

Pogue, L. L., \& AhYun, K. (2006). The effect of teacher nonverbal immediacy and credibility on student motivation and affective learning. Communication Education, 55, 331-344. doi:10.1080/03634520600748623

Preacher, K. J., \& Hayes, A. F. (2008). Contemporary approaches to assessing mediation in communication research. In A. F. Hayes, M. D. Slater, \& L. B. Snyder (Eds.), The Sage sourcebook of advanced data analysis methods for communication research (pp. 13-54). Thousand Oaks, CA: Sage.

Punyanunt-Carter, N. M. (2006). College students' perceptions of what teaching assistants are self-disclosing in the classroom. College Student Journal, 40, 3-10.

Remer, P., Roffey, B. H., \& Buckholtz, A. (1983). Differential effects of positive versus negative self-involving counseling responses. Journal of Counseling Psychology, 30, 121-125. doi:10.1037/0022-0167.30.1.121 
Richmond, V. P., Gorham, J. S., \& McCroskey, J. C. (1987). The relationship between selected immediacy behaviors and cognitive learning. Annals of the International Communication Association, 10, 574-590. doi:10.1080/23808985.1987.11678663

Rodriguez, J. I., Plax, T. G., \& Kearney, P. (1996). Clarifying the relationship between teacher nonverbal immediacy and student cognitive learning: Affective learning as the central causal mediator. Communication Education, 45, 293-305. doi:10.1080/03634529609379059

Rosenshine, B. V., \& Furst, N. F. (1971). Research on teacher performance criteria. In B. O. Smith (Ed.), Research in teacher education (pp. 37-72). Englewood Cliffs, NJ: Prentice Hall.

Rouse, R. E., \& Bradley, D. (1989). Personally shared reading: How teacher selfdisclosure effect student self-disclosure. Middle School, 20, 34-35. doi:10.1016/j.tate.2008.07.011

Rubin, Z. (1970). Measurement of romantic love. Journal of Personality and Social Psychology, 16, 265-273. doi:10.1037/h0029841

Russ, T., Simonds, C., \& Hunt, S. (2002). Coming out in the classroom...An occupational hazard?: The influence of sexual orientation on teacher credibility and perceived student learning. Communication Education, 51, 311-324. doi:10.1080/03634520216516

Sadoski, M. (2001). Resolving the effects of concreteness on interest, comprehension, and learning important ideas from text. Educational Psychology Review, 13, 263281. doi:10.1023/A:1016675822931

Scheer, S. D. (1999). Strategies for teaching youth development in the undergraduate 
classroom. College Student Journal, 33, 154-161.

Schrodt, P. (2013). Content relevance and students' comfort with disclosure as moderators of instructor disclosures and credibility in the college classroom. Communication Education, 62, 352-375. doi:10.1080/03634523.2013.807348

Scott, M. D., \& Nussbaum, J. F. (1981). Student perceptions of instructor communication behaviors and their relationship to student evaluation. Communication Education, 30, 44-53. doi:10.1080/03634528109378452

Sidelinger, R. J., \& Bolen, D. M. (2015). Compulsive communication in the classroom: Is the talkaholic teacher a misbehaving instructor? Western Journal of Communication, 79, 174-196. doi:10.1080/10570314.2014.943416

Sidelinger, R. J., \& Bolen, D. M. (2016). Instructor credibility as a mediator of instructors' compulsive communication and student communication satisfaction in the college classroom. Communication Research Reports, 33, 24-31. doi:10.1080/08824096.2015.1117438

Simpson, J. S. (2010). Critical race theory and critical communication pedagogy. In D. L. Fasset \& J. T. Warren (Eds.), The SAGE handbook of communication and instruction (pp. 361-384). Los Angeles, CA: Sage.

Smythe, M. J., \& Hess, J. A. (2005). Are student self-reports a valid method for measuring teacher nonverbal immediacy? Communication Education, 54, 170179. doi:10.1080/03634520500213389

Sorensen, G. (1989). The relationship among teachers' self-disclosive statements, students' perceptions, and affective learning. Communication Education, 38, 259276. doi:10.1080/03634528909378762 
Stoltz, M., Young, R., \& Bryant, K. (2012). Self-disclosure and student cognitive learning. Unpublished manuscript, Valdosta State University, Valdosta, Georgia.

Stoltz, M., Young, R., \& Bryant, K. (2014). Can teacher self-disclosure increase student cognitive learning? College Student Journal, 7, 166-172.

Strangeways, A., \& Papatraianou, L. H. (2016). Case-based learning for classroom ready teachers: Addressing the theory practice disjunction through narrative pedagogy. Australian Journal of Teacher Education, 41, 117-134.

Suskie, L. (2018). Assessing students learning: A common sense guide (3rd ed.). San Francisco, CA: Jossey-Bass.

Sweller, J., Ayres, P., \& Kalyuga, S. (2011). Cognitive load theory. New York, NY: Springer.

Sweller, J., \& Chandler, P. (1994). Why some material is difficult to learn. Cognition and Instruction, 12, 185-233. doi:10.1207/s1532690xci1203_1

Sweller, J., van Merrienboer, J. J. G., \& Pass, F. G. W. C. (1998). Cognitive architecture and instructional design. Educational Psychology Review, 10, 251-296. doi:10.1023/A:1022193728205

Titsworth, S., \& Mazer, J. P. (2016). Teacher clarity: An analysis of current research and future directions. In P. Witt (Ed.), Handbooks of communication science: Communication and learning (pp. 105-128). Berlin, Germany: De Gruyter Mouton.

Titsworth, S., Mazer, J. P., Goodboy, A. K., Bolkan, S., \& Myers, S. A. (2015). Two meta-analyses exploring the relationship between teacher clarity and student learning. Communication Education, 64, 385-418. 
doi:10.1080/03634523.2015.1041998

Trad, L., Baker, N., Blackman, H., Glynn, K., Wright, A., \& Miller, A. N. (2012). Student incivility and instructor communication in the college classroom. Florida Communication Journal, 40, 47-53.

Vallade, J. I., \& Malachowski, C. M. (2015). Instructor misbehavior and forgiveness: An examination of student communicative outcomes in the aftermath of instructor misbehavior. Communication Education, 64, 301-324. doi:10.1080/03634523.2015.1038728

Vallade, J. I., \& Kaufmann, R. (2018). Investigating instructor misbehaviors in the online classroom. Communication Education, 67, 363-381.

doi:10.1080/03634523.2018.1467027

Walker, S. R. (1999). College teachers' use of self-disclosure messages and students' affective learning. Unpublished master's thesis, California State University, Long Beach, California.

Wambach, C., \& Brothen, T. (1997). Teacher self-disclosure and student classroom participation revisited. Teaching of Psychology, 24, 262-263. doi:10.1207/s15328023top2404_7

Wheeless, L. R., \& Grotz, J. (1976). Conceptualization and measurement of reported selfdisclosure. Human Communication Research, 2, 338-346. doi:10.1111/j.14682958.1976.tb00494.x

Wheeless, L. R., Kretzschmar-Young, S., \& Nesser, K. (1978). Relationships of four elements to immediate recall and student-instructor interaction. Western Speech Communication, 39, 131-140. doi:10.1080/10570317509373858 
Wilson, C. B. (1995). Self-disclosure by students to teachers: A phenomenological study of stories of faculty. Unpublished doctoral dissertation, Georgia State University, Atlanta, Georgia.

Woolfolk, A. E. (1979). Self-disclosure in the classroom. An experimental study. Contemporary Educational Psychology, 4, 132-139. doi:10.1016/0361476X7990067-5

Woolfolk, A. E., Garlinsky, K. S., \& Nicolich, M. J. (1977). The impact of teacher behavior, teacher sex, and student sex upon student self-disclosure. Contemporary Educational Psychology, 2, 124-132. doi:10.1016/0361-476x7790015-7

Woolfolk, A. E., \& Woolfolk, R. L. (1975). Student self-disclosure in response to teacher verbal and nonverbal behavior. The Journal of Experimental Education, 44, 3640. doi:10.1080/00220973.1975.11011509

Worthy, M., Gary, A. L., \& Kahn, G. M. (1969). Self-disclosure as an exchange process. Journal of Personality and Social Psychology, 13, 59-63. doi:10.1037/h0027990

Youells, F. E. (1981). The relationship of the teacher's self-disclosure/intimacy to the learner's knowledge/attitude in college sex and family living classes. Unpublished doctoral dissertation, East Stroudsburg State College, East Stroudsburg, Pennsylvania.

Yuan, K. -H., \& Bentler, P. M. (2000). Three likelihood-based methods for mean and covariance structure analysis with nonnormal missing data. Sociological Methodology, 30, 165-200. doi:10.1111/0081-1750.00078

Zajac, M. L. (2011). How students and teachers co-construct self-disclosure and emotion in the college classroom. Unpublished master's thesis, San Jose University, San 
Jose, California.

Zhang, Q. (2007). Teacher misbehaviors as learning demotivators in college classrooms: A cross-cultural investigation in China, Germany, Japan, and the United States. Communication Education, 56, 209-227. doi:10.1080/03634520601110104

Zhang, Q., \& Oetzel, J. G. (2006). A cross-cultural test of immediacy-learning models in Chinese classrooms. Communication Education, 55, 313-330. doi:10.1080/03634520600748599

Zhang, S. (2007). Preservice and K-12 inservice teachers' perceptions of appropriateness of teacher self-disclosure and its teaching effectiveness. Unpublished doctoral dissertation, Old Dominion University, Norfolk, Virginia.

Zhang, S. (2010). Secondary preservice teachers' perspectives on teacher self-disclosure as citizenship curriculum. Action in Teacher Education, 32, 82-96. doi:10.1080/01626620.2010.10463552

Zhang, S., Shi, Q., \& Hao, S. (2009). The appropriateness of teacher self-disclosure: A comparative study of China and the USA. Journal of Education for Teaching, 35, 225-239. doi:10.1080/02607470903091278 
Appendix A

“Communicating Affection” Lesson Script - Relevant Self-disclosures

1. [Communicating Affection] [Photo 1] Good afternoon everyone. My name is Professor Miles Payne. Thank you for joining me for class today. Today's lesson is entitled "Communicating Affection." So we are going to be talking about research that supports the importance of showing affection towards those people who we care about most in our lives. Moreover, we will discuss why people express affection and the effects of affection on physical and mental health.

2. [What is Affection?] Let's begin with the definition of affection. So what is affection? We define affection as "an emotional state of fondness and intense positive regard directed toward another target." The target is often another person, but it could also be an animal such as a pet as well. Today, we will focus on communicating affection between people. There are two important things to note about how affection is defined.

a. [Not a Basic Emotion] First, affection is not a simple, discrete emotion. The intense positive feelings that come from affection don't happen immediately like basic emotions such as surprise, fear, or anger. Feelings of affection develop over an extended period of time as a collective response to multiple positive stimuli to the same person. Yes, you may feel a pleasant surprise when you first meet a person, but this feeling is often not true affection comprised of genuine positive fondness for a person. [Photo 2] \{SELF-DISCLOSURE 1\} When I first met my wife Emma at this little Italian bar called Narcisi's near Pittsburgh, it turned out to be a wonderful evening. I found the courage to walk up to her and tell her how much I liked her beautiful dark brown hair. Emma responded with the most gorgeous smile. I was pleasantly surprised as to how happy she made me feel. However, this intense positive emotion of pleasant surprise was not affection until I learned more about Emma's interests, took her on multiple dates across Morgantown, had her meet all my family and friends back home near Pittsburgh, and developed a deep, lasting positive perception towards her. In this case, affection is not a basic emotion because it wasn't a sudden feeling. It took a while for me to develop true feelings of affection towards Emma over a period of time. Affection is different from basic emotions because the feelings of affection develop from many positive moments with the target over time.

b. [Not an Instinctual Response] Second, affection is not an instinctual response. Everyone has the capacity to feel affection, but people differ in their desire to feel affection. The extent to which people desire to feel affection depends on individual differences. \{SELF-DISCLOSURE 2\} Personally, I prefer a lot of affection in my life. The best part of my day is when my wife gives me a hug and kiss each day after I get home from 
teaching. I also really enjoy receiving hugs from my friends and family, both men and women, every time I see them. Not everyone may feel as comfortable receiving this much affection in these different interpersonal relationships. My affection preference illustrates how affection is not an instinctual response because people can differ in their desire to feel affection with my desire being at the higher end of the spectrum. In summary, affection is not an instinctual response because everyone has different preferences for how much affection they wish to feel.

3. [Expressing Affection] Let's say now that you want to show affection to someone in your life. So how do you express your affection to a person? Researchers have found that people express affection in three general ways: verbal statements, direct nonverbal gestures, and social support behaviors.

a. [Verbal Statements] The first way that people can express affection is through verbal statements. Verbal statements come in three different forms. An individual could use a verbal statement to convey positive feelings to the target person such as by saying "I like you" or "I love you." An individual could also use verbal statements to [Reinforce] reinforce the relationship status by saying things like "You're my best friend in the world" or "You are the most important person in my life." Other affectionate verbal statements may [Project Hopes for the Future] project hopes for the future such as "I want us to be together forever." Finally, verbal statements can also [Communicate Importance] communicate the importance of a relationship when an individual expresses how he or she would feel without it with statements like "I don't know what I would do without you." [Photo 3] [SELF-DISCLOSURE $3\}$ I feel as though my life would be empty and meaningless without Emma if I never met her at Narcisi's bar. If I told that to Emma tonight when I got home, then this would be an example of a verbal statement of affection that communicates the importance of a relationship. In other words, I am communicating the importance of my relationship with Emma by telling her how awful my life would be without her, thus expressing affection through a verbal statement. In summary, individuals can convey affection to others using verbal statements to highlight important positive aspects of their relationship with a person.

b. [Direct Nonverbal Gestures] The second way that people can express affection is through the use of direct nonverbal gestures. These are nonverbal forms of communication that are readily associated with affection within the culture that they are observed. In the United States, kissing, hugging, smiling, holding hands, and putting an arm around someone are all examples of behaviors that express affection. Even though these gestures are "direct," they are more ambiguous than verbal statements given that these behaviors can be carried out in many different 
ways. For example, a hug may vary in its level of affection expressed toward an individual depending on what type of hug it is. [Photo 4] \{SELF-DISCLOSURE 4\} When I was in high school, my one friend Tyler, my other friends, and I always gave our signature "big bear hugs" to each other because we all felt very comfortable receiving affection and showing it to one another. So, a long and embracing hug, like a "big bear hug," that completely wraps around a person will likely communicate more affection than a short, quick one-armed half-hearted hug. From my personal example, you can see how direct nonverbal gestures like big bear hugs are more ambiguous than verbal statements. Given the many differences in gestures, direct nonverbal gestures are more ambiguous and dependent on culture compared to verbal statements when it comes to communicating affection.

c. [Social Support Behaviors] The third way that people can express affection is by using social support behaviors. Social support behaviors demonstrate affection through acts of assistance. Some examples of social support may be offering to babysit, providing money during a financial crisis, or simply being a sympathetic listener during a difficult time like a breakup or a death. [Photo 5] \{SELF-DISCLOSURE 5\} When my good friend Jason went through a bad breakup last year, I was there to support him in any way that I could. I took him out to dinner at Mountain State for our favorite "Fire on the Mountain" pizza and made myself available to him whenever he needed anything. Taking Jason out to dinner and listening to him when he wanted to talk were social support behaviors. These were behaviors that allowed me to convey my affection to him by helping him out. Simply being a sympathetic listener for Jason conveyed affection and made our friendship the closest it has ever been. Overall, social support behaviors convey affection by assisting others in emotional ways like listening to someone or financial ways like giving money to a friend when they are in need.

4. [Affection Exchange Theory] Pulling together all of the affectionate communication research, Affection Exchange Theory was developed. The purpose of Affection Exchange Theory is to explain why people express affection to one another, how affection can be perceived negatively, and what consequences arise from the exchange of affection in regards to physical and mental health.

i. [Affection Contributes to Human Survival] Let's begin with why people express affection to one another. Why do we bother showing affection to one another? The main reason that people express affection to one another is because conveying affection contributes to human survival. Affection Exchange Theory assumes that the survival of the human race is the most important goal. Communicating affection can help this goal of ultimate 
survival. People who naturally express affection develop their relationships with others to a greater degree and have an advantage of procreation and survival compared to people who do not express affection often. For example, when parents show affection to their children, their children will be more likely to show affection to others and be more successful in reproducing. Therefore, the parents' genes will be passed down. Moreover, being affectionate to others may increase access to material resources like food and shelter, and emotional resources like emotional support. [Photo 6] \{SELF-DISCLOSURE 6\} My personal inclination for showing a lot of affection not only makes me and my family happier, but it also increases the desire for us to help one another by providing resources. In my household, I provide the resource of food. For example, I like to make my daughter Lily's favorite spaghetti casserole. Making Lily's favorite meal is one way that I show affection to her. I hope to pass down the importance of sharing affection to my daughter. In other words, I hope Lily will show the same affectionate support behaviors to her future family, which demonstrates how affection can help our family lineage carry on and contribute to human survival. Overall, researchers assume that affection is grounded in our biology and helps us continue on the human race whether we are consciously aware of it or not.

ii. [Affection can be Physiologically Aversive] Affection Exchange Theory also addresses when affectionate communication can be perceived negatively. People differ in the extent they wish to feel affection. When a person's tolerance for affection is violated, it can be physiologically aversive. In other words, our bodies have a negative physical response. Although affectionate expressions are normally perceived positively, these expressions have the potential to produce negative feelings under certain circumstances. For example, when a stranger touches another person in an affectionate manner, it may create a negative physical response such as with the person becoming stressed and shaky. [Photo 7] [SELFDISCLOSURE 7\} My buddies and I like to go camping up at Big Bear Lake every fall. When we were out by the fire one evening, my friend Jordan gave me a pat on the back for creating a wellbuilt fire. I did not have a negative physical response to his touch. Because he is not a stranger and I've known him since high school, I perceive his affectionate pat on the back in a positive manner. I would not perceive this pat on the back in the same positive manner if a stranger patted me on the back at night in the woods, which would be physiologically aversive and would produce a negative physical response that would make me jumpy and shaky. Ultimately, a negative physical response occurs when a 
person is in a situation where the affectionate behavior is perceived as hindering one's goal of survival.

iii. [Affectionate Feelings and Expressions are Different] Affection Exchange Theory also explains how affectionate feelings and affectionate expressions are distinct experiences. You can feel affection and you can express affection. They are different. It is important to make this distinction because affectionate feelings and affectionate expressions may not necessarily coincide. People can feel affection without expressing it. For example, a person may have affectionate feelings toward another person, but choose not to express these feelings out of fear of rejection. [Photo 8] [SELFDISCLOSURE 8 \} For my first official date with Emma, I took her to the botanical gardens at the Phipps Conservatory in Pittsburgh. After several more fun and romantic dates, I felt genuine affection towards Emma. However, I didn't immediately express it out of fear of being rejected by her. So for a short time, I felt affection toward Emma but I did not express my affection, which highlights how affectionate feelings and expressions are different. Conversely, people can express affection without feeling it. For example, a person may express affection toward their rude and controlling in-laws in order to keep the peace in the family, but not truly feel any affection towards them. Ultimately, affectionate feelings and expressions are distinct experiences.

5. [Affection and Health] So what's the big deal about affection? How does it affect us? It can actually affect people in very positive ways. The ways in which affection influences people's physical and mental health depends on whether a person is receiving affection or expressing it. The difference between receiving and expressing affection is important when it comes to health outcomes.

a. [Receiving Affection] Let's begin with the benefits of receiving affection. There is a great deal of research that suggests that receiving affectionate communication enhances mental health.

i. [Mental Health] Ultimately, receiving affection influences our mental health. Individuals have higher self-esteem when they receive affection often. Moreover, people feel more satisfied with their family members and marriage partners when they receive more affection from them. [Photo 9] \{SELF-DISCLOSURE 9\} When I received my bachelor's degree from Eastern Michigan University, it was an emotional day for me at graduation. I received affection from my parents, my friends, and my wife through verbal statements like "I am so proud of you" and direct nonverbal gestures like those signature big bear hugs. Receiving all of their affection increased my self-esteem and my 
relationship satisfaction. Receiving affection increased my selfesteem by making me feel better about myself and enhanced my relationship satisfaction towards my loved ones by making me feel happy that they are in my life. Overall, affectionate behaviors communicate positive feelings, which make people feel happier about themselves and their loved ones when they receive these positive expressions.

b. [Expressing Affection] Not only receiving affection, but also expressing affection to others may be beneficial to your health as well.

i. [Physical Health] When it comes to the effects of expressing affection and physical health, expressing affection to others leads to reduced levels of stress, lower vulnerability to stress, and increased activation of the reward system in the brain. The positive brain activation can make a person feel more calm and happy in general. [Photo 10] \{SELF-DISCLOSURE 10\} As I mentioned before, I appreciate a high level of affection in my family, especially with my wife Emma. While there are obvious benefits to receiving affection from my wife Emma, it's also beneficial for me to express affection back to her, such as when I told my wife the night before our wedding, "I can't wait to be married to you." Expressing affection at stressful times like right before my wedding, has the potential to reduce my stress and lower my vulnerability for stressing out more in the future. In summary, if you are feeling stressed out and you want to lower your stress, it is a good idea to show someone some affection.

ii. [Mental Health] For mental health, people who express affection often report increased happiness and engage in social interactions more frequently. More importantly, highly affectionate people are less likely to be depressed compared to non-affectionate individuals. [Photo 11] \{SELF-DISCLOSURE 11\} To avoid any issues with depression, my mantra is to show love to others, keeping in mind quotes like "live, laugh, love." I constantly show affection to those people that mean the most to me in my life. This could be how I give my daughter Lily a kiss on the cheek each time I tuck her in for bed. This could be how I help my wife with her paperwork whenever I can. Therefore, I am happier, more social, and buffered from the effects of depression when I get the chance to express affection to my family in these simple ways. In summary, it is just as important to express your affection to others as it is to receive affection from others when it comes to your physical and mental health.

6. [Communicating Affection] [Photo 12] In conclusion, affection is important for 
our everyday lives. We are all built with the need for affection and we have different ways of communicating it to others whether it be through verbal statements, direct nonverbal gestures, or social support behaviors. Affection exchange theory helps us better understand why people are affectionate to others for the benefit of human survival and passing on our genes to future generations. Moreover, affectionate communication has positive effects on our physical and mental health whether we are the ones receiving affection or expressing it to others. Ultimately, there is power in affection and I hope this lesson today has helped you learn more about the importance of affection in your everyday lives. Thank you for listening.

[END LIVE LECTURE. ADMINISTER FEEDBACK QUESTIONNAIRE.] 
Appendix B

\section{“Communicating Affection” Lesson Script - Irrelevant Self-disclosures}

1. [Communicating Affection] [Photo 1] Good afternoon everyone. My name is Professor Miles Payne. Thank you for joining me for class today. Today's lesson is entitled "Communicating Affection." So we are going to be talking about research that supports the importance of showing affection towards those people who we care about most in our lives. Moreover, we will discuss why people express affection and the effects of affection on physical and mental health.

2. [What is Affection?] Let's begin with the definition of affection. So what is affection? We define affection as "an emotional state of fondness and intense positive regard directed toward another target." The target is often another person, but it could also be an animal such as a pet as well. Today, we will focus on communicating affection between people. There are two important things to note about how affection is defined.

a. [Not a Basic Emotion] First, affection is not a simple, discrete emotion. The intense positive feelings that come from affection don't happen immediately like basic emotions such as surprise, fear, or anger. Feelings of affection develop over an extended period of time as a collective response to multiple positive stimuli to the same person. Yes, you may feel a pleasant surprise when you first meet a person, but this feeling is often not true affection comprised of genuine positive fondness for a person. [Photo 2] \{SELF-DISCLOSURE 1\} When I first met my wife Emma at this little Italian bar called Narcisi's near Pittsburgh, it turned out to be a wonderful evening. I found the courage to walk up to her and tell her how much I liked her beautiful dark brown hair. Emma responded with the most gorgeous smile. I was pleasantly surprised as to how happy she made me feel. I had such a great evening with Emma that night. Afterwards, we ended up sharing a charcuterie board and talking through the rest of the evening about our interests. I found out that her favorite band was Coldplay, which is also my favorite band. We also learned that we both had the same favorite song by them, which is a pretty love song called "Yellow." I felt that she was my soul mate. It was incredible how the stars aligned for us and how we had so much in common. Affection is different from basic emotions because the feelings of affection develop from many positive moments with the target over time.

b. [Not an Instinctual Response] Second, affection is not an instinctual response. Everyone has the capacity to feel affection, but people differ in their desire to feel affection. The extent to which people desire to feel affection depends on individual differences. \{SELF-DISCLOSURE 2\} Personally, I prefer a lot of affection in my life. The best part of my day 
is when my wife gives me a hug and kiss each day after I get home from teaching. I also really enjoy receiving hugs from my friends and family, both men and women, every time I see them. My six year old nephew Holden likes to cross his eyes and puff out his cheeks like some pufferfish every time I ask him for a hug and kiss. He is such a little weirdo, but I love him so much because he reminds me of myself when I was six years old. In summary, affection is not an instinctual response because everyone has different preferences for how much affection they wish to feel.

3. [Expressing Affection] Let's say now that you want to show affection to someone in your life. So how do you express your affection to a person? Researchers have found that people express affection in three general ways: verbal statements, direct nonverbal gestures, and social support behaviors.

a. [Verbal Statements] The first way that people can express affection is through verbal statements. Verbal statements come in three different forms. An individual could use a verbal statement to convey positive feelings to the target person such as by saying "I like you" or "I love you." An individual could also use verbal statements to [Reinforce] reinforce the relationship status by saying things like "You're my best friend in the world" or "You are the most important person in my life." Other affectionate verbal statements may [Project Hopes for the Future] project hopes for the future such as "I want us to be together forever." Finally, verbal statements can also [Communicate Importance] communicate the importance of a relationship when an individual expresses how he or she would feel without it with statements like "I don't know what I would do without you." [Photo 3] [SELF-DISCLOSURE 3 I I feel as though my life would be empty and meaningless without Emma if I never met her at Narcisi's bar. We truly understand one another and have so much in common. For example, we both have the same favorite movie: Titanic. We watch it together at least once a month. We love that movie so much that we often refer to each other as Jack and Rose. I guess we are just a couple of hopeless romantics. In summary, individuals can convey affection to others using verbal statements to highlight important positive aspects of their relationship with a person.

b. [Direct Nonverbal Gestures] The second way that people can express affection is through the use of direct nonverbal gestures. These are nonverbal forms of communication that are readily associated with affection within the culture that they are observed. In the United States, kissing, hugging, smiling, holding hands, and putting an arm around someone are all examples of behaviors that express affection. Even though these gestures are "direct," they are more ambiguous than verbal statements given that these behaviors can be carried out in many different 
ways. For example, a hug may vary in its level of affection expressed toward an individual depending on what type of hug it is. [Photo 4] \{SELF-DISCLOSURE 4\} When I was in high school, my one friend Tyler, my other friends, and I always gave our signature "big bear hugs" to each other because we all felt very comfortable receiving affection and showing it to one another. They were a good group of friends to have throughout high school. We always enjoyed getting together for football and playing racing video games like Need for Speed: Underground. I'm sure you all did similar things with your friends throughout high school. Given the many differences in gestures, direct nonverbal gestures are more ambiguous and dependent on culture compared to verbal statements when it comes to communicating affection.

c. [Social Support Behaviors] The third way that people can express affection is by using social support behaviors. Social support behaviors demonstrate affection through acts of assistance. Some examples of social support may be offering to babysit, providing money during a financial crisis, or simply being a sympathetic listener during a difficult time like a breakup or a death. [Photo 5] \{SELF-DISCLOSURE 5\} When my good friend Jason went through a bad breakup last year, I was there to support him in any way that I could. I took him out to dinner at Mountain State for our favorite "Fire on the Mountain" pizza and made myself available to him whenever he needed anything. I think Mountain State has the best food in town. Pizza is my favorite food, so of course I am a little biased. I love going there to order pizzas with different toppings like sausage, basil, and pineapple. If you haven't been there yet, you should go to try one of their brick-oven pizzas. Overall, social support behaviors convey affection by assisting others in emotional ways like listening to someone or financial ways like giving money to a friend when they are in need.

4. [Affection Exchange Theory] Pulling together all of the affectionate communication research, Affection Exchange Theory was developed. The purpose of Affection Exchange Theory is to explain why people express affection to one another, how affection can be perceived negatively, and what consequences arise from the exchange of affection in regards to physical and mental health.

i. [Affection Contributes to Human Survival] Let's begin with why people express affection to one another. Why do we bother showing affection to one another? The main reason that people express affection to one another is because conveying affection contributes to human survival. Affection Exchange Theory assumes that the survival of the human race is the most important goal. Communicating affection can help this goal of ultimate survival. People who naturally express affection develop their 
relationships with others to a greater degree and have an advantage of procreation and survival compared to people who do not express affection often. For example, when parents show affection to their children, their children will be more likely to show affection to others and be more successful in reproducing. Therefore, the parents' genes will be passed down. Moreover, being affectionate to others may increase access to material resources like food and shelter, and emotional resources like emotional support. [Photo 6] \{SELF-DISCLOSURE 6\} My personal inclination for showing a lot of affection not only makes me and my family happier, but it also increases the desire for us to help one another by providing resources. In my household, I provide the resource of food. For example, I like to make my daughter Lily's favorite spaghetti casserole. I have this incredible recipe. It includes angel hair spaghetti, ground beef, sour cream, white sauce, and parmesan cheese. The family goes crazy for it. I think it is the perfect comfort food to eat on a cold, rainy day when you just want to stay inside and binge out on a Netflix series. Overall, researchers assume that affection is grounded in our biology and helps us continue on the human race whether we are consciously aware of it or not.

ii. [Affection can be Physiologically Aversive] Affection Exchange Theory also addresses when affectionate communication can be perceived negatively. People differ in the extent they wish to feel affection. When a person's tolerance for affection is violated, it can be physiologically aversive. In other words, our bodies have a negative physical response. Although affectionate expressions are normally perceived positively, these expressions have the potential to produce negative feelings under certain circumstances. For example, when a stranger touches another person in an affectionate manner, it may create a negative physical response such as with the person becoming stressed and shaky. [Photo 7] [SELFDISCLOSURE 7\} My buddies and I like to go camping up at Big Bear Lake every fall. When we were out by the fire one evening, my friend Jordan gave me a pat on the back for creating a wellbuilt fire. I learned how to build fires from being a boy scout when I was younger. As a boy scout, I had to learn skills like building fires, tying knots, and cooking different animals like fish, squirrel, and rabbits. I also learned how to roast a marshmallow perfectly. So if any of you like s'more, I can make the best one you will ever have tasted. My friends call me the s'more master. Ultimately, a negative physical response occurs when a person is in a situation where the affectionate behavior is perceived as hindering one's goal of survival. 
iii. [Affectionate Feelings and Expressions are Different] Affection Exchange Theory also explains how affectionate feelings and affectionate expressions are distinct experiences. You can feel affection and you can express affection. They are different. It is important to make this distinction because affectionate feelings and affectionate expressions may not necessarily coincide. People can feel affection without expressing it. For example, a person may have affectionate feelings toward another person, but choose not to express these feelings out of fear of rejection. [Photo 8] [SELFDISCLOSURE 8\} For my first official date with Emma, I took her to the botanical gardens at the Phipps Conservatory in Pittsburgh. After several more fun and romantic dates, I felt genuine affection towards Emma. I took Emma to the Conservatory because she loves flowers. When we were there, we also saw a bunch of miniature Bonsai trees that are grown to mimic the shape and scale of full size trees. I think that those little Bonsai trees are so interesting. I plan to get one for myself. Conversely, people can express affection without feeling it. For example, a person may express affection toward their rude and controlling in-laws in order to keep the peace in the family, but not truly feel any affection towards them. Ultimately, affectionate feelings and expressions are distinct experiences.

5. [Affection and Health] So what's the big deal about affection? How does it affect us? It can actually affect people in very positive ways. The ways in which affection influences people's physical and mental health depends on whether a person is receiving affection or expressing it. The difference between receiving and expressing affection is important when it comes to health outcomes.

a. [Receiving Affection] Let's begin with the benefits of receiving affection. There is a great deal of research that suggests that receiving affectionate communication enhances mental health.

i. [Mental Health] Ultimately, receiving affection influences our mental health. Individuals have higher self-esteem when they receive affection often. Moreover, people feel more satisfied with their family members and marriage partners when they receive more affection from them. [Photo 9] \{SELF-DISCLOSURE 9\} When I received my bachelor's degree from Eastern Michigan University, it was an emotional day for me at graduation. I received affection from my parents, my friends, and my wife through verbal statements like "I am so proud of you" and direct nonverbal gestures like those signature big bear hugs. At that graduation, I gave a speech where I shared my favorite quote by Confucius: "It does not matter how slowly you go as long as you do not stop." I've always felt that quote was inspiring to people of 
all ages, but especially older people who are not as quick as they used to be. Overall, affectionate behaviors communicate positive feelings, which make people feel happier about themselves and their loved ones when they receive these positive expressions.

b. [Expressing Affection] Not only receiving affection, but also expressing affection to others may be beneficial to your health as well.

i. [Physical Health] When it comes to the effects of expressing affection and physical health, expressing affection to others leads to reduced levels of stress, reduced vulnerability to stress, and increased activation of the reward system in the brain. The positive brain activation can make a person feel more calm and happy in general. [Photo 10] \{SELF-DISCLOSURE 10\} As I mentioned before, I appreciate a high level of affection in my family, especially with my wife Emma. This reminds me when I told my wife the night before our wedding, "I can't wait to be married to you." I didn't get cold feet or anything like that, I was so excited for our big day. I was especially excited because we hired a jazz band called "The Swinging Pharaohs" and I love jazz music. In summary, if you are feeling stressed out and you want to lower your stress, it is a good idea to show someone some affection.

ii. [Mental Health] For mental health, people who express affection often report increased happiness and engage in social interactions more frequently. More importantly, highly affectionate people are less likely to be depressed compared to non-affectionate individuals. [Photo 11] \{SELF-DISCLOSURE 11\} To avoid any issues with depression, my mantra is to show love to others, keeping in mind quotes like "live, laugh, love." I constantly show affection to those people that mean the most to me in my life. I also like to volunteer. I used to volunteer for Habitat for Humanity where I would help build houses. I used to be their head carpenter where I was tasked with building the wooden floors, the walls, and the rooves. I did it because I like staying active and working with my hands. It's always been very fulfilling to me. In summary, it is just as important to express your affection to others as it is to receive affection from others when it comes to your physical and mental health.

6. [Communicating Affection] [Photo 12] In conclusion, affection is important for our everyday lives. We are all built with the need for affection and we have different ways of communicating it to others whether it be through verbal statements, direct nonverbal gestures, or social support behaviors. Affection exchange theory helps us better understand why people are affectionate to others for the benefit of human survival and passing on our genes to future generations. 
Moreover, affectionate communication has positive effects on our physical and mental health whether we are the ones receiving affection or expressing it to others. Ultimately, there is power in affection and I hope this lesson today has helped you learn more about the importance of affection in your everyday lives. Thank you for listening.

[END LIVE LECTURE. ADMINISTER FEEDBACK QUESTIONNAIRE.] 
Appendix C

“Communicating Affection" PowerPoint Presentation

\section{Communicating Affection}

WWest VirginiaUniversity

\section{What is Affection?}

- Not a Basic Emotion

- Not an Instinctual Response 


\section{Expressing Affection}

- Verbal Statements

- Reinforce

- Project Hopes for the Future

- Communicate Importance

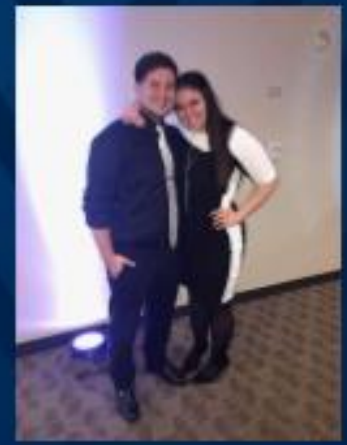

W-WesthigginiaUniversity

\section{Expressing Affection}

- Direct Nonverbal Gestures

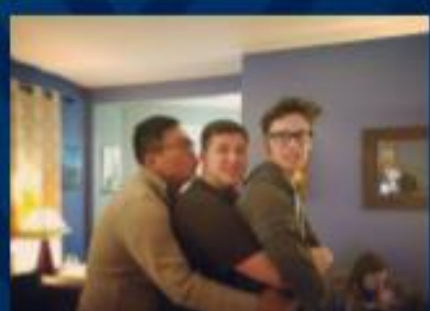




\section{Expressing Affection}

- Social Support Behaviors

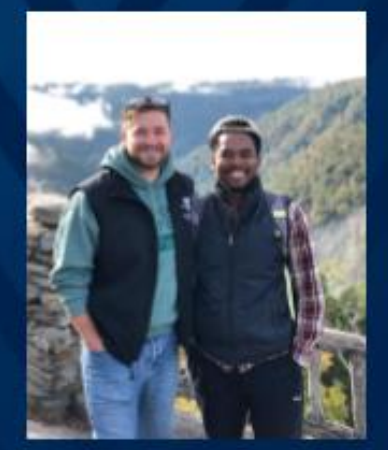

West VuginiaUniversity

\section{Affection Exchange Theory}

- Affection Contributes to Human Survival

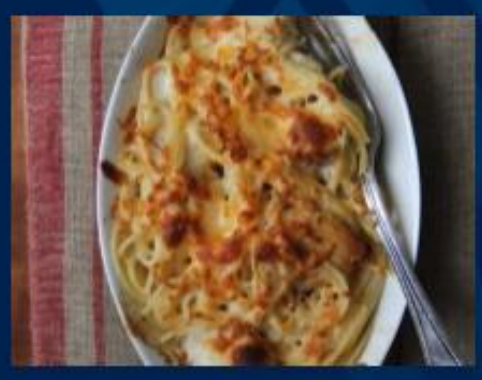




\section{Affection Exchange Theory}

- Affection can be Physiologically Aversive

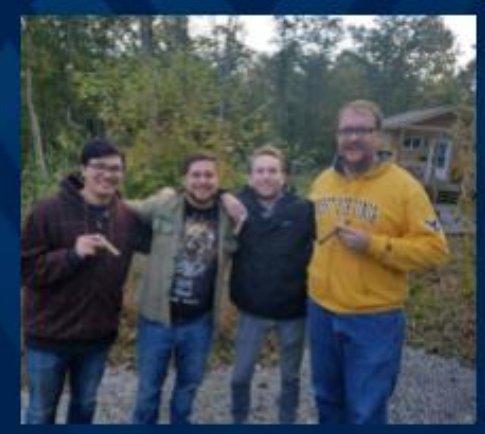

\section{Affection Exchange Theory}

- Affectionate Feelings and Expressions are Different

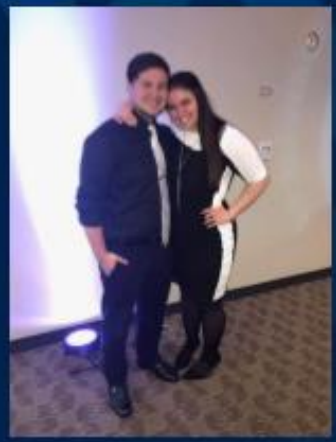




\section{Affection and Health}

- Receiving Affection

- Mental Health

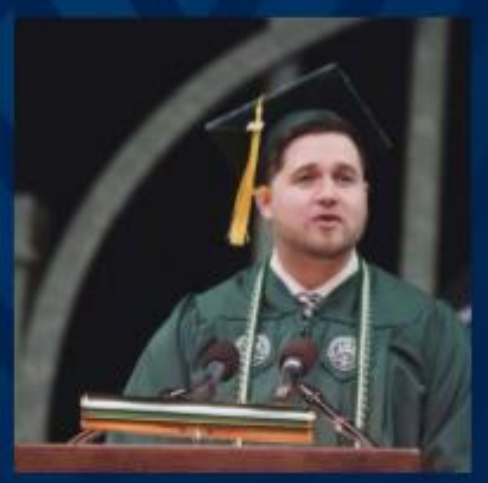

W.WesthiginiaUniversty

\section{Affection and Health}

- Expressing Affection

- Physical Health

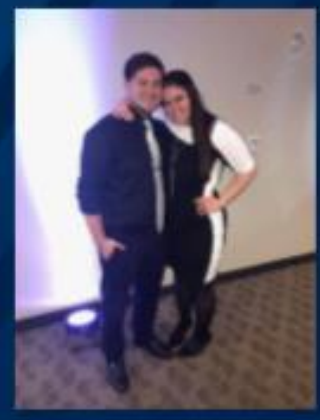

- Mental Health

Live 


\section{Communicating Affection}


Appendix D

\section{Pilot Study Cover Letter}

\section{Dear Student,}

This cover letter is a request for you to take part in a research survey designed to study how students perceive instructor self-disclosures. This project is being conducted by Principal Investigator Dr. Alan Goodboy and Co-Investigator Stephen M. Kromka both in the Department of Communication Studies at West Virginia University. This study will take approximately 10 minutes to complete. Your participation is greatly appreciated.

To participate in this research study, you must be at least 18 years of age and enrolled at West Virginia University. Your involvement in this project will remain completely anonymous. Please complete the questionnaire independently and be sure to read the instructions carefully and answer honestly. There is no right or wrong answer. Participation in this study is voluntary. You may skip certain questions if you want and you may stop completing the questionnaire at any time without fear of penalty. If you have already completed this study before in another course, we ask that you do not complete it a second time. Your actual performance in this study or your refusal to participate or withdrawal from this study will in no way affect your class standing, grades, job status, or status in any athletic or other activity associated with West Virginia University. There are no known risks associated with participating in this study.

Completing and returning this questionnaire indicates that you have agreed to participate in this study. Findings from this pilot study will be used for future research studies.

If you would like more information about this research project after today, please contact Co- Investigator Stephen M. Kromka at smk0023@mix.wvu.edu. This study has been acknowledged by West Virginia University's Institutional Review Board, and is on file as Protocol \#1912805477.

Thank you for your participation.

Sincerely,

Dr. Alan Goodboy

Professor

Principal Investigator

alan.goodboy@mail.wvu.edu
Stephen M. Kromka M.A.

Ph.D. Candidate

Co-Investigator

smk0023@mix.wvu.edu 


\section{Appendix E}

\section{Pilot Study Instructions}

The researcher will ask you to listen to several short audio samples of instructor self-disclosures from a lesson on affectionate communication. Instructor self-disclosure occurs when an instructor shares personal information that is not readily available to students. We ask that you listen carefully to the instructor in the same manner as you would for one of your current college instructors. The researcher will play each audio sample one at a time. After each sample plays, the researcher will pause so that you can rate the instructor self-disclosure using the scales on the next page.

While each audio sample is playing, we ask that you please refrain from doing any other tasks (smartphone, laptops, reading, etc.) that may distract you and/or the students around you. Thank you very much for your cooperation. 


\section{Appendix F}

\section{Pilot Study Questionnaire}

Please read the following definitions for relevance and perceived realism. The researcher will then ask you to complete the items on this questionnaire in regards to your perceptions of each instructor self-disclosure audio sample within the context of the lesson on affectionate communication.

$* * * * * * * * * * * * * * * * * * * * * * * * * * * * * * * * * * * * * * * * * * * * * * * * * * * * * * * * * * * * * * *$

\section{Relevance}

The extent to which the instructor's self-disclosure relates back to the course material and helps you understand the importance of the content. In other words, how relevant was the self-disclosure to the lesson.

\section{Perceived Realism}

The extent to which the ideas in the instructor self-disclosure is very similar to ideas that one would encounter in a real classroom. In other words, how realistic was the selfdisclosure.

\begin{tabular}{|c|c|c|c|c|c|c|c|c|}
\hline \multicolumn{9}{|c|}{ Self-disclosure 1} \\
\hline 1. Irrelevant & 1 & 2 & 3 & 4 & 5 & 6 & 7 & Relevant \\
\hline 2. Unrealistic & 1 & 2 & 3 & 4 & 5 & 6 & 7 & Realistic \\
\hline \multicolumn{9}{|c|}{ Self-disclosure 2} \\
\hline 1. Irrelevant & 1 & 2 & 3 & 4 & 5 & 6 & 7 & Relevant \\
\hline 2. Unrealistic & 1 & 2 & 3 & 4 & 5 & 6 & 7 & Realistic \\
\hline \multicolumn{9}{|c|}{ Self-disclosure 3} \\
\hline 1. Irrelevant & 1 & 2 & 3 & 4 & 5 & 6 & 7 & Relevant \\
\hline 2. Unrealistic & 1 & 2 & 3 & 4 & 5 & 6 & 7 & Realistic \\
\hline \multicolumn{9}{|c|}{ Self-disclosure 4} \\
\hline 1. Irrelevant & 1 & 2 & 3 & 4 & 5 & 6 & 7 & Relevant \\
\hline 2. Unrealistic & 1 & 2 & 3 & 4 & 5 & 6 & 7 & Realistic \\
\hline \multicolumn{9}{|c|}{ Self-disclosure 5} \\
\hline 1. Irrelevant & 1 & 2 & 3 & 4 & 5 & 6 & 7 & Relevant \\
\hline 2. Unrealistic & 1 & 2 & 3 & 4 & 5 & 6 & 7 & Realistic \\
\hline \multicolumn{9}{|c|}{ Self-disclosure 6} \\
\hline 1. Irrelevant & 1 & 2 & 3 & 4 & 5 & 6 & 7 & Relevant \\
\hline 2. Unrealistic & 1 & 2 & 3 & 4 & 5 & 6 & 7 & Realistic \\
\hline
\end{tabular}




\begin{tabular}{|c|c|c|c|c|c|c|c|c|}
\hline \multicolumn{9}{|c|}{ Self-disclosure 7} \\
\hline 1. Irrelevant & 1 & 2 & 3 & 4 & 5 & 6 & 7 & Relevant \\
\hline 2. Unrealistic & 1 & 2 & 3 & 4 & 5 & 6 & 7 & Realistic \\
\hline \multicolumn{9}{|c|}{ Self-disclosure 8} \\
\hline 1. Irrelevant & 1 & 2 & 3 & 4 & 5 & 6 & 7 & Relevant \\
\hline 2. Unrealistic & 1 & 2 & 3 & 4 & 5 & 6 & 7 & Realistic \\
\hline \multicolumn{9}{|c|}{ Self-disclosure 9} \\
\hline 1. Irrelevant & 1 & 2 & 3 & 4 & 5 & 6 & 7 & Relevant \\
\hline 2. Unrealistic & 1 & 2 & 3 & 4 & 5 & 6 & 7 & Realistic \\
\hline \multicolumn{9}{|c|}{ Self-disclosure 10} \\
\hline 1. Irrelevant & 1 & 2 & 3 & 4 & 5 & 6 & 7 & Relevant \\
\hline 2. Unrealistic & 1 & 2 & 3 & 4 & 5 & 6 & 7 & Realistic \\
\hline \multicolumn{9}{|c|}{ Self-disclosure 11} \\
\hline 1. Irrelevant & 1 & 2 & 3 & 4 & 5 & 6 & 7 & Relevant \\
\hline 2. Unrealistic & 1 & 2 & 3 & 4 & 5 & 6 & 7 & Realistic \\
\hline
\end{tabular}

Thank you very much for your help! 


\section{Appendix G}

Demographic Information Questions

Your age:

Your sex (check one):

__ Male Male to Female Transgender __ Nonbinary

Female Female to Male Transgender Other Prefer Not to Answer

Your class rank (check one): First Year Sophomore Junior Senior Other

Your cultural background (check one): Asian/Asian American Native American Black/African-American White/Caucasian Hispanic Middle Eastern Other (specify):

Your current GPA: 
Appendix $\mathrm{H}$

\author{
Email Recruitment Script
}

If you are a student at West Virginia University, currently enrolled in a communication studies course, and are at least 18 years old, you are eligible to participate in a WVU IRB-approved research study examining how students perceive effective instruction in the classroom. This is a 2-PART research study that adds up to a total of 60 minutes of research extra credit.

\title{
Part 1:
}

Part 1 is an online Qualtrics survey that will ask you to provide some information about yourself and allow you to sign up for Part 2 of the study. It will take approximately 10 minutes to complete. After you complete this short survey, it will provide you with the information you will need to complete Part 2 of the study that will take place sometime next week. You must complete this Part 1 online survey in order to be eligible to participate in Part 2 of the study.

\section{Part 2:}

Part 2 is a live lecture lesson scheduled in (insert classroom location) on the following dates/ times: (insert dates and times here). You must be available to attend all of these dates/times in order to participate in Part 2 of this study. However, you will be chosen to only attend one of these live lecture sessions. The Part 2 live lecture lesson will take approximately 50 minutes to complete. You will receive a physical research receipt (worth a total of 60 minutes of research extra credit) at the end of the Part 2 live lecture lesson. You must complete both Part 1 and Part 2 to receive extra credit for your participation in this study.

Eligible students may earn extra credit for participation in this research study. To find out if you are eligible, please contact your instructor and/or consult your course syllabus policy on extra credit. There are $\mathbf{2}$ Parts to this study that add up to 60 minutes of research extra credit: Part $1=10$ minutes \& Part $2=50$ minutes.

This study is being conducted by Dr. Alan K. Goodboy and Stephen M. Kromka in WVU's Department of Communication Studies. This study has been approved by West Virginia University's Institutional Review Board, and is on file as Protocol \#1912805477. If you have any questions about this study, please email Coinvestigator Stephen M. Kromka at smk0023@ mix.wvu.edu.

If you are eligible for this study and are available for all of the above listed dates/times, please follow the link to the Part 1 online survey below:

\section{Part 1 Online Qualtrics Survey Link:} https://wvu.qualtrics.com/jfe/form/SV_3rg6mD7gQvNBIpv

Thank you for your time and have a great day, 
Dr. Alan K. Goodboy

Professor

Principal Investigator

agoodboy@mail.wvu.edu
Stephen M. Kromka

Ph.D. Candidate

Co-investigator

smk0023@mix.wvu.edu 


\section{Appendix I}

\section{Pre-class Announcement Recruitment Script}

Hello everyone,

Good afternoon. My name is Stephen Kromka and I am a Ph.D. student in the communication studies department at West Virginia University. I am currently conducting a research study on student learning. If you are a student at West Virginia University, currently enrolled in a communication studies course, and are at least 18 years old, you are eligible to participate in a WVU IRB-approved research study examining how students perceive effective instruction in the classroom. This is a 2PART research study that adds up to a total of 60 minutes of research extra credit.

\section{Part 1:}

Part 1 is an online Qualtrics survey that will ask you to provide some information about yourself and allow you to sign up for Part 2 of the study. It will take approximately 10 minutes to complete. After you complete this short survey, it will provide you with the information you will need to complete Part 2 of the study that will take place sometime next week. You must complete this Part 1 online survey in order to be eligible to participate in Part 2 of the study.

\section{Part 2:}

Part 2 is a live lecture lesson scheduled in (insert classroom location) on the following dates/ times: (insert dates and times here). You must be available to attend all of these dates/times in order to participate in Part 2 of this study. However, you will be chosen to only attend one of these live lecture sessions. The Part 2 live lecture lesson will take approximately 50 minutes to complete. You will receive a physical research receipt (worth a total of 60 minutes of research extra credit) at the end of the Part 2 live lecture lesson. You must complete both Part 1 and Part 2 to receive extra credit for your participation in this study.

Eligible students may earn extra credit for participation in this research study. To find out if you are eligible, please contact your instructor and/or consult your course syllabus policy on extra credit. There are 2 Parts to this study that add up to 60 minutes of research extra credit: Part $1=10$ minutes $\&$ Part $2=50$ minutes.

\section{If you have any questions about this study, please email Co-investigator Stephen M. Kromka at smk0023@mix.wvu.edu.}

If you are eligible for this study and are available for all of the above listed dates/times, please write down the following the link to the Part 1 online survey:

\section{Part 1 Online Qualtrics Survey Link:} https://wvu.qualtrics.com/jfe/form/SV_3rg6mD7gQvNBIpv Thank you for your time and have a great day. 
Appendix $\mathbf{J}$

Printed Bulletin Board "Mach Form” Recruitment Script

Title: Effective Instructional Strategies during a Live Lecture Lesson

Protocol Number: 1912805477

PI: Dr. Alan K. Goodboy

PI E-mail: agoodboy@mail.wvu.edu

Co-PI: Stephen M. Kromka

Co-PI E-mail: smk0023@mix.wvu.edu

Purpose of Study (1 sentence): The purpose of this research study is to examine the effects of instructional strategies on student learning in a live lecture lesson.

To be eligible for participation in this study, you must meet the following inclusion criteria:

You are only eligible to participate in this research study if: (a) you are a student at West Virginia University, (b) you are currently enrolled in a communication studies course, (c) you are over the age of 18, and (d) you are available to attend a live lecture lesson on the following dates/times: (insert dates and times).

Time Commitment: 60 minutes (Part $1=10$ minutes $\&$ Part $2=50$ minutes)

Data Collection Location: Online Survey (Part 1) AND (Insert classroom location here) (Part 2)

Data Collection Date \& Time: Part 1 Online Qualtrics Survey Link:

https://wvu.qualtrics.com/jfe/form/SV_3rg6mD7gQvNBIpv \& Part 2 Dates and Times: (Insert live lecture lesson dates and times) 
Appendix K

Part 1 Online Qualtrics Sign-up Survey

Dear Participant:

You are invited to take part in a research study entitled "Effective Instructional Strategies during a Live Lecture Lesson" designed to examine college students' perceptions of instructor communication behaviors during a lesson. The purpose of this research study is to better understand the effects of instructional strategies on student learning in a live lecture lesson. This project is being conducted by Principal Investigator Alan K.

Goodboy and Co-Investigator Stephen M. Kromka. These researchers are part of the Department of Communication Studies at West Virginia University.

To participate in this 2-Part study, you must be: (a) a student at West Virginia University, (b) currently enrolled in a communication studies course, (c) be at least 18 years old, and (d) available to attend a live lecture lesson on the following dates/times: (insert dates and times).

This Part 1 online Qualtrics sign-up survey will take approximately 10 minutes to complete. Your involvement in this study will remain completely anonymous. There are no right or wrong answers in the questionnaire and your participation is completely voluntary. You may skip questions and stop completing the questionnaire at any time without fear of penalty. Your actual performance in this research study will in no way impact your class standing, grades, job status, or status in any athletic or other activity associated with West Virginia University. There are no known risks associated with participating in this study.

You will create a unique identification code during this Part 1 survey that will only be known to you. Please keep this code for your records, as you will be asked to provide it when you attend the Part 2 live lecture lesson.

As a student enrolled in a COMM course, you may be eligible to receive research credit (extra credit) for participation in this study. To find out if you are eligible, please contact your instructor and/or review your course syllabus. Your course syllabus should also include details regarding how much extra credit you may be eligible for (as well as how many research opportunities you can attempt for that class). Students not wishing to volunteer for this study are able to receive extra credit by completing an alternative assignment. For students in eligible classes, your instructor will provide more information on the alternative assignment. You will receive a physical research receipt (worth a total of 60 minutes of research extra credit) at the end of the Part 2 live lecture lesson.

If you would like more information about this research study, please contact Coinvestigator Stephen M. Kromka at smk0023@mix.wvu.edu. This study has been acknowledged by West Virginia University's Institutional Review Board, and is on file as Protocol \#1912805477. 
Thank you very much for your participation.

Dr. Alan K. Goodboy

Professor

Principal Investigator

agoodboy@mail.wvu.edu
Stephen Kromka

Ph.D. Candidate

Co-investigator

smk0023@mix.wvu.edu

I have read the information above and...

- Agree, and would like to continue the Part 1 online sign-up survey.

$* * * * * * * * * * * * * * * * * * * * * * * * * * * * * * * * * * * * * * * * * * * * * * * * * * * * * * * * * * * * *$

Use the scales below to indicate, in general, how comfortable you are with instructors who share personal information during class. Circle one number on each set of bipolar scales to indicate your judgment or evaluation of instructors who self-disclose in class. The closer the response is to an adjective, the more certain you are of your evaluation. There is neither a right nor a wrong answer.

\begin{tabular}{l|l|l|l|l|l|l|l|r}
\hline 1. Uncomfortable & 1 & 2 & 3 & 4 & 5 & 6 & 7 & Comfortable \\
\hline 2. Worried & 1 & 2 & 3 & 4 & 5 & 6 & 7 & At ease \\
\hline 3. Restless & 1 & 2 & 3 & 4 & 5 & 6 & 7 & Content \\
\hline
\end{tabular}

Next, please provide some information about yourself:

4. Your age:

5. Your sex (check one):

_ Male __ Male to Female Transgender

Female Female to Male Transgender

Nonbinary

Other

Prefer Not to

Answer

6. Your class rank (check one):

First Year

Sophomore

Junior

Senior

Other

7. The cultural background with which you most closely identify (check one):

Asian/Asian American

Black/African-American

Hispanic 
Native American

White/Caucasian

Middle Eastern

Other (specify):

8. Your current GPA:

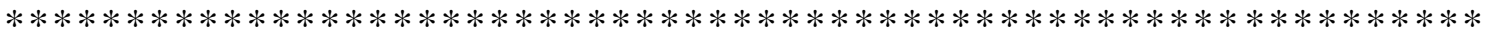

As mentioned in the cover letter, this is a 2-Part study: (1) Part 1 is to complete the current online survey in order to receive a date/time to attend a live lecture lesson and (2) Part 2 is to attend the live lecture lesson session at your assigned date/time. In order to match up the information from Part 1 and Part 2, we need you to create a unique identification code. To be clear, this unique identification code will only be used to match up information from Part 1 and Part 2 of the study. This identification code will be removed before data analysis. Remember, your actual performance in this research study will in no way impact your class standing, grades, job status, or status in any athletic or other activity associated with West Virginia University.

Now, we ask that you please create your own unique identification code using the following directions. Please provide the first three letters of your favorite color and the last four digits of your phone number (for example: BLU5888). Please keep this code for your records, as you will be asked to provide it when you attend the Part 2 live lecture lesson session.

My unique identification code is:

$* * * * * * * * * * * * * * * * * * * * * * * * * * * * * * * * * * * * * * * * * * * * * * * * * * * * * * * * * * * * *$

Thank you for providing your information and creating your unique identification code. Now, you will be assigned a date/time to attend the Part 2 live lecture lesson session. Please click the "next" button below to receive a date/time to attend the Part 2 live lecture lesson session.

*Students will be randomly assigned to one of the four following Part 2 live lecture lesson messages*

1. You have been assigned to attend a live lecture lesson on (insert date) in (insert classroom location) from (insert start time) to (insert end time). Please take a moment to record this date, time, and location. In order to complete Part 2 of this study and receive research extra credit, you must arrive to the classroom at least 5 minutes before (insert start time). Other dates and times were scheduled for this study, but due to classroom size limitations, we need you to come to this designated date and time. If you attempt to attend a different live lecture lesson session (that you were not assigned), the researcher will not allow you to enter the classroom and you will not be able to participate in the Part 2 live lecture lesson portion of this study.

2. You have been assigned to attend a live lecture lesson on (insert date) in (insert classroom location) from (insert start time) to (insert end time). Please take a moment 
to record this date, time, and location. In order to complete Part 2 of this study and receive research extra credit, you must arrive to the classroom at least 5 minutes before (insert start time). Other dates and times were scheduled for this study, but due to classroom size limitations, we need you to come to this designated date and time. If you attempt to attend a different live lecture lesson session (that you were not assigned), the researcher will not allow you to enter the classroom and you will not be able to participate in the Part 2 live lecture lesson portion of this study.

3. You have been assigned to attend a live lecture lesson on (insert date) in (insert classroom location) from (insert start time) to (insert end time). Please take a moment to record this date, time, and location. In order to complete Part 2 of this study and receive research extra credit, you must arrive to the classroom at least 5 minutes before (insert start time). Other dates and times were scheduled for this study, but due to classroom size limitations, we need you to come to this designated date and time. If you attempt to attend a different live lecture lesson session (that you were not assigned), the researcher will not allow you to enter the classroom and you will not be able to participate in the Part 2 live lecture lesson portion of this study.

4. You have been assigned to attend a live lecture lesson on (insert date) in (insert classroom location) from (insert start time) to (insert end time). Please take a moment to record this date, time, and location. In order to complete Part 2 of this study and receive research extra credit, you must arrive to the classroom at least 5 minutes before (insert start time). Other dates and times were scheduled for this study, but due to classroom size limitations, we need you to come to this designated date and time. If you attempt to attend a different live lecture lesson session (that you were not assigned), the researcher will not allow you to enter the classroom and you will not be able to participate in the Part 2 live lecture lesson portion of this study.

*The randomly assigned Part 2 live lecture lesson message will be followed by this signup prompt*

To confirm your assigned Part 2 live lecture lesson session, please respond to the following prompt.

Earlier in this survey, you created a unique identification code. Please provide your unique identification code in the space below. Remember, this code was the first three letters of your favorite color followed by the last four digits of your phone number (for example: BLU5888).

My unique identification code is:

$* * * * * * * * * * * * * * * * * * * * * * * * * * * * * * * * * * * * * * * * * * * * * * * * * * * * * * * * * * * * *$

You have just completed the Part 1 online survey portion of this study. Thank you for signing up and confirming your designated Part 2 live lecture lesson session. We will see you at your assigned date and time. 
Appendix L

Part 2 Reminder Email for the Week of the Study

*The following email will be sent the week of the Part 2 live lecture lesson.

Email Subject: REMINDER for Upcoming "Effective Instructional Strategies during a Live Lecture Lesson" Study to Receive Research Extra Credit

Dear WVU Communication Studies Student,

You have recently signed up to participate in a 2-Part research study entitled "Effective Instructional Strategies during a Live Lecture Lesson.”

Thank you for recently completing the Part 1 online Qualtrics survey to sign up for the study.

We wanted to send you a courtesy reminder that the Part 2 Live Lecture Lesson will take place this week.

In order to participate in the Part 2 Live Lecture Lesson, you must attend the Live Lecture Lesson on (insert date) in (insert classroom location) at (insert time).

We ask that you arrive at least 5 minutes before (insert time) so we can begin the lesson on time and dismiss students as soon as the study is complete.

We look forward to seeing you on (insert date) in (insert classroom location) at (insert time).

Thank you for your time and participation,

Stephen Kromka and Dr. Alan Goodboy

This research study is being conducted by principal investigator Dr. Alan K. Goodboy and co-investigator Stephen M. Kromka. This study has been approved by West Virginia University's Institutional Review Board, and is on file as Protocol \#1912805477. If you have any questions about this research study, please email Co-investigator Stephen M. Kromkaatsmk0023@mix.wvu.edu. 
Appendix M

Part 2 Reminder Email for the Day of the Study

*The following email will be sent the day of the Part 2 live lecture lesson.

Email Subject: REMINDER for TODAY'S “Effective Instructional Strategies during a Live Lecture Lesson" Study to Receive Research Extra Credit

Dear WVU Communication Studies Student,

You have recently signed up to participate in a 2-Part research study entitled "Effective Instructional Strategies during a Live Lecture Lesson.”

Thank you for recently completing the Part 1 online Qualtrics survey to sign up for the study.

We wanted to send you a courtesy reminder that the Part 2 Live Lecture Lesson will be taking place TODAY.

In order to participate in the Part 2 Live Lecture Lesson, you must attend the Live Lecture Lesson today (insert date) in (insert classroom location) at (insert time).

We ask that you arrive at least 5 minutes before (insert time) so we can begin the lesson on time and dismiss students as soon as the study is complete.

We look forward to seeing you TODAY in (insert classroom location) at (insert time).

Thank you for your time and participation,

Stephen Kromka and Dr. Alan Goodboy

This research study is being conducted by principal investigator Dr. Alan K. Goodboy and co-investigator Stephen M. Kromka. This study has been approved by West Virginia University's Institutional Review Board, and is on file as Protocol \#1912805477. If you have any questions about this research study, please email Co-investigator Stephen M. Kromkaatsmk0023@mix.wvu.edu. 
Appendix N

Feedback Questionnaire

Dear students,

Thank you very much for attending this Part 2 live lecture lesson session for the "Effective Instructional Strategies during a Live Lecture Lesson" research study. We ask that you pay close attention to the instructor's lecture in the same manner as you would for your current college courses.

The professor that you will have today is interested in pursuing a career in teaching. The professor has asked for your feedback on his teaching. Please wait until the professor has completed his lecture and the researcher makes an announcement before you begin to fill out this feedback questionnaire.

Keep in mind that there are no right or wrong answers in this feedback questionnaire and your participation is completely voluntary. You may skip questions and stop completing the questionnaire at any time without fear of penalty. Your completion of this feedback questionnaire will in no way impact your class standing, grades, job status, or status in any athletic or other activity associated with West Virginia University.

Lastly, we will ask you to provide your unique identification code that you created in the Part 1 online survey. Remember, this unique identification code will be removed before data analysis.

Thank you for your helpful feedback today,

Stephen Kromka 
Please do not look at the following pages of the feedback questionnaire until instructed to do so by the researcher. 
In order to participate in this current study, you were asked to complete the Part 1 online survey and create a unique identification code. Please write your unique identification code in the space provided. Remember, this code was the first three letters of your favorite color followed by the last four digits of your phone number (for example: BLU5888). Please write legibly.

My unique identification code is:

Please complete the items on this questionnaire in regard to your perceptions of the instructor's lesson.

Use the scale below to indicate the extent to which the instructor's personal selfdisclosures were relevant to the lesson content. Write your answer in the space provided. There is neither a right nor a wrong answer.

\begin{tabular}{|c|c|c|c|c|c|c|}
\hline $\begin{array}{c}\text { Strongly } \\
\text { Disagree }\end{array}$ & $\begin{array}{c}\text { Moderately } \\
\text { Disagree }\end{array}$ & $\begin{array}{c}\text { Slightly } \\
\text { Disagree }\end{array}$ & $\begin{array}{c}\text { Neither } \\
\text { Disagree } \\
\text { nor Agree }\end{array}$ & $\begin{array}{c}\text { Slightly } \\
\text { Agree }\end{array}$ & $\begin{array}{c}\text { Moderately } \\
\text { Agree }\end{array}$ & $\begin{array}{c}\text { Strongly } \\
\text { Agree }\end{array}$ \\
1 & 2 & 3 & 4 & 5 & 6 & 7 \\
\hline
\end{tabular}

1. The instructor used personal examples to show the importance of a concept.

2. The instructor used his own experiences to introduce a concept.

3. The instructor provided personal explanations that made the content relevant.

4. The instructor provided personal examples which helped me understand the importance of the content.

5. The instructor linked current course content to other areas of content through the use of personal examples. 
Use the scales below to indicate your feelings about the instructor. Circle one number on each set of bipolar scales to indicate your judgment or evaluation of today's instructor. The closer the response is to an adjective, the more certain you are of your evaluation. There is neither a right nor a wrong answer.

My attitude about this instructor is:

\begin{tabular}{l|l|l|l|l|l|l|l|r|}
\hline 6. Good & 1 & 2 & 3 & 4 & 5 & 6 & 7 & Bad \\
\hline 7. Worthless & 1 & 2 & 3 & 4 & 5 & 6 & 7 & Valuable \\
\hline 8. Fair & 1 & 2 & 3 & 4 & 5 & 6 & 7 & Unfair \\
\hline 9. Positive & 1 & 2 & 3 & 4 & 5 & 6 & 7 & Negative \\
\hline
\end{tabular}

The likelihood of actually enrolling in another course with this instructor if my schedule would permit would be:

\begin{tabular}{l|l|l|l|l|l|l|l|r}
\hline 10. Likely & 1 & 2 & 3 & 4 & 5 & 6 & 7 & Unlikely \\
\hline 11. Impossible & 1 & 2 & 3 & 4 & 5 & 6 & 7 & Possible \\
\hline 12. Probable & 1 & 2 & 3 & 4 & 5 & 6 & 7 & Improbable \\
\hline 13. Would Not & 1 & 2 & 3 & 4 & 5 & 6 & 7 & Would \\
\hline
\end{tabular}

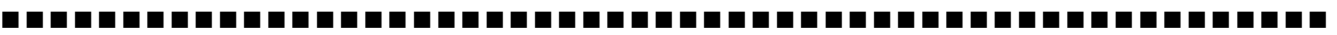

Use the scale below to indicate your perceptions of the instructor's lesson. Write your answer in the space provided. There is neither a right nor a wrong answer.

\begin{tabular}{|c|c|c|c|c|c|c|}
\hline $\begin{array}{c}\text { Strongly } \\
\text { Disagree }\end{array}$ & $\begin{array}{c}\text { Moderately } \\
\text { Disagree }\end{array}$ & $\begin{array}{c}\text { Slightly } \\
\text { Disagree }\end{array}$ & $\begin{array}{c}\text { Neither } \\
\text { Disagree } \\
\text { nor Agree }\end{array}$ & $\begin{array}{c}\text { Slightly } \\
\text { Agree }\end{array}$ & $\begin{array}{c}\text { Moderately } \\
\text { Agree }\end{array}$ & $\begin{array}{c}\text { Strongly } \\
\text { Agree }\end{array}$ \\
1 & 2 & 3 & 4 & 5 & 6 & 7 \\
\hline
\end{tabular}

14. The instructor went off topic when lecturing.

15. The instructor went on unrelated tangents when we were discussing ideas in class.

16. In the lecture, we often received information that was not essential to learning course concepts.

17. There was a lot of unnecessary information in the lecture. 
Use the scale below to indicate your perception of the instructor. Circle the number that best represents your perception. There is neither a right nor a wrong answer.

\begin{tabular}{|l|l|l|l|l|l|l|l|l|}
\hline 18. Incompetent & 1 & 2 & 3 & 4 & 5 & 6 & 7 & Competent \\
\hline 19. Dishonest & 1 & 2 & 3 & 4 & 5 & 6 & 7 & Honest \\
\hline $\begin{array}{l}\text { 20. Doesn't care about } \\
\text { me }\end{array}$ & 1 & 2 & 3 & 4 & 5 & 6 & 7 & Cares about me \\
\hline
\end{tabular}

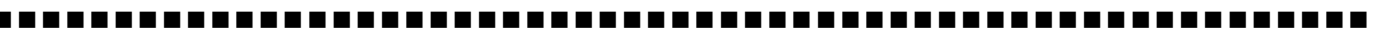

Use the scale below to indicate the extent of your familiarity with the lesson material on affectionate communication. Write your answer in the space provided. There is neither a right nor a wrong answer.

\begin{tabular}{|c|c|c|c|c|}
\hline Not at All & Barely & A little & Somewhat & Very Much \\
1 & 2 & 3 & 4 & 5 \\
\hline
\end{tabular}

21. How familiar were you with the topic before today?

22. How much did you already know about this topic before today?

23. To what extent had you been exposed to the material in this lesson in the past?

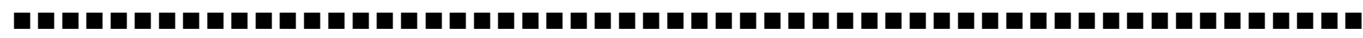

Use the scale below to indicate the extent of the difficulty of the lesson. Higher values reflect higher difficulty and lower values reflect lower difficulty. Write your answer in the space provided. There is neither a right nor a wrong answer.

\begin{tabular}{|c|c|c|c|c|c|c|c|c|}
\hline $\begin{array}{c}\text { Very } \\
\text { low }\end{array}$ & Low & $\begin{array}{c}\text { Moderately } \\
\text { low }\end{array}$ & $\begin{array}{c}\text { Slightly } \\
\text { low }\end{array}$ & Neutral & $\begin{array}{c}\text { Slightly } \\
\text { high }\end{array}$ & $\begin{array}{c}\text { Moderately } \\
\text { high }\end{array}$ & High & $\begin{array}{c}\text { Very } \\
\text { high }\end{array}$ \\
1 & 2 & 3 & 4 & 5 & 6 & 7 & 8 & 9 \\
\hline
\end{tabular}

24. How difficult was the material to understand?

25. Have you ever had Miles Payne as an instructor before? (Circle one)

Yes or No

26. Have you ever heard this lesson before from a previous research study? (Circle one) Yes or No 


\section{Appendix O}

\section{Researcher Introduction Script}

*The researcher will read the following script before the instructor begins the lesson*

Hello everyone. Thank you all very much for helping to complete this 2-Part research study called "Effective Instructional Strategies during a Live Lecture Lesson." You are here because you completed the Part 1 online survey that provided you with the information to attend this Part 2 live lecture lesson session today. Thank you so much for coming.

In front of you is the feedback questionnaire. As the front page states, the reason that you are here today is that professor Miles Payne is interested in pursuing a career in teaching. The professor has asked for your honest feedback on his teaching. We appreciate all of you being here to help provide the professor with honest feedback.

We ask that you please wait until the professor has completed his lecture and the researcher - that's me - makes an announcement before you begin to complete this feedback questionnaire.

In a moment, the professor will begin his lesson on affectionate communication. We ask that you please listen carefully to the professor in the same manner that you would for your own current college instructors. After the professor finishes his lesson, I will instruct you to begin completing the feedback questionnaire. This questionnaire will ask you to provide your unique identification code that you created in the Part 1 online survey, to answer some questions about the professor, and to complete a short test on today's lesson material.

One more thing. There is a camera set up to record the professor during the lesson. To be clear, this camera will only be set to record the professor. No students will be recorded during this lesson.

At this point, I ask you to please turn to the next page that provides you with space in case you would like to take notes. Please do not flip to the following pages of the feedback questionnaire until I have instructed you to do so. I will provide you with more directions after Miles has finished his lesson.

I now ask that you give your full, undivided attention to your professor for today's lesson, Miles Payne. 


\section{Appendix P}

\section{Researcher Pre-Feedback Questionnaire Script}

Thank you very much for your lesson today, Miles. You may now leave the classroom. Now, I ask that all of you to please listen to the following directions.

In a moment, I will ask you to flip the page to begin filling out the feedback questionnaire. You will have 15 minutes to complete the feedback questionnaire. After you complete the feedback questionnaire, I ask that you place the feedback questionnaire packet in the envelope provided and seal the envelope. Please do not put any identifying information on the feedback questionnaire or the envelope such as your name or Student Identification Number. Your unique identification code on the questionnaire will suffice. If you finish early, I ask that you please sit and wait quietly until I dismiss you. After the 15 minute time period, I will dismiss the class. You will then place your sealed envelope in this closed box. After you have placed the envelope in the box, the 2-part research study will then be finished.

Please be sure to see me before you leave to obtain your extra credit research receipt that you will give to your communication instructor to receive research extra credit in your class.

At this time, I ask that you flip the page and begin completing the feedback questionnaire. 


\section{Appendix Q}

Extra Credit Research Receipt

Research Study Receipt: "Effective Instructional Strategies during a Live Lecture Lesson."

Protocol \#1912805477

Name

Date

Instructor

COMM

This receipt is confirmation that the student whose name is written above completed a research study for Principal Investigator Alan K. Goodboy and Co-Investigator Stephen M. Kromka. This 2-Part research study took approximately 60 minutes to complete. 


\section{Appendix R}

Teacher Self-disclosure Scale for Relevance

(Cayanus \& Martin, 2008)

Use the scale below to indicate the extent to which the instructor's personal selfdisclosures were relevant to the lesson content. Write your answer in the space provided. There is neither a right nor a wrong answer.

\begin{tabular}{|c|c|c|c|c|c|c|}
\hline $\begin{array}{c}\text { Strongly } \\
\text { Disagree }\end{array}$ & $\begin{array}{c}\text { Moderately } \\
\text { Disagree }\end{array}$ & $\begin{array}{c}\text { Slightly } \\
\text { Disagree }\end{array}$ & $\begin{array}{c}\text { Neither } \\
\text { Disagree } \\
\text { nor Agree }\end{array}$ & $\begin{array}{c}\text { Slightly } \\
\text { Agree }\end{array}$ & $\begin{array}{c}\text { Moderately } \\
\text { Agree }\end{array}$ & $\begin{array}{c}\text { Strongly } \\
\text { Agree }\end{array}$ \\
1 & 2 & 3 & 4 & 5 & 6 & 7 \\
\hline
\end{tabular}

1. The instructor used personal examples to show the importance of a concept.

2. The instructor used his own experiences to introduce a concept.

3. The instructor provided personal explanations that made the content relevant.

4. The instructor provided personal examples which helped me understand the importance of the content.

5. The instructor linked current course content to other areas of content through the use of personal examples. 


\section{Appendix S}

Instructional Affect Assessment Instrument for Instructor

(McCroskey, 1994)

Use the scales below to indicate your feelings about the instructor. Circle one number on each set of bipolar scales to indicate your judgment or evaluation of today's instructor. The closer the response is to an adjective, the more certain you are of your evaluation. There is neither a right nor a wrong answer.

My attitude about this instructor is:

\begin{tabular}{l|l|l|l|l|l|l|l|r}
\hline Good & 1 & 2 & 3 & 4 & 5 & 6 & 7 & Bad \\
\hline Worthless & 1 & 2 & 3 & 4 & 5 & 6 & 7 & Valuable \\
\hline Fair & 1 & 2 & 3 & 4 & 5 & 6 & 7 & Unfair \\
\hline Positive & 1 & 2 & 3 & 4 & 5 & 6 & 7 & Negative \\
\hline
\end{tabular}

The likelihood of actually enrolling in another course with this instructor if my schedule would permit would be:

\begin{tabular}{l|l|l|l|l|l|l|l|r}
\hline Likely & 1 & 2 & 3 & 4 & 5 & 6 & 7 & Unlikely \\
\hline Impossible & 1 & 2 & 3 & 4 & 5 & 6 & 7 & Possible \\
\hline Probable & 1 & 2 & 3 & 4 & 5 & 6 & 7 & Improbable \\
\hline Would Not & 1 & 2 & 3 & 4 & 5 & 6 & 7 & Would \\
\hline
\end{tabular}




\author{
Appendix T \\ Clarity Indicators Scale - Coherence
}

(Bolkan, 2017)

Use the scale below to indicate your perceptions of the instructor's lesson. Write your answer in the space provided. There is neither a right nor a wrong answer.

\begin{tabular}{|c|c|c|c|c|c|c|}
\hline $\begin{array}{c}\text { Strongly } \\
\text { Disagree }\end{array}$ & $\begin{array}{c}\text { Moderately } \\
\text { Disagree }\end{array}$ & $\begin{array}{c}\text { Slightly } \\
\text { Disagree }\end{array}$ & $\begin{array}{c}\text { Neither } \\
\text { Disagree } \\
\text { nor Agree }\end{array}$ & $\begin{array}{c}\text { Slightly } \\
\text { Agree }\end{array}$ & $\begin{array}{c}\text { Moderately } \\
\text { Agree }\end{array}$ & $\begin{array}{c}\text { Strongly } \\
\text { Agree }\end{array}$ \\
1 & 2 & 3 & 4 & 5 & 6 & 7 \\
\hline
\end{tabular}

1. The instructor went off topic when lecturing.

2. The instructor went on unrelated tangents when we were discussing ideas in class.

3. In the lecture, we often received information that was not essential to learning course concepts.

4. There was a lot of unnecessary information in the lecture. 


\section{Appendix U}

Test

INSTRUCTIONS: This test consists of 15 questions to assess your knowledge on affectionate communication. Please circle the best answer for each question. Please $\underline{\boldsymbol{D O}}$ NOT look back at your notes when completing this test.

1. Affection can be best described as

a) an emotional state of fondness and intense positive feelings toward a person

b) a simple discrete emotion similar to surprise, fear, or anger

c) the overt physical attraction to another person

d) an instinctual response that is identical for every human being

2. Affection is not a emotion.
a) complex
b) secondary
c) basic
d) deep

3. Affection is not an instinctual response because people
a) must take classes on how to feel affection
b) do not have the capacity to feel affection
c) all want the same amount of affection
d) differ in their desire to feel affection

4. An individual can use person such by saying things like "I love you." to convey positive feelings to a
a) verbal statements
b) direct nonverbal gestures
c) social support behaviors
d) reflexive movements

5. People who use to express affection do so to reinforce a relationship status, project hopes for the future, and communicate the importance of a relationship.
a) verbal statements
b) direct nonverbal gestures
c) social support behaviors
d) reflexive movements

6. and smiling. are ways that people can express affection through kissing, hugging,

a) Verbal statements

b) Direct nonverbal gestures

c) Social support behaviors

d) Reflexive movements 
7. Conveying affection using is more ambiguous compared to using

a) social support behaviors; reflexive movements

b) reflexive movements; social support behaviors

c) direct nonverbal gestures; verbal statements

d) verbal statements; direct nonverbal gestures

8. An example of a is being a sympathetic listener to a friend during a difficult time.
a) verbal statements
b) direct nonverbal gesture
c) social support behavior
d) reflexive movement

9. explains why people express affection, how affection can be perceived negatively, and what health consequences arise from exchanging affection.
a) Social learning theory
b) Emotional response theory
c) Affection exchange theory
d) Politeness theory

10. The main reason why people express affection to one another is because conveying affection
a) decreases access to emotional resources
b) decreases access to material resources
c) contributes to human survival
d) contributes to emotional protection

11. When a person's tolerance for affection is violated under certain circumstances, affection can be physiologically aversive, which produces a
a) negative physical response
b) positive physical response
c) negative emotional response
d) positive emotional response

12. Affectionate feelings and expressions are one another.
a) equal to
b) different from
c) divergent from
d) similar to 
13. Receiving affection influences one's mental health by increasing and
a) relationship satisfaction; anxiety
b) anxiety; loneliness
c) loneliness; self-esteem
d) self-esteem; relationship satisfaction

14. If you want to reduce your stress, what should you do?
a) express affection
b) receive affection
c) reject affection
d) suppress affection

15. Highly affectionate people are less likely to be compared to non-affectionate people.
a) social
b) calm
c) happy
d) depressed

This is the end of the feedback questionnaire. Now, place the questionnaire in the envelope provided, seal the envelope, and wait for the researcher to dismiss the class. The researcher will then give you the extra credit research receipt.

Thank you for providing your helpful feedback for this study! 


\section{Appendix V}

Shortened Student Comfort with Instructor Self-disclosure Scale

(Schrodt, 2013)

Use the scales below to indicate, in general, how comfortable you are with instructors who share personal information during class. Circle one number on each set of bipolar scales to indicate your judgment or evaluation of instructors who self-disclose in class. The closer the response is to an adjective, the more certain you are of your evaluation. There is neither a right nor a wrong answer.

\begin{tabular}{l|l|l|l|l|l|l|l|r}
\hline Uncomfortable & 1 & 2 & 3 & 4 & 5 & 6 & 7 & Comfortable \\
\hline Worried & 1 & 2 & 3 & 4 & 5 & 6 & 7 & At ease \\
\hline Restless & 1 & 2 & 3 & 4 & 5 & 6 & 7 & Content \\
\hline
\end{tabular}




\title{
Appendix W
}

\author{
Shortened Instructor Credibility Scale
}

(McCroskey \& Teven, 1999)

Use the scale below to indicate your perception of the instructor. Circle the number that best represents your perception. There is neither a right nor a wrong answer.

\begin{tabular}{|l|l|l|l|l|l|l|l|l|}
\hline 1. Incompetent & 1 & 2 & 3 & 4 & 5 & 6 & 7 & Competent \\
\hline 2. Dishonest & 1 & 2 & 3 & 4 & 5 & 6 & 7 & Honest \\
\hline 3. Doesn't care about me & 1 & 2 & 3 & 4 & 5 & 6 & 7 & Cares about me \\
\hline
\end{tabular}




\section{Appendix X}

Perceived Familiarity Scale

(Bolkan, Goodboy, \& Kelsey, 2016)

Use the scale below to indicate the extent of your familiarity with the lesson material on affectionate communication. Write your answer in the space provided. There is neither a right nor a wrong answer.

\begin{tabular}{|c|c|c|c|c|c|c|}
\hline $\begin{array}{c}\text { Strongly } \\
\text { Disagree }\end{array}$ & $\begin{array}{c}\text { Moderately } \\
\text { Disagree }\end{array}$ & $\begin{array}{c}\text { Slightly } \\
\text { Disagree }\end{array}$ & $\begin{array}{c}\text { Neither } \\
\text { Disagree } \\
\text { nor Agree }\end{array}$ & $\begin{array}{c}\text { Slightly } \\
\text { Agree }\end{array}$ & $\begin{array}{c}\text { Moderately } \\
\text { Agree }\end{array}$ & $\begin{array}{c}\text { Strongly } \\
\text { Agree }\end{array}$ \\
1 & 2 & 3 & 4 & 5 & 6 & 7 \\
\hline
\end{tabular}

1. How familiar were you with the topic before today?

2. How much did you already know about this topic before today?

3. To what extent had you been exposed to the material in this lesson in the past? 


\section{Appendix Y}

\section{Perceived Difficulty Scale}

Use the scale below to indicate the extent of the difficulty of the lesson. Higher values reflect higher difficulty and lower values reflect lower difficulty. Write your answer in the space provided. There is neither a right nor a wrong answer.

\begin{tabular}{|c|c|c|c|c|c|c|c|c|}
\hline $\begin{array}{c}\text { Very } \\
\text { low }\end{array}$ & Low & $\begin{array}{c}\text { Moderately } \\
\text { low }\end{array}$ & $\begin{array}{c}\text { Slightly } \\
\text { low }\end{array}$ & Neutral & $\begin{array}{c}\text { Slightly } \\
\text { high }\end{array}$ & $\begin{array}{c}\text { Moderately } \\
\text { high }\end{array}$ & High & $\begin{array}{c}\text { Very } \\
\text { high }\end{array}$ \\
1 & 2 & 3 & 4 & 5 & 6 & 7 & 8 & 9 \\
\hline
\end{tabular}

1. How difficult was the material to understand? 